\title{
NBSIR 75.655
}

\section{Report No. 5}

\section{Analysis of Findings of Four Tank-Car Accident Reports}

C. G. Interrante, J. G. Early and G. E. Hicho

Mechanical Properties Metallurgy Division Institute for Materials National Bureau of Sta Washington, D. C. 20

January 1975

Summary Report
Interrante, C. G., Early, J. G., Hicho, G. E., Analysis of findings of four tank-car accident reports, DOT Report No. FRA-OR\&D/75-50, 70 pages (Available as PB/251-097 from the National Technical Information Service, Springtield, VA, 2216I, Jan. 1975).

$$
\text { NBSAR. } 5-6.55
$$

Prepared for

Federal Railroad Administration

Department of Transportation

Washington, D. C. 20591 

NBSIR 75-655

Report No. 5

ANALYSIS OF FINDINGS OF FOUR

TANK-CAR ACCIDENT REPORTS

C. G. Interrante, J. G. Early and G. E. Hicho

Mechanical Properties Section

Metallurgy Division

Institute for Materials Research

National Bureau of Standards

Washington, D. C. 20234

January 1975

Summary Report

Prepared for

Federal Rail road Administration

Department of Transportation

Washington, D. C. 20591

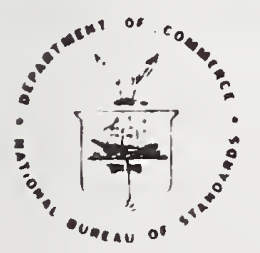

U. S. DEPARTMENT OF COMMERCE, Frederick B. Dem. Secretary

NATIONAL BUPEAU OF STANDAROS, Richerd W. Roboris. Direcior 



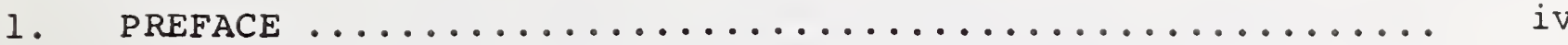

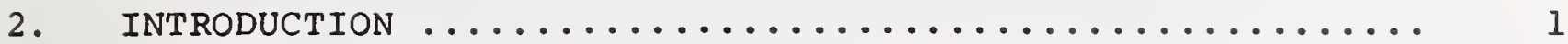

$2.1 \quad$ Background $\ldots \ldots \ldots \ldots \ldots \ldots \ldots \ldots \ldots \ldots \ldots \ldots \ldots \ldots$

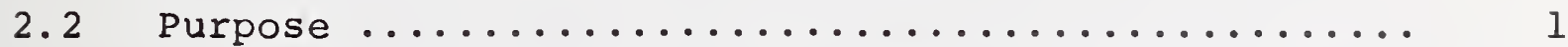

2.3 Scope of this Report .................... 1

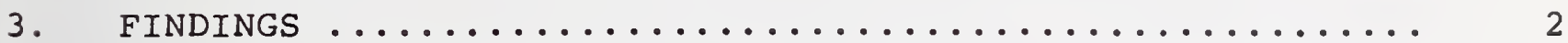

3.1 Specified Properties $\ldots \ldots \ldots \ldots \ldots \ldots \ldots \ldots \ldots \ldots$

3.1.1 Chemical composition .............. 3

3.1.2 Tensile properties ............... 6

3.1.3 Bend-test performance ............. 9

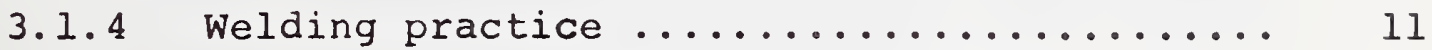

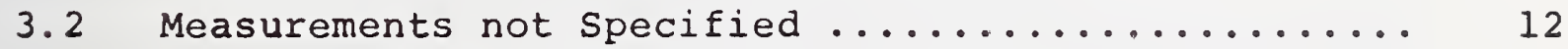

3.2.1 Hardness test results .............. 12

3.2.2 Macroscopic observations ............. 14

3.2.3 Microscopic observations ............ 18

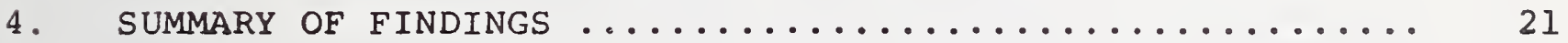

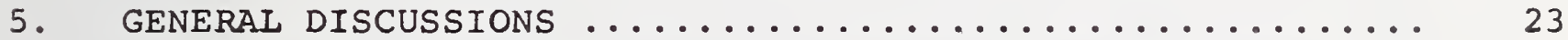

5.1 Effect of Inclusions on Mechanical Properties...... 23

5.2 Anisotropy of Mechanical Properties ............ 24

5.3 Observations of Unusual and Undesirable Features... 25 in Samples From Three Head Plates .............

5.4 South Byron Shell Plate Steel .............. 26

5.5 Abusive Service Requirements $\ldots \ldots \ldots \ldots \ldots \ldots \ldots$

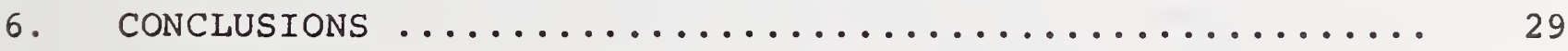

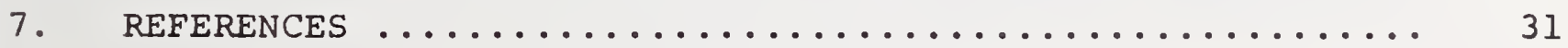


1. Identification of Samples Taken from Tank Cars ..........

2. Summary of Compositional Findings

3. Summary of Tensile Test Results

4. Abbreviated Summary of Bend Test Results

5. Summary of Observations Related to Welding Practice .......

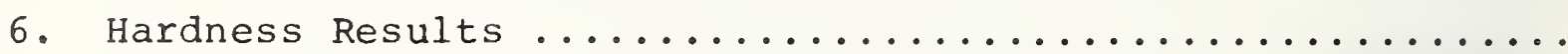

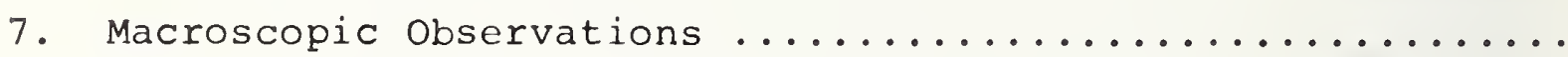

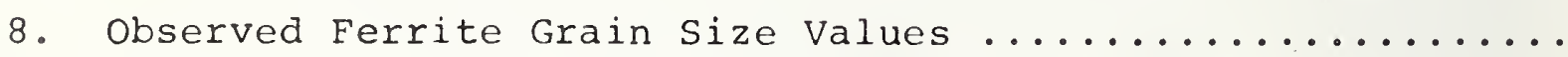

9. Inclusion Ratings by ASTM E-45 Method A for Five Plates Used for Studies of Mechanical Properties .............

10. QTM Inclusion Content Ratings in Area Percent for Five

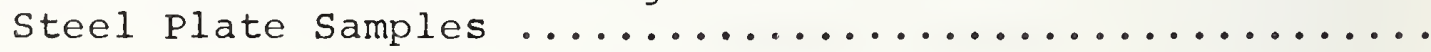

11. Comparisons of Results of Inclusion Ratings by

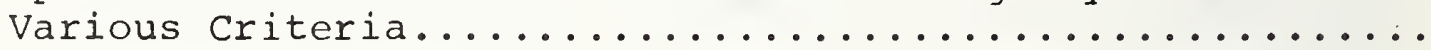

\section{FIGURES}

1. Comparison of Lonqitudinal and Transveŕse Ductility of AAR TCl28 steels of Various Strength Levels

2. Profile View of Crescent City Sample FRA-3 in the B Plane

3. Weld Cross-Section Taken from Callao Sample $\mathrm{K}-11$ at the Weld Between Shell Courses 4 and $5 \ldots \ldots \ldots \ldots \ldots \ldots$

4. Montage of Microstructure Through the Cross-Section of Callao Head Plate $\mathrm{K}-1$ with Hardness Values Shown

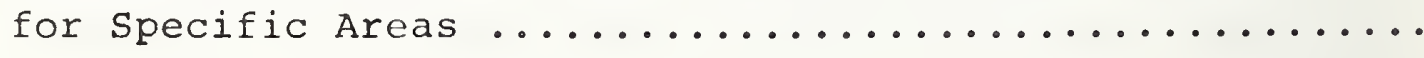

5. Comparison of Tensile Strength and Hardness of the

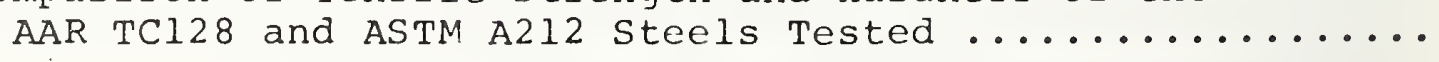

6. Profile Views of Fractures Taken from Crescent City

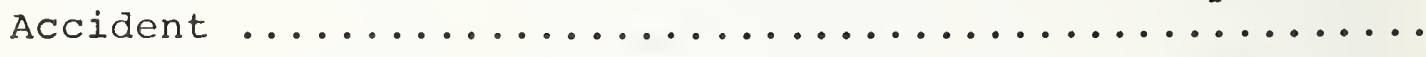

7. Profile Views of Fractures Taken from the Callao and

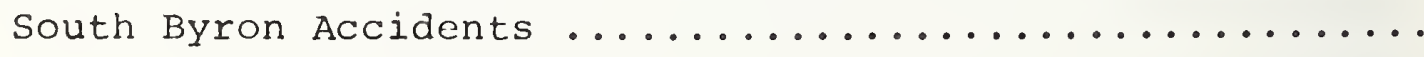


FIGURES (Continued)

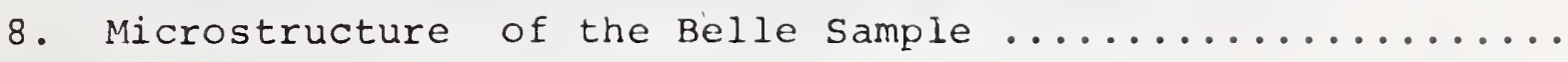

9. Drawing Showing the Three Mutually Perpendicular

Planes Associated With the Rolling Diection in

A Plate

10. Microstructure of the South Byron Shell Plate Sample,

As Observed on Three Mutually Perpendicular Planes ......

11. Microstructure of the Crescent City Shell Plate Sample

FRA-2, as Observed on Three Mutually Perpendicular

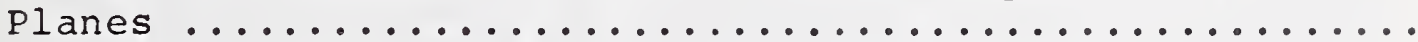

12. Microstructure of the Callao Head Plate $\mathrm{K}-1$, as

Observed on Three Mutually Perpendicular Planes

13. Microstructure of the Callao Shell Plate $K-5$, as

Observed on Three Mutually Perpendicular Planes ........

APPENDIX A - Specifications AAR M128-65, -69 and -70;

ASTM A212-65

APPENDIX B - Summary of Chemical Compositions ..............

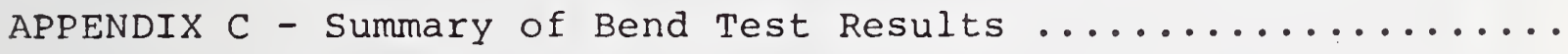

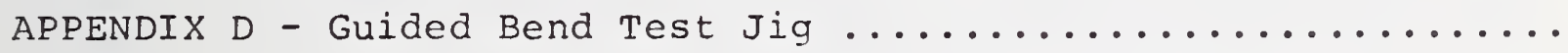




\section{PREFACE}

A comprehensive overview of the findings and metallurgical analyses of tests conducted at the National Bureau of Standards on samples of tank-car materials submitted by the Federal Railroad Administration is presented. The submitted samples were taken from tank cars which had been involved in accidents during the period January 1970 to January 1971. The testing conducted during the metallurgical analyses included full chemical analyses, ambient temperature tensile tests on longitudinal and transverse specimens, quantitative metallography to determine ferrite grain size, pearlite colony size, and inclusion content, size, and shape, hardness tests, bend tests on longitudinal and transverse specimens, and a very comprehensive program of impact testing, which is covered in a separate report on Impact Properties.

The data, which are presented in the Findings section of this report and which are summarized and discussed in the Summary and in the General Discussions, represent a valuable body of information from which the Conclusions were drawn. These summaries and conclusions on the properties of these steels, and the metallurgical factors affecting these properties, when taken in conjunction with the service requirements and the observed behaviors of the materials during the actual service failures, can be useful in making recommendations as to approaches to improved materials and improved specifications for the plate materials for tank cars.

While some attempt is made to relate the findings of laboratory tests of the materials to observations made at the accident sites and to the appearances of the fractures of the failed pieces submitted to the Bureau, the principle objectives are not to establish a cause of the failure for each of the five failed tank cars from which samples were submitted; rather, the intent is to determine if the plate samples conformed with the specifications to which the tank cars had been fabricated and to gather information pertinent to the question of the suitability of these materials for use as the plate materials of tank cars. Some departures from the requirements were found in these tests, mainly in the areas of chemical composition and bend requirements. These findings as well as others, such as those related to welding practices and those obtained through quantitative metallography, lead to some questions concerning the specifications for the materials and the possible means by which materials with improved performance under abusive service conditions may be specified in the light of an overall understanding of the problems and of the current materials technology. 
Report No. 5

Analysis of Findings from Four Tank-Car Accident Reports

\section{INTRODUCTION}

\subsection{Background}

Failures involving tank cars carrying hazardous materials have prompted the Federal Railroad Administration (FRA) to sponsor research studies aimed at the development of knowledge that could be used to prevent or minimize the sometimes catastrophic effects of these failures. As part of these studies, the FRA has requested that the National Bureau of Standards (NBS) conduct metallurgical analyses on steel samples taken from tank cars that were failed in four of the accidents which occurred during the period January 1970 to January 1971.

\subsection{Purpose}

The principal purpose of the metallurgical analyses was to determine if the steel samples conformed with the specifications to which the tank cars had reportedly been fabricated. Another objective was to gather information pertinent to the question of the suitability of the specifications for steels used as plate material of tank cars carrying hazardous materials. Thus, the information developed in the analyses of tank car samples is useful as a basis for understanding both the mechanical properties of the steels when fabricated as tank cars and the pertinent metallurgical factors that govern these properties, and this information may ultimately lead to a better understanding of and perhaps improvements of the mechanical integrity of tank cars, particularly under abusive service conditions.

\subsection{Scope of the Report}

The results summarized in this report of the metallurgical analyses conducted by NBS on steel samples takep from failed tank cars includes the findings of four accident reports ${ }^{-4)}$, each of which gives information on one or more steel plate samples taken from one failed tank car at each accident site, except for the Crescent City site from which samples were taken from two failed cars. 
As shown in Table 1, a total of 19 steel samples were submitted by FRA for these analyses. Each sample represents either a single plate of steel or two plates with a weldment joining the plates. Shell plates, cold-formed and hot-formed head plates are included. Three different grades of steel are represented: AAR TC128-A-69, AAR TC128-B-65, and ASTM A212-B-65. The pertinent specifications for these grades are given in Appendix $A$.

We note that in the specifications for plate materials for these tank cars, properties are specified for plates in the as-rolled condition and the plate samples taken for these studies were in the as-formed and stress-relieved condition. Furthermore, in the accidents, these plates could have received some reforming and/or heating during and following the failures of the tank cars. Therefore, the plates used for studies of the mechanical properties were plates selected to have (1) only minor or negligible amounts of reforming and (2) paint present on the surface, which indicates that the plate was not subject to excessively high temperatures. With these as prerequisites for the plates selected for studies of mechanical properties, it is believed that the observations and properties reported in the four reports that are here summarized are germane to the plates in the tank cars in service, except where noted otherwise.

\section{FINDINGS}

In this report, two categories of findings are given: (1) Those relating directly to the specifications to which the tank cars were constructed--presented in section 3.1, these findings indicate whether or not the steels and the fabricational procedures meet the requirements of the specification on chemical compositions, tensile properties, bend behaviors, and welding practice; and (2) those measurements and observations not specified but which relate to the question of the suitability of the steels for use as the plate material of tank cars--this second category, given as section 3.2, is somewhat more complex and in some instances more subjective and qualitative; it involves measurements of mechanical properties, such as hardness, and other measurements and observations, such as thickness measurements and metallographic observations of the microstructures, the types of inclusions and the percentage content of inclusions.

Each of these topics is presented and discussed here in the findings section of this report. The findings are then summarized and some general discussions, which may relate findings of more than one of these topics, are given. Finally, recommendations are made, based on the findings and analyses given here.

\footnotetext{
*For some plates, more than one sample was taken to represent the plate.
} 
Although some references to the results of impact tests are made in this summary, a full sumary of impact test results is presented as a separate report on the findings and significance of the impact tests conducted at NBS.

\subsection{Specified Properties}

\subsubsection{Chemical Composition}

Check chemical analyses were conducted by the Analytical Chemistry Division of NBS to determine whether or not the chemical composition of the plate samples taken from the failed tank cars conformed to the applicable specifications.

Specifications of the chemical requirements for the AAR TC128 steels and the ASTM A212-B steel are given as ladle analyses for various elements. Ladle analyses represent the liquid composition of the heat of steel from which plates are ultimately formed. Differences between ladle analyses and check analyses from finished plates represent chemical segregation. Chemical segregation occurs not only between ingots but also within an ingot, and therefore the location of the check analysis sample is very important.

A general procedure was followed regarding the location of the samples for check chemical analyses and the chemical detection techniques employed. Samples for chemical analysis were taken from the quarterthickness position in the plate or weld, as specified in ASTM Method E59-67 which treats the sampling of steel for determination of chemical composition. Optical emission spectrometric analysis was used for the determination of manganese $\left(M_{n}\right)$, phosphorus $(P)$, sulfur $(S)$, silicon (Si), vanadium (V), copper (Cu), nickel (Ni), chromium (Cr), molybdenum (Mo), al uminum $(A l)$, titanium ( $\mathrm{Ti}$ ), niobium (Nb), and zirconium $(\mathrm{Zr})$. Carbon (C) was determined by combustion-therma Iconductivity analysis. Exceptions to this general procedure occurred.

A complete summary of the chemical compositions as determined by the NBS check analyses is listed in Appendix B along with the applicable specifications ( $m i n$, max, range) and the available producers'..ladle analyses. Ten steel plate samples are grouped on the bas is of the specification to which they were produced: Four are ASTM A212-B-65

*Exceptions: (i) In the Belle, W. Va. accident, the sample taken for chemical analysis was removed from the surface of the plate rather than from the quarterthickness position. The phosphorus content was determined by photometric analysis (ASTM E350) and the sulfur by combustion-titration analysis (ASTM E395). (ii) In the Callao, Mo. accident, optical emission spectroscopy was used to determine all of the elements, including carbon. 
steels, five are AAR TC128-B-65 steels, and one is an AAR TC128-A-69 steel. Each check analysis represents a separate steel plate except for the shell plate samples FRA-1 and FRA-2, which were taken from the same plate. In addition to these plate samples, one analysis of a weldment (Callao, K-2) is given.

These analyses show that the check analyses for 3 of the 10 plates, for all specified elements, meet the chemical requirements of the applicable specification, and that all of the producers' ladle analyses - only 5 were available - are within the specifications. Thus for brevity, the present discussion will concern only (1) those analyses of elements with compositions outside of the specified range and (2) other analyses that in some other way are considered significant. See Table 2 for a summary of significant compositional findings.

We note that product analysis tolerances are not given in the specifications applicable to the three grades of steel. Thus, the question of how much the composition can vary, under a specified minimum or over a specified maximum limit, is an open question. To make a judgment on this question, it is useful to refer to ASTM Specification A6-70, which governs general delivery requirements of rolled steel plates and other shapes for structural uses. This specification allows the purchaser to make a check analysis of finished material representing each heat: Sampling of the finished material must be done in accordance with ASTM Method E59, and the chemical composition of the material shall conform to the requirements of the product specification, subject to the applicable product analysis tolerances given in A6-70. These tolerances were used in interpreting our findings on check analyses. However, the specified sample locations could not be followed because our plate samples were not taken from the ends (top and bottom) of the plate.

Carbon - In general, the carbon level in the check analyses of a11 10 plate samples was close to or above the maximum limit of the specified ladle analyses. As shown in Table 2, check analyses of one plate of A212-B steel, four plates of TC128-B-65, and one plate of TC128-A-69 steel revealed carbon contents in excess of specification limits by amounts varying from 0.01 to 0.05 weight percent. The analysis tolerance for carbon, as given in ASTM A6-70 for carbon-steel plates, permits a check analysis to be 0.04 percent by weight over the maximum specified ladle analysis. Using this ASTM criterion, only plate sample FRA-3 of AAR TC128-B-65 steel, taken from the Crescent City accident, falls outside the tolerance limit and thereby fails to meet the specification requirement. The other four TC128 steel plates and the three A212 steel plates meet the requirements. The consistently high level of carbon, measured in our 10 test samples and in the 5 ladle analyses, indicates that steel producers work to the top of the permissible range for carbon and that this is done to assure that the strength requirements will be met. 
Manganese - The check analyses for manganese have a greater variability than those for carbon, al though the manganese contents of only 3 of the 10 plate samples are above the specified maximum. One plate of A212-B steel (Crescent City) and 2 plates of TC128-B steel (Crescent City and South Byron) exceed the specification limits in amounts ranging from 0.01 to 0.05 percent by weight, as shown in Table 2. Using the criteria of ASTM A6-70, the analysis tolerance for manganese is 0.04 percent by weight over the maximum specification limit. By the argument given above for carbon, only one TC128-B plate sample, FRA-3 (Crescent City), exceeds the maximum allowed chemical variation. The two other plates, a TC128-B steel (South Byron) and a A212-B steel (Crescent City), meet the compositional requirements.

Sulphur and Phosphorus - Check analyses for sulfur and phosphorus indicate that, although all of the plate samples are with in the specified maximum limits, one or both of the elements are close to their limits for four steels: 1 plate of A212 steel (Crescent City), 2 plates of TC128-B-65 steel (Crescent City and South Byron), and 1 plate of TC128-A-69 steel (Belle), as shown in Table 2. The sulfur contents of the Crescent City shell plate samples FRA-5, FRA-3 and the A-head portion of FRA-2 were $0.047,0.04$ and 0.03 weight percent, respectively, and the South Byron plate sample contained 0.04 weight percent sulfur. All of these sulfur contents are near but within the specified maximum limit of 0.05 weight percent. The phosphorus levels of the Belle plate sample and plate sample FRA-3 (Crescent City) were 0.03 and 0.027 weight percent respectively; while these values are considerably higher than those determined in all other plate samples, they are within the specified maximum of 0.04 weight percent phosphorus.

\section{Veoxidation Practice - Specifications TC128-65 and TC128-69}

require a fine-grain steelmaking practice, while specification A212-B allows either coarse- or fine-grain practice. The check analyses for al uminum and/or vanadium showed that all of the plate samples except two had been produced to fine-grain practice. The levels of al uminum and/or vanadium present in one sample, A-head, FRA-2 (Crescent City). of the four A212 steel plates and in one sample, K-5 (Callao), of the six TC128 steel plates (see Table 2), indicate that the steels for these two plates were produced in accordance with coarse-grain practice. Therefore, the TC128-B steel sample, K-5 (Callao), was not produced in accordance with fine-grain practice required by the specification.

* The al uminum and/or vanadium check analyses indicate whether the steel was deoxidized by a combination of silicon and one or both of these grain-refining deoxidizers. When these elements are present only at very low levels, a fine-grain dioxidation practice was not used. 


\subsubsection{Tensile Properties}

A complete summary of the tensile test results from three head plate samples, three shell plate samples, and three weld samples--all taken from the four accidents--is shown in Table 3. Tension specimens were prepared in accordance with the appropriate product specification and tested in accordance with ASTM Methods and Definitions A370-71.

Test Specimens - The tension test specimens, 0.250 inches in diameter with a T-inch-gage length, were taken as closely as possible from the quarterthickness position of the plate. Longitudinal and transverse specimens were tested for each plate and weldment, except only transverse tensile specimens were taken from the head plate of FRA-2 due to insufficient material.

*The General Conditions for velivery section of the specifications for AAR TC128-69, AAR TC128-65, and ASTM A212-65 tank-car steels require that materials furnished to these specifications must conform to the applicable requirements of ASTM Specifications A20-67 and A20-65 respectively. Specifications A20-67 and A20-65 require for plates 1-1/2 inch and under in thickness, tension test specimens shall be Standard Rectangular Tension Test Specimens with 8-inch-gage length and for plates over 1-1/2 inches in thickness, tension test specimens shall be Standard Round Tension Test Specimens with 2-inch-gage length, 0.505 inches in diameter. For plates up to 4 inches in thickness, Standard Rectangular Test Specimens with 8-inch-gage length can be used if testing machine capacity exists. However, both A20-67 and A20-65 require the tests to be conducted in accordance with the ASTM Methods and Definitions A370, for the Mechanical Testing of Steel Products. ASTM A370-68 allows Standard Round Tension Test Specimens and Small Size Specimens proportional to the Standard Round Specimen to be used when it is necessary to test material from which the Standard Rectangular Test Specimens of 8-inch- and 2-inch-gage length cannot be prepared. Because the amount of plate material available for machining test samples was sometimes limited in our studies, it would not always have been feasible to prepare the Standard Rectangular Tension Specimens. The Standard Round Tension Test Specimen, 0.505 inches in diameter, has a 2-inch-gage length, thus allowing direct comparison between test result and specification; however, the threaded end section requires a diameter of $3 / 4$ inches, which exceeds the plate thickness of the head and shell plates tested. Thus, for test consistency from plate to plate, the tensile test specimens were machined to standard 0.250-inch-diameter round test specimens with a 1-inch-gage length.

\footnotetext{
*A1though the specifications ASTM A212-65, AAR TC128-65, and AAR TC128-69 do not specify test specimen orientation. ASTM A370-71 does specify that wrought steel products are usually tested in the longitudinal direction but that where size permits and service justifies it, transverse testing is done.
} 
Strength Levels - The measured values of tensile strength and yield strength for four of the six plate samples tested were with in the specification limits. The two plate samples outside the specified limits were the South Byron shell plate sample (an AAR TC128-65 steel) and the Belle head plate sample (an AAR TC128-69 steel). For. the South Byron sample, the longitudinal and transverse tensile-strength values exceeded (by up to $2 \%$ ) the specified maximum limit, but the yield-strength values met the requirements and were well above the specification minimum level. For the Belle sample, the longitudinal yield-strength values were below (by up to $8 \%$ ) the specified minimum yield strength.

Yield point phenomena, as measured by a distinct yield point or a lower-yield point, were observed in both longitudinal and transverse specimens in four of the six plate samples but were not seen in any of the specimens from the AAR TC128-69 Belle head-plate sample or in three of the four specimens from the AAR TC128-65 Callao $(K-1)$ head-plate sample. The presence or absence of yield-point phenomena can provide information on the recent thermal mechanical history of the test sample.

Tensile Ductility - Tensile ductility data for all six plate samples were measured by percent elongation in a l-inch-gage length and by percent reduction in area at the fracture. For all plates tested, the ductility as measured by percent elongation exceeded the minimum specification requirements. For the $\mathrm{TC} 128$ steels the longitudinal ductility was approximately 10 percent higher than the transverse ductility; for one A212 steel tested, this value is only 4 percent. This latter finding indicates the degree of the anisotropy of tensile ductility of the plates and grades of steel tested. This result is illustrated in Figure 1 where percent elongation is plotted against the ultimate tensile strength for all AAR TC128 steels tested. The graph includes both head and shell plate specimens and illustrates that the anisotropy is independent of whether the test specimens were from head or shell plates.

Reduction-in-area measurements are not specified in either ASTM A212-65 or AAR M128, but they provide a useful check of the elongation results, as percent-reduction-in-area measurements are independent of the gage length of the specimen. The trends for reductionin-area data given in Table 3 are similar to those for elongation data.

Weldments - The three weldment samples (one weld of ASTM A212 plates and two welds of AAR-TC128 plates) have acceptable elongation values, and their tensile- and yield-strength levels meet the minimum requirements for the plates, indicating that the joint efficiency is 1.0 for all welds tested. 
Ferrite Grain Size - Also tabulated (in Table 3) for the six steels on which tensile data were taken are the ferrite-grain-size determinations as measured in accordance with ASTM E112 Method of Vetermining Average Grain Size in Metals. The effects of grain size on yield strength, hardenability, and toughness has long been known. Three of the plate samples have ferrite grain size numbers in the range of 7 or 8 . One plate sample of A212-B steel that was not produced to fine-grain practice (FRA-2, A-head, Crescent City), has a ferrite grain size of 6 and is coarser than the other five plates, which were made to fine-grain practice. One plate sample has a uniformiy finer grain size than the others, the Belle sample (a AAR-TCI28 steel), which contains sufficient vanadium to satisfy the requirements for Grade $A$ of the MI28 specification. Lastly, a hot-formed head plate (K-1, A-head, Callao) of TC128-B steel has a variable microstructure with ferrite grain sizes varying from 7 to 9 through the thickness of the plate.

* The ferrite grain size is not specified in either ASTM A212 of AAR M128, but indirect reference is made to austenite grain size through the specification requirement of coarse- or fine-grain practice, i.e., the austenite grain size existing just before cooling through the transformation temperature sha11 be fine or coarse. ASTM A212 allows either fine- or coarse-grain practice while AAR MT28 specifies fine-grain practice only. The microstructures of both ASTM A212 and AAR TC128 steels consist of proeutectoid ferrite and pearlite, and the coarseness of the pearlite colonies (surrounded by ferrite at the prior austenite grain boundaries) can represent the grain size of the austenite, prior to its transformation. to ferrite and pearlite. However, there is a problem in attempting to correlate ferrite grain size with deoxidation practice for steels which are not reaustenitized after hot rolling (i.e., shell plates and coldformed head plates). A fine-grain practice can reliably control the austenitic grain size of reaustenitized steel provided that excessively high austenitizing temperatures are not used. The grain size for hot-rolled steels (even when produced to fine-grain practice) may be coarse if the rolling finishing temperature is high, as it frequently is. Thus a specification of fine-grain practice will not consistently result in fine-grained steel, unless the plates are normalized after rolling or unless the finishing temperature for hot rolling (or the reaustenitizing temperature allowed for hot forming) can be specified and rigidly controlled in a manner that always results in a fine-grained austenite. 
Ferrite grain size is primarily controlled by the prior austenite grain size and by the cooling rate through the transformation temperature. Thus it is affected by deoxidation practice, the finishing temperature of rolling or forming operations, and the rate of cooling after these operations.

\subsubsection{Bend-Tests Performance}

Bend tests were conducted on 24 specimens of plate steels and on 4 specimens of weldments. A complete summary of these test results is given in Appendix $C$.

For tests of plate steels, pairs of longitudinal and transverse bend specimens were prepared and tested. Bend tests were conducted in accordance with the requirements of ASTM Designation A370-68 Standard Methods and Definitions for Mechanical Testing of Steel Products. Specimens of $3 / 8$-inch thickness were bent through an inside diameter of $3 / 4$ inches, so as to provide a ratio of bend diameter (d) to thickness $(t)$ equal to 2 , as required for the ASTM A212 and the AAR TC128 steels tested. Tests of transverse specimens are not required. For the weldments, side-bend specimens were tested and a less severe bend ratio of 4 was used to meet the test conditions given in the methods of ASTM E190-64 for the guided-bend test for ductility of welds. The apparatus used for all bend tests is that given in Appendix $W$ of the AAR Specifications for Tank Cars and given here as Appendix D.

* Dimensions of all test specimens were 3/8-inch thick $\times 1-1 / 2$ inch wide ${ }^{*} 6$-inch long, except that the width of the side-bend specimens for welds is the plate thickness.

The wigth of the bend specimens significantly affects the bend ductility. Dieter ${ }^{2}$ has reported that ductility, in terms of the bend angle before cracking occurs in a material in bending, decreases with increasing values of the width to thickness ratio, w/t, until a terminal level is achieved at a $w / t$ equal to about 8 . As this ratio of $w / t$ increases, the ratio of the transverse stress to the circumferential stress also increases and the bend ductility of the specimen decreases. Therefore, in order to have a bend test specimen of "intermediate" severity, the $\mathrm{w} / \mathrm{t}$ ratio of 4 was chosen for the bend specimens tested at NBS. However, we note that adherence to ASTM Specification A20, referred to in both of the steel plate specifications, would permit a specimen thickness equal to the plate thickness. The width is $1-1 / 2$ inches. Thus, the width to thickness ratio for 5/8-inch thick plates $(w / t)$ would equal approximately 2.4 ; this test may be a test at a severity level different from that conducted by NBS, as the $w / t$ ratio of the NBS tests was 4.0 with a $1-1 / 2-i n c h$ wide by $3 / 8$-inch thick specimen. 
The results of bend tests for a total of 28 specimens are given in Table 4 in an abreviated form. Fourteen specimens from three accident sites (including four side-bend weld specimens from two of these sites) passed the required bend test, whereas six shell-plate specimens, including two specimens of the required longitudinal orientation, from the South Byron accident failed the required bend test.

Bend tests are used to assess surface quality and ductility, and the failures of all six of the standard South Byron bend specimens indicate that ductility of this steel may be inadequate, and this conclusion seems consistent with the results of tensile tests in which the steel met the elongation requirement by only a small margin but it is not consistent ${ }^{(2)}$ with the results of the mill bend tests required for delivery of the plate. This is discussed in section 5.4.

Six additional South Byron shell-plate specimens were tested at non-standard $d / t$ ratios. Two of these failed in tests more severe $(d / t=1.7)$ than the specification requirement and four of these passed in tests less severe $(d / t=4.0)$ than the specification requirements.

Two additional bend specimens taken from the Callao head plate were tested in a non-standard manner after one longitudinal specimen and one transverse specimen passed the required bend test with the outside surface of the tank car being the outer curve of the bend. In these two non-standard tests, the specimens were tested with the outside surface of the tank car being the inner curve of the bend. The transverse head-plate-sample K2-6 failed this test. Cracks were visible at an angle of bend of approximately $120^{\circ}$. With further bending, the cracks extended until the specimen fractured into two pieces at $180^{\circ}$ of bend. While this failure is not considered a failure of the bend requirement for this steel, the failure is instructive. This transverse specimen failed at a relatively low bend angle of $120^{\circ}$ and the longitudinal specimen did not fail, indicating that the tendency for bend-test failure will be greater for transverse bend specimens. * Furthermore, the steel of the failed specimen was different from the steel for specimens tested in the standard manner in that the outer curve of the bend represented the steel near the center of the plate for the non-standard test whereas it represented the plate surface in the standard test. In addition, the inclusion content near the mid-thickness and center of the plate is greater than that near the plate surfaces. Thus, these tests indicate that the tendency to fail in the bend test increases with the inclusion content, which is to some extent dependent upon the thickness location within the plate, and that in these steels transverse specimens have less bend ductility than longitudinal specimens.

This finding is consistent with the results of the failures of the six South Byron standard bend tests. The two longitudinal specimens failed by crazing only, whereas all four transverse specimens failed at relatively low angles of bend. 


\subsubsection{Welding Practice}

The specifications for the steels used in the tank cars of the four accident reports state that "Welding technique is of fundamental importance and it is presupposed that welding procedures will be in accordance with good practice" (M128 specifications) and "Welding technique, etc....... in accordance with approved methods" (A212 specifications). Accordingly, weldments submitted to NBS for these metallurgical analyses were examined and tested to gather information on the methods and practices used in welding of the tank cars.

Of the 19 plate samples submitted to NBS, six contained weldments and two additional plates contained a weld heat affected zone (HAZ) with little or no weld metal. These eight plates were visually examined and various tests were made on their weldments and HAZ regions. The visual examinations included inspection of fractures related to the weldment or its HAZ and examination for the alignment of the plates being welded. On three of these weldments, the tests were extensive and included side-bend tests, tensile tests, and selected hardness tests. The three weldments examined in this detailed way include two weldments that joined the "A" head plate to the first shell course of a tank car; one of these weldments joined two A212-B steel plates (sample FRA-2), and the other one joined TC128-B steel plates (sample $\mathrm{K}-2)$. The third weldment joined one shell course to another shell course of TC128-B steel (sample K-8). In addition, chemical analyses were made on one weldment and impact tests (not reported here) were made on selected weld-metal and HAZ specimens taken from three of these plates. The results of these examinations and tests are summarized in Table 5.

For the three weldments most extensively tested, with side-bend tests, tensile tests and measurements of hardness, the results indicate that: (1) The ductility of these weldments is good. All passed the bend test and the ductility in tensile tests exceeded the elongation requirements of the plates being joined. (2) The joint efficiency of the weldments was 1.0 , i.e., the strength of the weldment meets or exceeds the required strength for the plates that it joins. (3) The hardness of these weldments is satisfactory, being uniformly hard enough in the weld-metal region to match the strength requirements of the plate steels and being soft enough in the HAZ region to indicate that the plates were properly stress relieved after welding.

Each of the two plate samples that contained an HAZ but little or no weld metal, samples K-6 (Callao) and FRA-2 (Crescent City), contained a region in which a crack propagated along a heat affected zone, a tendency which would be expected to increase with increasing values of HAZ hardness. For TCl28 steel, the maximum measured Knoop hardness in the HAZ corresponds to that of steel with tensile strength of about $117 \mathrm{Ksi}$. This value is not excessive in comparison with the tensile strength of about $90 \mathrm{Ksi}$ of unaffected base metal. 
The fracture of FRA-3 (Crescent City) may have contributed to the failure of tank car designation SOEX 3219. This was concluded upon finding a region of high hardness ( $R_{c} 28$ ) and a secondary crack. These were observed near the surface of the plate sample at a location near the fracture. This region is believed to be an HAZ of a welded attachment that was improperly stress relieved. See Figure 2. The region of higher hardness in the HAZ of this weldment would be expected to have limited ductility and the presence of the secondary crack is illustrative of this point. However, it is also possible that the cracking started outside of the HAZ region and followed the HAZ only because of the less favorable stress state due to the joint contour.

Six of the eight weld related samples contained weldments that were visually examined for plate alignment. The alignment for five of the six plates was satisfactory, but the sixth plate, sample K-11, (Callao) was not properly aligned and it contained an unusually wide circumferential weldment. This was the weld between shell courses 4 and 5 of TC GATX 94451 . A section taken from this weldment, shown in Figure 3 indicates that this weldment contains a total of seven weld passes: It has four large weld passes presumed to be submerged-arc welds and three small passes. Two of the large passes were the first to be deposited, one from each side of the weld groove. Then, the other two large passes were deposited on one side of this weldment while three small passes were deposited on the other side of the weldment. It appears that these later 5 passes were deposited to smooth out the discontinuity of a misalignment of the plates that arose after the first two passes had been deposited. The offset of these plates in this region was measured at NBS to be about 0.203 inches and this value exceeds, by 0.047 inches, the tolerance prescribed in the AAR SPECIFICATIONS FOR TANK CARS, January 1, $1970 \mathrm{kd}$. (Appendix W, Table 15.03(a). This is an example of poor welding practice.

\subsection{Measurements not Specified}

\subsubsection{Hardness Test Results}

Hardness is not a specification requirement, but hardness measurements can be very instructive in metallurgical analyses. Hardness measurements were taken on 19 specimens from 11 plate samples. The results of these measurements are given in Table 6 . For all the samples except the Belle head-plate sample, the measurements were taken on planes perpendicular to the plate surfaces. On the Belle sample these were taken on a plane parallel to the surface of the plate. Most of the hardness measurements were Rockwell B measurements, but one set of Brinell measurements were taken and three sets of knoop hardness measurements were taken, two in heat-affected-zone (HAZ) regions and one set through the thickness of a plate steel sample. 
The hardness results indicate that for the steels investigated, the hardness throughout each plate sample (with the exception of the head plate from the Callao accident) is generally uniform. The results also show that the average hardness is $R_{B} 80.2$ for the ASTM A212 steels tested and $R_{B} 92.8$ for the AAR TC128 steels tested. The A212 steels have average hardness values of 80.3 for the shell plate and 79.9 for the head plate. For the AAR TC128 steels the averages are $R_{B} 93.1$, and $R_{B} 92.3$, respectively, for the shell and head plates.

Hardness measurements taken on the "mixed" microstructure shown in Figure 4, a microstructure which varies greatly from the outside to the inside of the head plate, clearly points up this microstructural dissparity. The average hardness near the outside, where the microstructure is finer is about $R_{B} 88$, whereas near the inside surface where the microstructure is coarser, the average hardness is about $R_{B} 94$.

Hardness measurements alone are difficult to assess since hardness is not a well-defined property. However, empirical relations between hardness and tensile strength exist for most carbon steel \& $_{6}$ ) One such correlation is shown as the continuous curve of Figure 5. Also plotted are the average measured values of hardness for the six plate steels tested in the four accident reports. The INBS data and the empirical curve compare as favorably as might be expected for this type of correlation, and the Figure points up that hardness can be a useful gage of tensile strength. However, hardness is most useful in metallurgical analyses as a tool for gaging variability of mechanical properties within a given material.

Hardness measurements taken on the heat-affected zone ( $H A Z$ ) of the Callao plate sample K-8 indicate that as expected, the HAZ hardness is appreciably greater than the hardness of the unaffected base metal of this AAR TC128 steel. Regions of higher hardness, such as those found in the HAZ of weldments, could either act as sites of crack initiation under overload conditions or they could provide paths for easier crack propagation under unusual combinations of stress and weld geometry. Further, residual stresses in as-welded structures may be just as important as microstructure (or hardness) in causing crack initiation or propagation in certain regions. Therefore thermal stress relief is beneficial to both hardness and stress reduction.

Figure 2 shows a cross sectional view of TC128-B sample FRA-3 and a "white" area, marked $A$, which was believed to be a weld HAZ. The average Knoop hardness value in Region $A$ was 295, which converts to $R_{C} 28$. The average knoop hardness of an area remote from the $H A Z$ was 238, which converts to $R_{B} 97$. These results indicate that region $A$ is significantly higher in hardness than the hardness of (the surrounding base metal in sample FRA-3. In addition, it is believed that this 
hardness value is abnormally high and higher than the hardness that would be obtained in a weld HAZ in this steel after a stress-relief treatment at the recommended temperatures of 1100 to $1200 \mathrm{~F}$. A metallographic analys is showed that the unaffected base metal of sample FRA-3 contained spherical carbide precipitates which indicated that the bulk of this sample had been stress-relieved at relatively high temperatures. Thus, it is concluded that Region A of Figure 2 in sample FRA-3 is an HAZ of some head plate attachment, which was not given a proper post-weld stress-relief heat treatment, perhaps because it was produced after the stress-relief treatment. In service, this local site would have a much greater potential for crack initiation when compared with properly stress-relieved metal.

\subsubsection{Macroscopic Observations}

A total of 11 plate samples taken from 4 accident sites were examined. Three plates were ASTM A212-B-65 steel, six were AAR TC128-B-65 steel, and one was AAR TC128-A-69 steel. Thirty-one different areas of the fracture surfaces of these plate samples were examined to determine the type and condition of paint on the outside plate surfaces and to classify the observed fracture modes. Fracture profile sections taken from each of the 31 selected sites and classified on the basis of the following four profile types: (1) NP, fracture face is nearly perpendicular to the plate surfaces; (2) shear, fracture face inclined approximately 45 degrees to the plate surfaces; (3) mixed, a combination of types (1) and (2); and (4) Tamellar tearing, fracture face contains steps or ledges that are parallel to the plate surfaces. Examples of each of these modes are shown in Figures 6 and 7, and a complete summary of the modes observed and other macroscopic observations is given in Table 7.

Plate thickness measurements were also taken at 24 of the 31 selected areas. These measurements were made along a line perpendicular to the fracture surface (at appropriate intervals) until the measured thickness became constant. Plate thickness was measured and the percent reduction in plate thickness was calculated for the region near the fracture surface. These plate thinning calculational results are given in Table 7 along with data on the $50 \%$ shear transition temperature determined from Charpy V-Notch (CVN) tests on 6 of the 11 plate

* The plate thinning percentage was based on the measured full plate thickness rather than the nominal plate thickness so as to provide a more accurate parameter for gaging the extent of deformation near the fracture. 
samples taken from the four accident reports*. The last two columns in Table 7 give the ambient temperature for each of the accidents and an estimate of the temperature of the steel sample at time of failure, based on an evaluation of the other data in the table. These data, combined with the plate appearance and fracture mode data, are shown in Table 7.

The presence and condition of paint on the outside surface of the plate samples is indicative of whether the plate was subjected

to fire. This indication can be used, along with the ambient temperature at the time of failure, in interpreting the signficance of other observations such as the fracture mode, the percent plate thinning, and the 50\%-shear transition temperature.

Only three plates, as is indicated in Table 7, gave evidence of having been subjected to fire in the accident. These three plates are from the Crescent City (two tank cars) and South Byron accidents, both of which involved fires and explosions of the tank cars. The South Byron plate was covered with paint that had blistered but not charred, indicating a moderate exposure to fire. Plates FRA-4 and FRA-5 from the Crescent City accident had, respectively, white powder and no paint on their surfaces, indicating a substantial exposure to fire.

The majority of the samples from the other two (Callao and Belle) accidents, as shown in Table 7 , have fracture modes that are predominately brittle with fractures that propagated in planes nearly perpendicular to the plate surfaces, i.e., the NP mode, whereas the samples from the Crescent City and South Byron accidents have fracture modes that are generally of the shear and mixed type, indicating a more ductile failure.

The tank cars involved in the Crescent City accident, SOEX 3037 and SOEX 3219, eventually exploded after being heated by a fire. Tank car 3037 contained plate samples FRA-1, FRA-2, and FRA-5, all ASTM A212-B steels, and tank car 3219 contained plate samples FRA-3 and FRA-4, both AAR TC128-B steels. The appearances of the fractures on the ASTM A212-B and AAR TC128-B plate samples are consistent with both the paint * observations on the plate surface and with the impact test results.

* Results of impact tests on these steels are discussed in a separate report.

* We have no data on the thermal behavior of the paint that was used on these two tank cars. 
Neither the outside surface of FRA-2 near the fracture surface nor any part of the plate surface of FRA-5 contained any paint residue. The fractures of these plates were of the ductile shear type with 13-percent plate thinning for the shell portion of FRA-2 and 23-percent thinning for FRA-5. These results indicate that fracture occurred at an elevated temperature. The 50\%-shear transition temperatures of both the shell and head parts of FRA-2 (not determined for FRA-5) are relatively high, about $85 \mathrm{~F}$ and $140 \mathrm{~F}$ respectively, being well above the ambient temperature of 53 F. Thus, it is concluded that these plates at the time of failure were heated significantly above the ambient temperature, probably in excess of $200 \mathrm{~F}$. The fracture of plate FRA-1, taken from another location in the shell plate that contained the shell plate portion of FRA-2, was brittle in appearance with only one-percent reduction in thickness and evidence of a red paint or primer on the plate surface. This plate was therefore probably not heated substantially at the time of failure, a conclusion which is in agreement with the fact that the CVN-50\%-shear temperature of this shell plate was about $85 \mathrm{~F}$, a temperature well above that of the ambient air.

Two of the three AAR TC128-B-65 steel samples, FRA-3 and FRA-4, contained, respectively, lamellar tearing and shear fractures (shown in Figures $6 \mathrm{a}$ and $6 \mathrm{~b}$ ) with thinning near the fracture being about 0.5 and 10 percent. The presence of paint on the surface of FRA-3, coupled with the negligible plate thinning at the fracture surface, suggests that this plate fractured at temperatures within the ductile-brittle transition region. The presence of paint residue and significant plate thinning of FRA-4 suggests that this plate fractured at temperatures above the transition temperature. CVN test data are not available for these plates.

The third plate sample of AAR TC128-B-65 steel believed to have been subjected to heat from a fire is from the South Byron accident. Examination of this shell plate sample shows that the paint was blistered, but there is little or no evidence of paint charring. The best estimate of the thermal behavior of the paint indicates that charring would occur at roughly 400 to $450 \mathrm{~F}$, and the paint would be completely burned off at $600 \mathrm{~F}^{*}$ Based on this estimate, it appears that the surface of the sample could not have exceeded $450 \mathrm{~F}$ and that the actual temperature was between the ambient temperature of $68 \mathrm{~F}$ and about $400 \mathrm{~F}$.

*A telephone conversation on 7-6-71 between Q. Banks (FRA) Washington, D.C. and $\dot{C}$. Graves (GATX) Sharon, Pa. provided this estimate. 
The fracture surface of the South Byron plate reveals a fracture mode which changes from one end of the fracture line (type NP), through a transition region (mixed type), to the other end (shear type) indicating that the temperature of this steel at the time of fracture was in the transition region. The 50\%-shear transition temperature for this plate is about $32 \mathrm{~F}$ as measured by CVN tests. Plate thinning measurements in areas of each fracture mode type ranged from three to six percent with the greatest thinning in the shear fracture region. Thus it is probable that a portion of the plate fractured at a temperature at which the resistance to fracture propagation is near the maximum for this particular plate. This temperature, called the upper-shelf temperature, was determined from the CVN tests to be approximately $80 \mathrm{~F}$ or higher. It is therefore concluded based on all of these observations that the plate temperature at the time of failure was above the ambient but presumed to be closer to the ambient temperature than to $400 \mathrm{~F}$.

The remaining five plate samples were taken from two accidents in which the failures were the result of severe impact loads. Samples from these tank cars were not heated either before or after the failure. These include four plates of AAR TC 128-B-65 steel from the Callao site and one plate of AAR TC128-A-69 from the Belle site.

Plate samples $K-1, K-3, K-5, K-6, K-7, K-9, K-10$, and $K-12$, from the four Callao plates contained a predominance of NP type fractures, indicating that fracture occured at temperatures below the ductilebrittle transition temperature. The $50 \%$-shear temperature, as measured by CVN tests, for the head plate, sample $K-1$, and for one shell plate (samples K-3, K-5, and $\mathrm{K}-6$ ), are, respectively, about $90 \mathrm{~F}$ and $55 \mathrm{~F}$. These transition temperatures are well above the ambient temperature of $15 \mathrm{~F}$, indicating brittle fracture would be expected. This conclusion is supported by the measurements of plate thickness which indicate that plate thinning is two percent or less.

The single plate sample of AAR TC128-A-69 steel, taken from the Belle head plate, failed at an ambient temperature of $-2 \mathrm{~F}$. The fracture surface of this sample indicates a mixed failure mode of primarily type NP with shear lips at the plate surfaces. This mode indicates that the temperature of the plate at failure was within the ductile-brittle transition and below the 50\%-shear transition temperature. The 50\%-shear temperature for this plate sample, measured by CVN tests, is between $-12 \mathrm{~F}$ and $-35 \mathrm{~F}$. C V V t test results suggest that at the ambient temperature the steel would be on the upper shelf with a 70-100\% shear fracture appearance. A probable explanation for these conflicting observations is given in the accident report: Prior to the accident, a crack existed near the HAZ of the weld between the stiffener plate and the head plate, and the impact of the accident caused this pre-existing crack to propagate partly into the head plate but primarily along the HAZ of the weld. Due to lack of material, CVN tests of HAZ specimens were not conducted; thus, the plate impact data is not representative of the HAZ and cannot be directly correlated with the mode of fracture. 


\subsubsection{Microscopic Observations}

The metallographic studies include observations of microstructures and inclusions and ratings of grain size and inclusion content. None of these observations and ratings are requirements of the specifications for A212 and TC128 steels. Grain size was rated by optical comparison using the standard grain size charts given in ASTM E112. Inclusion content was rated both by the method prescribed in ASTM E45, which uses the JK charts for the four basic types of inclusions, and by a quantitative television microscope (QTM) method, which rates the inclusion content as an area percent of the section being rated.

ASTM E45 is used to rate the relative quantity of each of four types of inclusions: Type A, sulfide; Type B, alumina; Type $C$, silicate; Type D, globular oxide. Within each type there are subtypes of thin and heavy; the heavy usually applies to heavy-section forgings . The worst field per 100 fields of inclusions of each type in any area (of 0.250-square inches) rated is given on a scale of 0 to 5. Zero represents nearly none and 5 represents the largest amount on this scale.

The QTM method rates the inclusion content as an area percentage at each of two magnifications, $\times 338$ and $\times 1300$, for specimens taken from the South Byron sample, and at one magnification, X338, for specimens taken from both the head and the shell plates of sample FRA-2 from the Crescent City accident, and from samples $K-1$ and $K-5$ from the Callao accident. The area percentage measurements were made at two quarterthickness locations and at the midthickness. In addition, for each 100 fields rated, the worst field and the number of fields with inclusion area greater than 0.5 percent, were tabulated.

Microstructures - A total of 22 metallographic samples sectioned from 15 plates were examined for general microstructure. This was done on one surface taken normal to the plate surfaces, as shown in Figure 8 , which shows the microstructure of the Belle sample at $\times 100$ and $\times 240$. The microstructures of several of the plates used for studies of the mechanical properties were observed on three mutually perpendicular surfaces oriented as shown in Figure 9. These microstructures are presented as Figures 10 through 13, respectively representing the South Byron sample, Crescent City-sample FRA-2 (she11) and Callao-samples $\mathrm{K}-1$ and $\mathrm{K}-5$. 
The microstructures shown represent the various microstructures observed in the 15 plates. These microstructures are not unexpected for carbon-manganese steels in the as-rolled condition, produced in accordance with the specifications for grades A212-B and TC128-A \& $-B$. Each of the microstructures shows some banding, with the banding being only moderate in shell plates K-5 and FRA-2, intermediate in the South Byron shell plate, and substantial in head plates $\mathrm{K}-1$ and Belle. The banded microstructure consists of alternate layers (parallel to the plate surfaces) of proeutectoid ferrite and pearlite. In unbanded microstructures, like most of that shown for plate K-5 in Figure 10, the ferrite and pearlite are more homogeneously distributed.

The results of ratings by the QTM method are given for 18 specimens taken from five plates in Table 10. The data indicate that for each of the steels rated, the rated inclusion content is similar for the quarterthickness and midthickness. The South Byron data, which were taken at two magnifications ( $\times 338$ and $\times 1300$ ), indicate that the area-percent values are about 10 percent greater at the higher magnification. This is true for all except the worst field ratings, which are somewhat more variable and which are about 30 percent greater at higher magnification. The ratings at higher magnification have greater accuracy due to higher resolution. However, the ratings at lower magnification cover a greater area with fewer observations, and they are considered sufficiently accurate for comparisons of the five plate steels rated by QTM at X338.

Table 11 gives a summary of the results of the inclusion ratings by ASTM Method A and by the QTM method at X338. Method A results for Type A thin are given for comparison with the QTM results for overall inclusion area percent, number of fields greater than $0.5 \%$, and Worst Field. The first four of the six steels listed were rated by both ASTM method A and the QTM method. A comparison of the results by each of the four criteria indicates that they all rank the steels in a consistent manner. Thus, even for cases in which only one criterion has been evaluated, the steel can be ranked.

We classify these steels into three arbitrary ranks: Rank 1 moderate content; Rank 2 - intermediate content; and Rand 3 - high content. Thus, the table ranks all six steels: Rank 1- A212-B shell of Crescent City and A212-B head of Crescent City; Rank 2- TC128-B shell of Callao and TC128-B head of Callao; Rank 3- TC128-B shell of South Byron and TC128-A of Belle. (zanding augments the anisotropy of mechanical properties due to inclusions. The mechanical properties of the unbanded steels would thus be expected to be more isotropic, with the properties being similar in the longitudinal and transverse directions (and perhaps, even in the thickness direction) of the plate, particularly for steels with low inclusion contents. 
The size of the pearlite colonies reflects the size of the prior austenite grains from which the pearlite and proeutectoid ferrite were formed on cooling after hot rolling. In these photomicrographs, the pearlite is coarse in the South Bryron shell plate and in the FRA-2 shell plate. It is intermediate in the K-5 shell plate and in the $K-1$ head plate and fine in the Belle head plate. The pearlite colonies of the cold-formed head plate steel of sample FRA-2 are much larger than any of the other steels used in our mechanical properties studies; this is consistent with the finding that this steel was not made to fine-grain practice.

More important than the size of the pearlite colonies is the ferrite grain size and the fraction of ferrite in the microstructure, as the mechanical properties of steels with less thapg9.4-percent carbon are more closely related to these parameters. The ratings of ferrite grain size for 14 steel plates are given in Table 8. The ASTM ferrite-grain-size number of the five steels used for studies of mechanical properties are as follows: Belle (8-9), South Byron (8), Crescent City FRA-2 shell (7), Callao K-1 (7-9), K-2 (8), K-5 (7). The higher numbers represent the finer ferrite grains.

When other factors are held constant, a decrease in ferrite grain size leads to an increase in yield strength, and toughness is generally improved at a given level of strength. Toughness can also be improved by increasing the fraction of ferrite, and this can be done by decreasing the carbon content. In addition, some of the processing and compositional variables can affect toughness by affecting ferrite grain size.

A microstructure of unexpectedly high variability was observed at one location in the TC128-B steel head-plate $\mathrm{K}-1$ of the Callao accident. This variability of microstructure is shown in Figure 4, a montage of $\times 30$ observations taken at various plate thickness locations from the inside surface to the outside surface of the plate. The microstructure of the inside locations is generally coarser, with coarse ferrite (7) and large pearlite colonies, when compared with that of the outside locations. The outside, with its finer microstructure, was observed to have better resistance to impact failures. The microstructures observed at other locations within sample $\mathrm{K}-1$, and in sample K-2 from another part of the same head plate, were similar to the coarser microstructure shown (in Figure 4) for the inside of the plate. This variability of microstructure is generally not desirable and it reflects variables associated with the hot-forming process used in the fabrication of this head plate. This variability is believed to give rise to nonuniform strength, ductility, and fracture resistance. Hardness measurements (see Seqtjon 3.22), which reflect the effect on strength and impact test results (to be presented in a separate report), were also greatly affected by the microstructural variability. 
Inclusion Measurements - Measurements of inclusions by both the ASTM and the QTM methods were taken only on longitudinal planes. In Figure 9 , the $C$ plane is the longitudinal plane that contains the principal rolling direction. Inclusions on this plane are shaped like needles. The B plane is a transverse plane that contains the cross-rolling direction. Inclusions on this plane appear shorter, and they may appear as dots in plates that have little cross rolling. The A plane is a short-transverse plane, parallel to the plate surfaces. Inclusions on it have irregular shapes, but they frequently contain one long dimension aligned in the principal rolling direction.

Inclusion analyses by the ASTM Method were conducted on 14 samples taken from five plates taken from the four accidents. Results of these ratings are summarized in Table 9, which shows that the principal type of inclusion in all steels rated is Type $A$, sulfide. The sulfides were particularly prominent in the South Byron sample, rated 3 to 5 (in various specimens) and in the Belle sample, rated 3 to 4 . Sulfides were intermediate at 2 to 3 in both Crescent City-sample FRA-2 and Callao-sample K-5, and they were only slightly less in Callao-sample K-l. The table also indicates that the sample rated highest in sulfides, South Byron, also rated highest in alumina and globular oxides (types B $\& D)$, and it was the only sample with any significant silicates, Type $C$.

\section{SUMMARY OF FINDINGS}

4.1 Check analyses of seven of the 10 plates analyzed failed to meet the chemical compositional requirements for the ladle analysis to which the steel had been produced, but all of the Producers' ladle analyses (five were available) met the requirements.

4.2 The carbon level in check analyses was generally near the maximum specified limit for ladle, and four check analyses exceeded this ladle limit.

4.3 Three of the 10 check analyses for manganese exceeded the maximum specified limit for ladle analysis.

4.4 Check analyses for sulfur and phosphorous indicated that one or both of these elements were near the maximum specified ladle analysis for four of the 10 plate samples.

4.5 One of the 10 plates analyzed for chemical composition failed to meet the requirement for deoxidation practice. 
4.6 Specimens taken from two of the six plate samples tested had strength levels outside of the requirements for strength level.

4.7 Although all six steels tested met the elongation requirements, bend speciemens of one of these steels failed to meet the bend requirements.

4.8 The tensile test results of four TC128 steels indicated that the ductility of these plates is anisotropic with longitudinal specimens having 10 percent greater elongation than transverse specimens for any tensile strength level from 85 to $105 \mathrm{Ksi}$. Bend test results of two of these steels were consistent with and supportive of this finding.

4.9 ASTM ferrite grain size numbers of TC128 steels varied from 7 to 9 , and those of two A212 steels were 7 and 6 , with the 6 representing a steel not produced to fine-grain practice. Only one of the TC128 steels was known to have not been produced to fine-grain practice and it had an ASTM ferrite grain size number of 7 . The only other TC128 steel sample, on which NBS made chemical anlysis, with this grain size was from a hot-formed head-plate sample with a highly variable microstructure which apparently resulted from excessive heating for hot forming.

4.10 Of six weldments examined for plate alignment, one weldment failed the alignment requirement prescribed by AAR by an amount of 0.047 inches.

4.11 Three weldments tested had a joint efficiency of 1.0 , and all had acceptable ductility in bend and tensile tests. Two of these three were head/shell weldments and one was a shell/shell weldment. The hardness results of the HAZ in each of these weldments indicated that they were properly stress relieved.

4.12 Two additional samples contained weld HAZ regions along which crack propagation had occurred. Hardness measurements of one of these HAZ regions, located at a head plate attachment, indicated that it had been improperly stress relieved.

4.13 Of the five tank cars involved in the four accidents from which samples were taken, three of the cars had been heated (at least in parts of the car) to temperatures above that of the ambient air.

4.14 Plates believed to have been heated at the time of fracture had fracture modes, generally of the shear mode and mixed mode, indicating that the mode of failure was ductile in plates failed at temperatures above that of the ambient air. 
4.15 Plates believed to have been at the temperature of the ambient air at the time of fracture generally had fractures that were predominantly nearly perpendicular to the plate surfaces, indicating brittle failure of the steel.

4.16 The observed fracture mode on plates examined was consistent with results of measurements of plate thinning near the fracture and with results of impact test measurements.

4.17 A microstructure of unexpectedly high variablity was observed at one location of the TCl28-B steel head-plate sample $K-1$ of the Callao accident. This variability is believed to be generally not desirable and it reflects variables (uncontrolled) in the hot-forming process used for fabricating this head plate.

4.18 Inclusion content ratings indicate that for six steels rated, two of the steels can be classified into each of three arbitrary ranks of moderate, intermediate, and high.

\section{GENERAL DISCUSSIONS}

\subsection{Effects of Inclusions on Mechanical Properties}

In general, the mechanical properties of steels are unfavorably affected by the presence of inclusions in steels. These effects can be moderate to severe, and they become increasingly important as the tensile strength is increased. The controlling factors are the composition 2 shape, distribution, and volume percent of the inclusions in the steel. (2) These factors can be and are today controlled (at a price) in normal steelmaking practice, and methods for improving the techniques and for making them more economical are receiving attention both here and abroad.

The inclusion contents of the six steel plate samples analyzed in this report fell into three arbitrary ranks of steel quality with two steels in each of the ranks: Rank 1--moderate content: Rank 2-intermediate content: Rank 3--high content. We note that this distribution of inclusion contents is broad, but that none of the specification requirements for the steels tested require special mill practice to control inclusion levels in these steels. Thus, it is interesting to note that two of the six steels tested have moderate inclusion contents, and these two were apparently produced under normal mill practices. 
The principal type of inclusions in all six of the steels analyzed at NBS is manganese sulfide, and the content of sulfides in steel is proportional to the sulfur content. Various treatments have proven effective in lowering the sulfur of steels. Treatments such as those involving additives to the hot blast-furnace iron permit the sulfur content of the finished steel to be in the range of 0.005 to 0.010 percent by weight. These levels are to be compared with the levels of the results of NBS laboratory check analyses for sulfur given in this report for 10 steels and one weldment. These contents vary from 0.012 to 0.04 percent by weight, and they meet the specification requirement of 0.05 percent maximum. Steels with lower sulfur contents are not only tougher but they have more isotropic mechanical properties.

Other techniques, used to minimize the undersirable effects of inclusions, control inclusion composition and shape. This is done either by increased use of cross rolling of the plates or by using additives in the refining of molten steel. Additives of rare earth metals or of titanium are commonly used to form a type of inclusion with greatly decreased tendencies for elongation during hot rolling. The result of this improved composition and shape of inclusions is improved product performance with less anisotropy and with improved transverse ductility and toughness.

It is recognized that sulfur is a principal impurity of blast furnace iron, that sulfur is difficult to remove in the commonly used refining facilities, and that it is costly either to decrease the sulfur level or to control the effects of sulfur in steels. We point up the fact that the technology exists for lowering the sulfur content to improve the quality of steels; this technology has undergone many changes even in recent years, and it is one of the many alternatives for improving the isotropy and fracture properties of steels.

\subsection{Anisotropy of Mechanical Properties}

The ductility of rolled steel plates tends to be greater in tests of longitudinal specimens than in tests of transverse specimens. This was shown in Figure 1 for tensile tests of steels of various strength levels. In general, longitudinal tensile ductility, as measured by percent elongation, was about 10-percent greater than the transverse ductility, Similarly, in bend tests the results given earlier showed that the onset of cracking of transverse specimens occurred at smaller angles of bend than that of longitudinal specimens (Appendix $\mathrm{C}$ ). 
The effect of this anisotropy on the tensile ductility as measured in tensile and bend tests is not so large as to give rise to great concern to designers of tank cars. However, its effect on the fracture process in general and on crack propagation behaviors in particular can be much greater than the effect on ductility. Therefore, anisotropy can be very significant and very important in a metallurgical analysis of the materials used for tank cars subjected to abusive service conditions, and our future efforts will be directed toward providing a more complete understanding of its significance for the plate materials used in the construction of tank cars.

In a metallurgical analysis (2) of a steel shell plate taken from tank car PPGX9990 involved in an accident near South Byron, New York, it was concluded that the fracture of this car, which exploded after being subject to fire, "...circumscribed the tank car because the shell plate was anisotropic- (in mechanical properties) with lower resistance to crack propagation in the circumferential direction of the tank car, which was the (final) rolling direction of the plate." Because this type of fracture separates a tank car into two sections, it promotes "rocketing" of either or both sections. It is therefore considered undesirable and more hazardous than al ternative types of fracture, such as punctures that leak but do not propagate or fractures that propagate along the length of the tank car. Further, a tank car with improved safety would result either from the use of materials that are more isotropic or from designs that preclude circumferential fracture.

\subsection{Observations of Unusual and Undesirable Features in Samples From Three Head Plates}

Of the steel plate samples examined at NBS, five samples contained small parts from three head plates. These are the Belle sample, FRA-2 and FKA-3 from Crescent City, and K-1 and K-2 from Callao, each taken from a different tank car. Four of these five head-plate samples (all except FRA-2 which apparently was heated prior to fracture) had metallurgical anomalies considered to be deleterious from the viewpoint of their relative resistance to fracture.

The Belle sample was believed to contain an HAZ crack that existed before the final fracture. This was a part-through crack that is believed to have contributed to the failure of the tank car. Further, this crack propagated for some distance along the HAZ of a weldment of a stiffener plate, and then it terminated in the unaffected base metal of the head plate. This behavior indicates that the weld HAZ had significantly lower resistance to crack propagation compared to that of the unaffected base metal. 
Sample FRA-3 (from Crescent City) contained a hard zone wi th a secondary crack in a region believed to be an improperly stress-relieved HAZ of a head-plate attachment. The hard zone is believed to have contributed to the failure of this tank car, but it is possible that geometrical effects of the weld were contributing to the failure.

From the Callao A-head plate, sample K-l had an undesirable microstructure of unexpectedly high variability and sample K-2 had a relatively coarse microstructure. This variability is believed to reflect improperly controlled variables in the hot-forming process used to fabricate this head plate. Hardness tests indicated that mechanical properties are significantly affected by this microstructural variability, and impact tests indicated that the variability has a marked effect on the crack propagation behaviors of this steel.

These observations of various anomalies, two of which involved welding practices and properties of weldments and one of which involved hot-forming practices, indicate to us that for the tank cars involved in the three accidents (four tank cars) from which these samples were taken, the ability to withstand abusive service had been deteriorated. These anomalous observations are particularly disconcerting when one recognizes that, in service, the two head plates of a tank car are generally more likely to be subject to abusive loading conditions than are any of the many shell plates of a tank car.

\subsection{South Byron Shell Plate Steel}

The tank car involved in the South Byron, New York, accident failed in a manner not uncommon in acfidents resulting in tank car explosions. A circumferential type $(2)$ of fracture separated the tank car into two sections and led to the propulsion of one of them. The results of the metallurgical analysis of a sample of a fractured shell plate from this car is both interesting and instructive.

The findings for this AAR TC128-B plate steel sample taken from this summary report are as follows:

(a) carbon and manganese levels slightly exceed the maximum specified limit.

(b) sulfur content is high and near the maximum specified limit.

(c) vanadium and aluminum levels indicate that the steel was produced in accordance with fine-grain practice by deoxidation with a combination of silicon and both of these grain-refining deoxidizers. 
(d) the plate sample contained the highest total inclusion content of all plates tested; rated highest in sulfides, alumina and globular oxides; and was the only plate with any significant amount of silicates.

(e) measured tensile strength slightly exceeded the maximum specified limit and was greater than that of any of the other plates tested.

(f) measured yield strength was well above the specified minimum value and greater than that of any of the other plates tested.

(g) tensile ductility, as measured by percent elongation, was slightly above the minimum specified value and lowest of all plates tested.

(h) all specimens tested failed the required bend test: longitudinal specimens, which are required by the manufacturer of the plate, failed by crazing of the external surface, and transverse specimens, which are not required, fractured completely and at relatively low angles of bend.

Based on the anlysis of these findings, it could reasonably be concluded that this steel plate satisfied the intent of the material requirements (although marginally) of the appropriate specification, AAR M128. However, specimens taken from this plate did fail the bend test, which is a performance requirement, but met the other performance requirements: yield strength, tensile strength, and percent elongation, al though the latter two are met only marginally. The probable explanations for the test behavior of this plate sample are both interesting and instructive.

The high tensile strength (maximum allowed) and the high yield strength are probably a result of the high levels of carbon and manganese. In the sample they are both at the maximum allowed. The marginally low tensile ductility is consistent with the high observed value of tensile strength.

The high total inclusion content, principally manganese sulfide but including alumina, globular oxides and silicates, is consistent with the high sulfur level and use of aluminum as a deoxidizer and grain refiner. The use of aluminum in the steel deoxidation process is known to result in the inclusions being morf) stringer-like, rather than globular as when silicon is used alone. 
The crazing of the surfaces of the longitudinal bend test specimens is not unexpected because the surface experiences maximum tensile stress and thus maximum strain, and because this plate had higher inclusion content and lower measured values of elongation and reduction of area than that of any of the other steels tested. The transverse bend test specimens would be expected to be more sensitive to the inclusions present (total content, shape, and distribution), and the complete fracture of these specimens is consistent with the high inclusion content.

Although this plate marginally satisfied both the material and performance requirements (bend test excepted) of the AAR M128 specification, the cooperative effects of producing a steel at the limits of compositional requirements for carbon, manganese, and sulfur, yielded a plate with marginal properties. The mechanical properties and other observations on this steel plate sample point up the strong need for improvements in the control over the quality of steel used as plate material in tank cars.

\subsection{Abusive Service Requirements}

Railway tank car service failures occur principally after exposure of tank cars to elevated temperatures and to severe impact loads at ambient (and perhaps at elevated) temperatures. Each of these abusive service conditions can lead to hazardous ruptures. Thus, the safety of tank cars under these abusive service conditions becomes an important question for consideration.

The problem of developing a tank car with superior safety is particularly complex. Understanding must be developed on the mechanisms of failures, the frequency of failure under various types of abusive conditions, the properties of the materials used in construction of existing tank cars, and the alternatives of materials available for tank car service. In addition, many other factors must be considered, such as cost of materials, the feasibility of implementing various proposed design changes, and the cost of capital equipment needed for such changes.

From the materials viewpoint, the tank-car construction industry uses such large tonnages of steels that the requirement for steels with improved properties can be a major stimulus to improve steel production practice. It can also be a stimulus for the development of superior and economical steels for this application. 
NBS is undertaking to explore the currently available materials that could be used as plate materials for tank cars. Steels with properties that are likely to lead to increased resistance to hazardous failures will be selected as candidate steels. Prerequisite to the development of a satisfactory compilation of candidate steels is a satisfactory understanding of the materials requirements. Some of this information will be made available through the current studies at NBS, but other complementary information must be collected. This includes:

1. For elevated-temperature abusive service conditions, expected temperatures and time at temperature. failures.

2. Minimum and median temperatures of ambient temperature service

3. Frequency and location (in the tank cars) of ambient-temperature service failures. A concise summary of this information along with other pertinent information will be very useful and necessary for the reasons given above.

\section{CONCLUSIONS}

6.1 Materials with improved resistance to both ambient-and elevated-temperature failure should be sought on a continuing bas is for use as plate materials in tank cars, so that the safety and economy of these cars will be abreast of the technology of the times.

6.2 Among the alternatives for improving service performance of the plate materials used for tank cars, consideration should be given to the use of steels of uniformly good quality, as for example, by decreasing the sulfur level below the 0.05 percent by weight now considered acceptable.

6.3 Steps should be taken to improve the fracture resistance of head plate steels and all weldments of these steels. These should include but not necessarily be limited to a thorough review of head plate forming, welding, and stress-relief practices. 
6.4 The decreased ductility and the marked decrease in fracture resistance in the final rolling direction of plates used for tank cars has been observed to promote an undesirable circumferencial fracture. A tank car with improved safety would result either from the use of materials (especially for shell plates) that are more isotropic or from designs that preclude circumferencial fracture.

6.5 In specifications for the chemical compositional requirements, tolerances should be clearly prescribed for chemical check analyses of each of the specified elements.

\section{AKNOWLEUGEMENT}

The authors would like to thank Mr. D. E. Harne for his assistance in making hardness measurements and in preparing the figures and tables used in this report. 
1. G. E. Hicho and C. H. Brady, "hazARdous Materials tank CARS EVALUATION OF TANK CAR SHELL CONSTRUCTION MATERIAL", (RepOrt No. 1), NBS Report 312.01/14, September 28, 1970.

2. C. G. Interrante and G. E. Hicho, "METALLURGICAL ANALYSIS OF A STEEL SHELL PLATE TAKEN FROM A TANK CAR ACCIDENT NEAR SOUTH BYRON, NEW YORK", (Report NO. 2), NBS Report 312.01/35, October 22, 1971 .

3. C. G. Interrante, G. E. Hicho, and D. E. Harne, "A METALLURGICAL ANALYSIS OF FIVE STEEL PLATES TAKEN FROM A TANK CAR ACCIDENT NEAR CRESCENT CITY, ILLINOIS", (Report NO. 3), NBS Report $312.01 / 39$, March 10, 1972 .

4. C. G. Interrante, G. E. Hicho, and D. E. Harne, "A METALLURGiCAI ANALYSIS OF ELEVEN STEEL PLATES TAKEN FROM A TANK CAR ACCIDENT NEAR CALLAO, MISSOURI", (Report No.4), NBS Report 312.01/51, September 19,1972 .

5. G. E. Dieter, Mechanical Metallurgy, McGraw-Hill Book Co., New York City, 1961, pp. 557-562.

6. Army-Navy Approximate Hardness Tensile Strength Relationship of Carbon and Low Alloy Steels (AN-QQ-H-201).

7. Handbook 268, Modern Steels and Their properties, The Bethlehem Steel Company, Bethlehem, Pennsylvania, 1949.

8. R. A. Grange, "Effect of Microstructural Banding in Steels", Metallurgical Transactions, 1971, pp. 417-426.

9. R. M. Brick and A. Phillips, Structure and Properties of Alloys, McGraw-Hill Book Co., New York City, 1949, p. 252. 10. Metals Hanabook, The American Society for Metals, Cleveland, Ohio, 1948, p. 450 . 



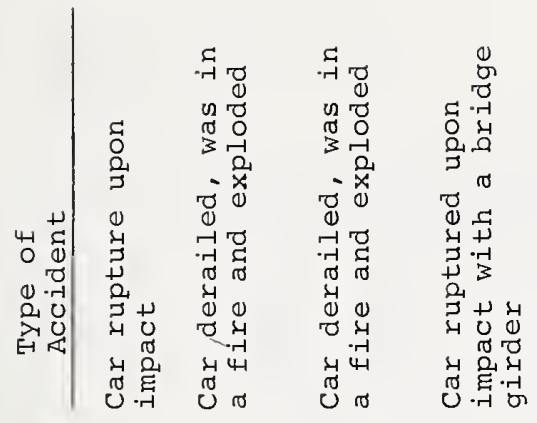

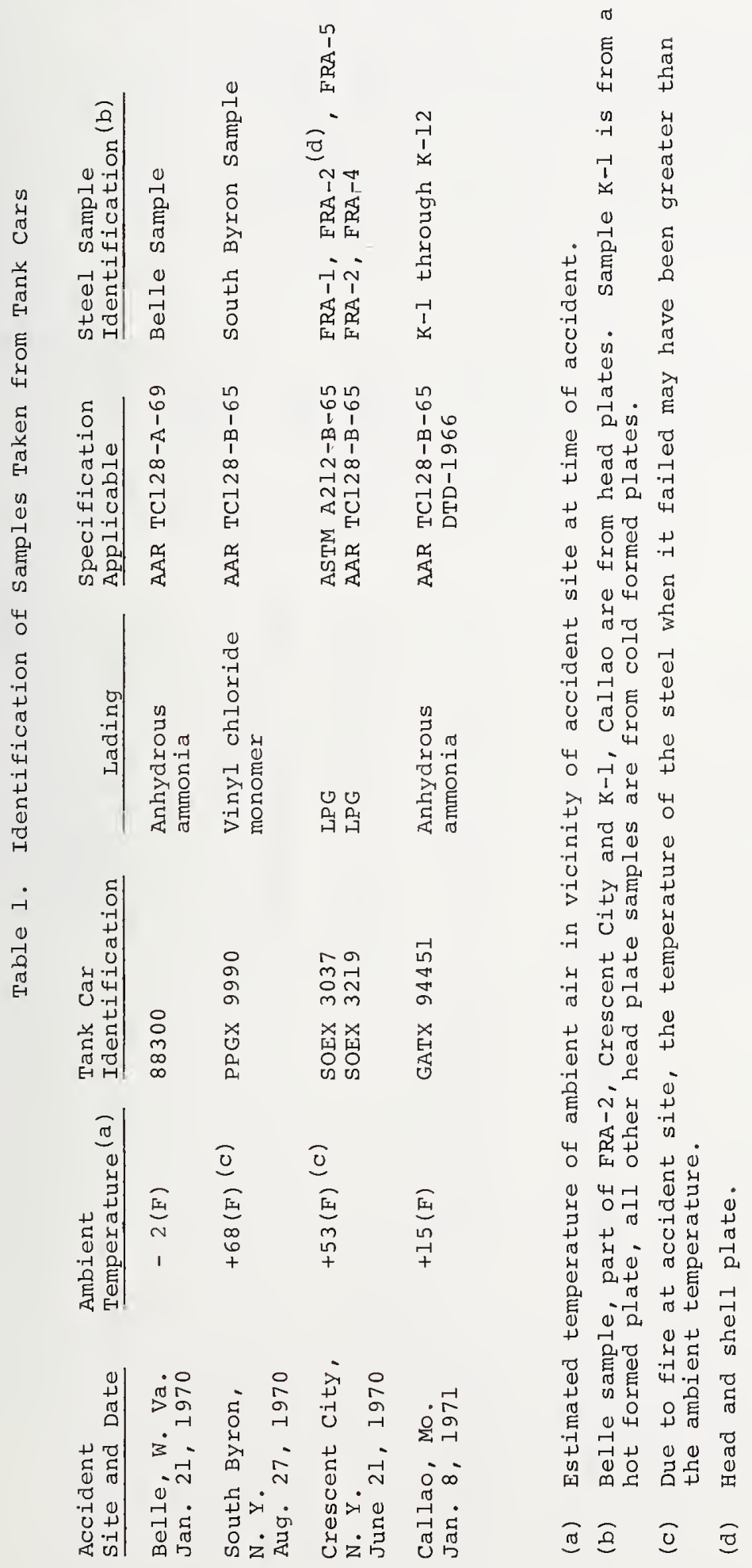





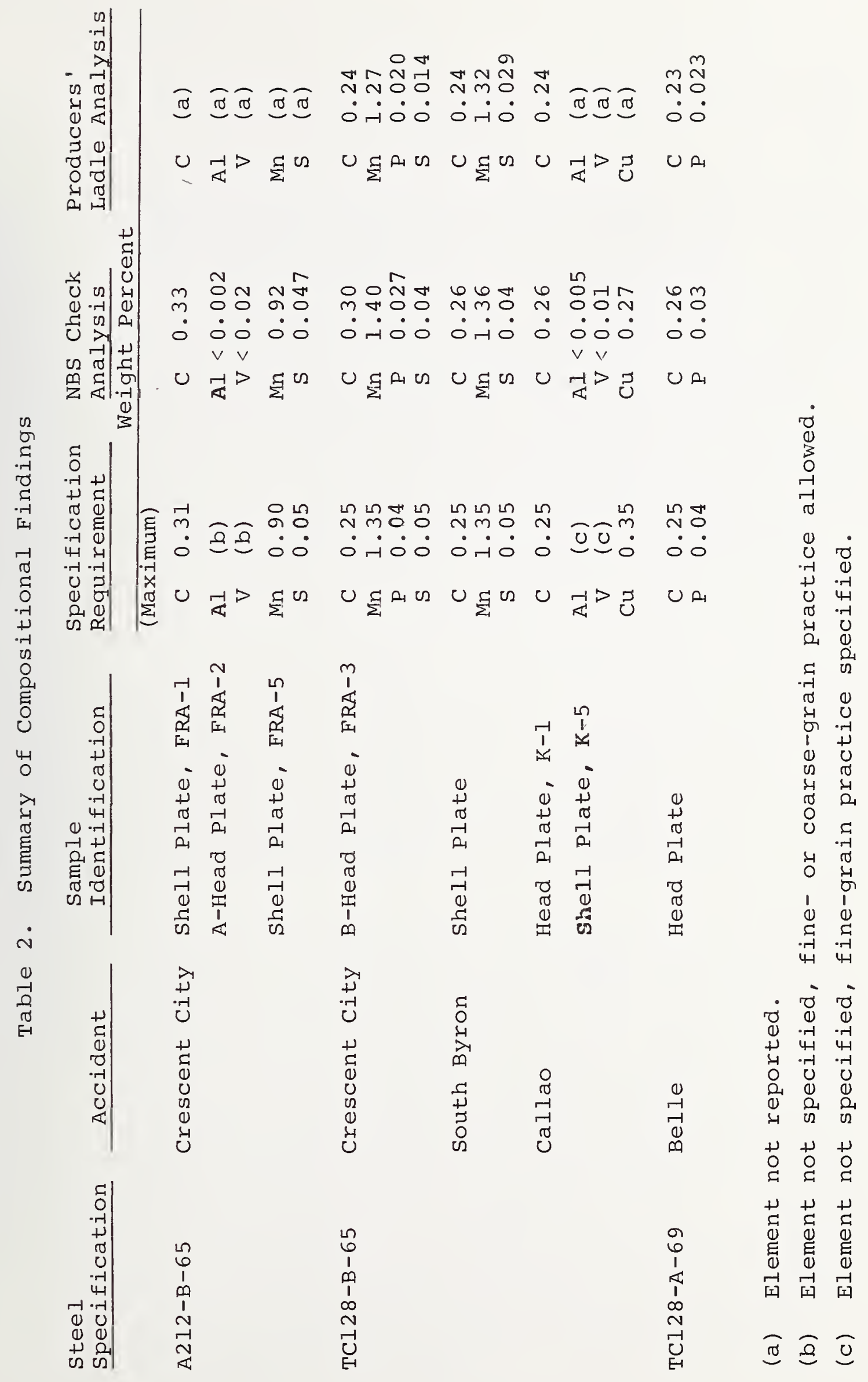





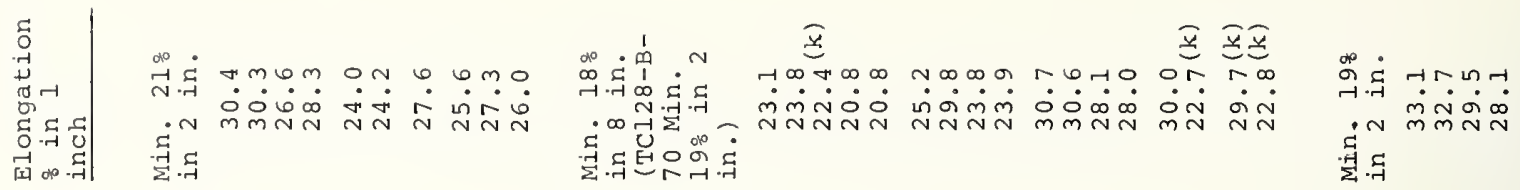

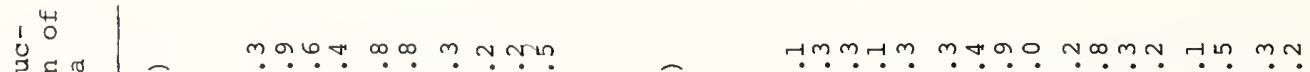

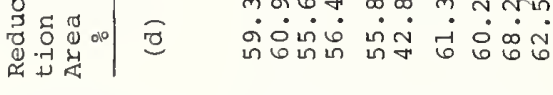

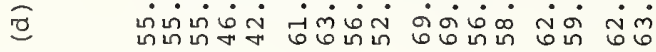

ชิ

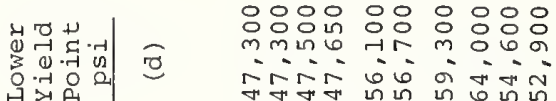

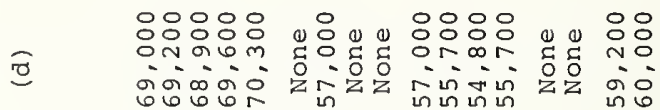

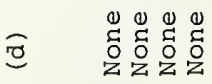

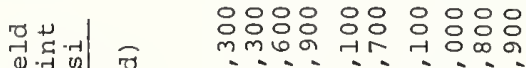

웃유

శิ

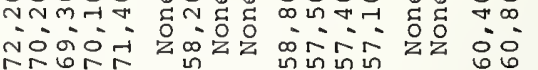

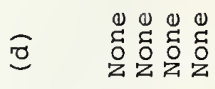

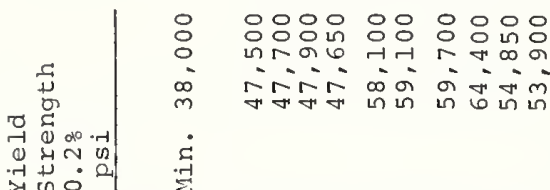

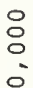

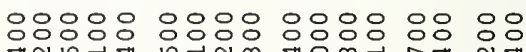

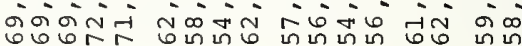

$\therefore 8: \circ:$

$\therefore$ in

in

㝴

: :

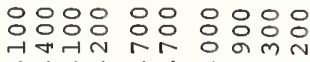

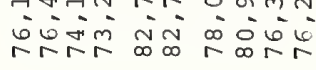

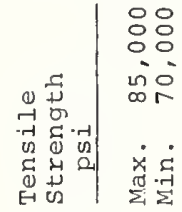

-ime

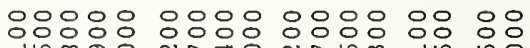

He⿰氵工力口

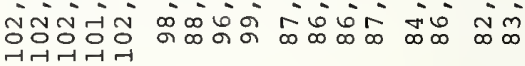

द्व

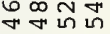

这完

$\therefore:$

$\therefore: 0:$

in $4-7$

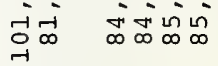

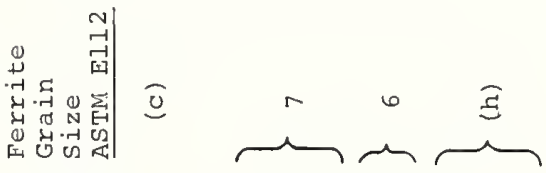

ก

离这

.

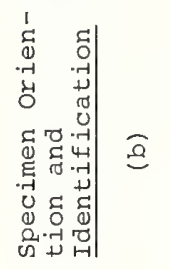

Q

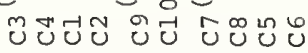
$\begin{array}{lllllllll}1 & 1 & 1 & 1 & 1 & 1 & 1 & 1 & 1\end{array}$

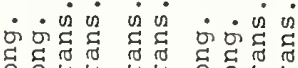

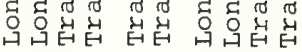
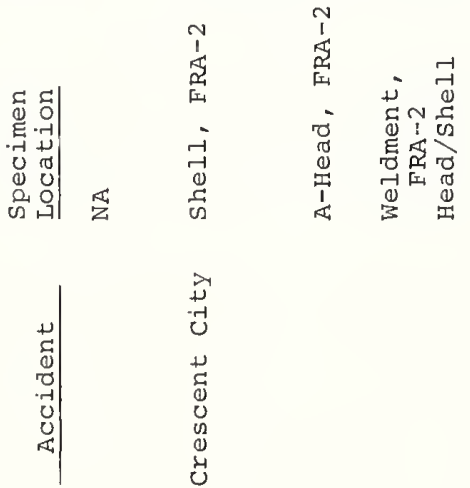

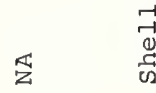
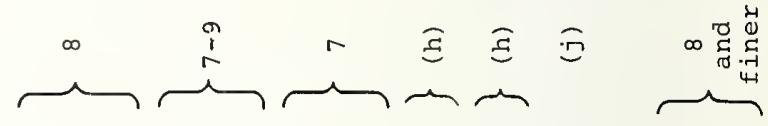

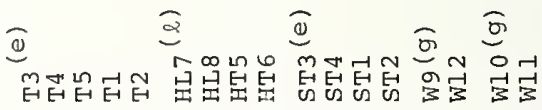

a

$\begin{array}{llllllllllllllllll}1 & 1 & 1 & 1 & 1 & 1 & 1 & 1 & 1 & 1 & 1 & 1 & 1 & 1 & 1 & 1 & 1 & 1\end{array}$

$\widehat{\Psi}$ thm

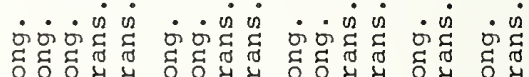
$\begin{array}{llll}1 & 1 & 1 & 1\end{array}$

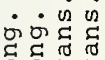

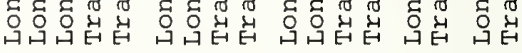

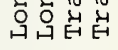
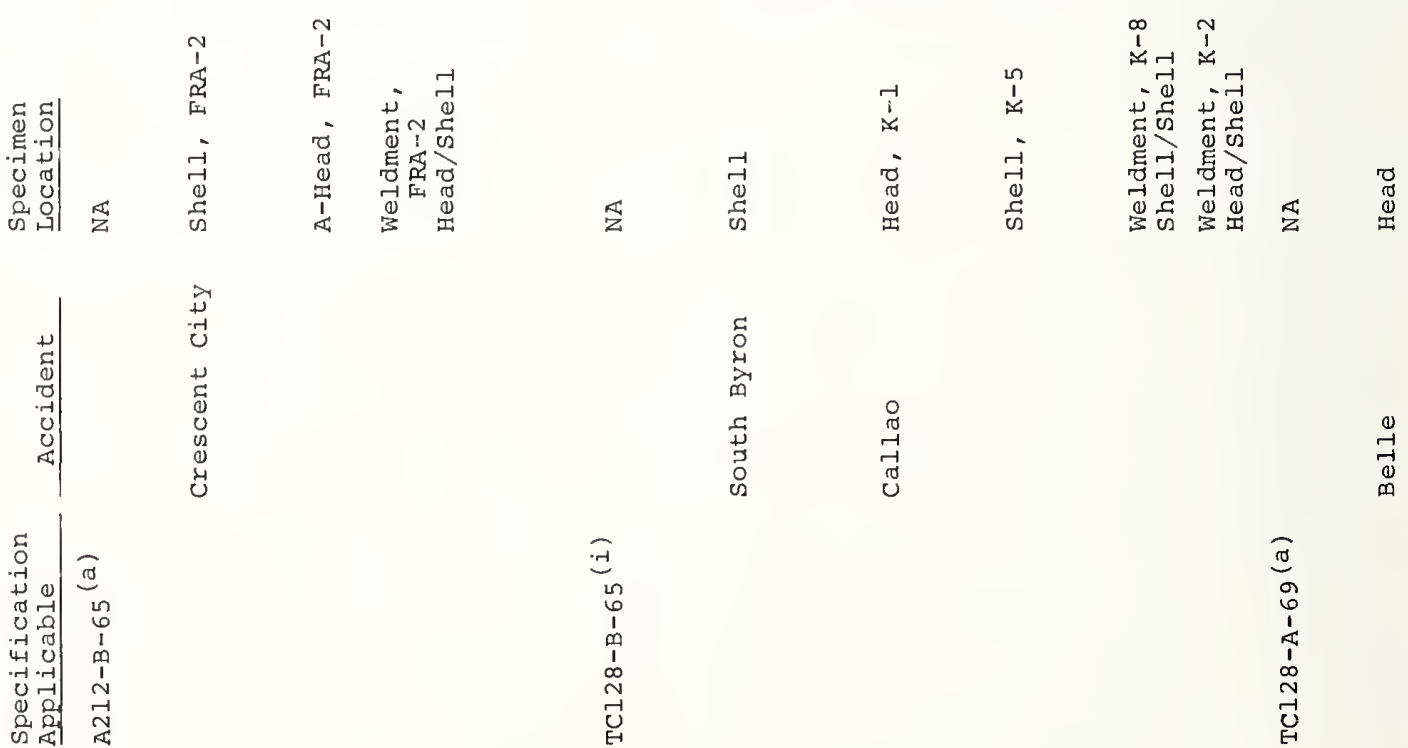
(a) A comparison of elongation data obtained from different sizes of specimens of the same material can be made provided the ratio of the gage length to cross-sectional dimensions is held constant. Since the ratio of the square root of the cross-sectional area to the gage length is the same for the specimen with a $0.500-i n c h-$ diameter with a 2-inch-gage and for the specimen with a 0.250-inchdiameter with a l-inch-gage length, the elongation data from the l-inch-gage length specimen can be directly compared to the specification requirement based on a 2-inch-gage length.

(b) Although the specifications ASTM A212-65, AAR TC128-65, and AAR TCl28-69 do not specify test specimen orientation, ASTM A370-71 does specify that wrought steel products are usually tested in the longitudinal direction but that where size permits and service justifies it, transverse testing is done.

(c) Not specified, either fine- or coarse-grain practice allowed.

(d) Not specified.

(e) The letter/number code refers to the specimen numbers as reported in the particular accident report. Long. and Trans. refer to the longitudinal and transverse specimen axis orientation with respect to the principal rolling direction.

(f) The number of letter/number codes given here refer to the specimen numbers reported in the particular accident report. It is usually difficult, in the case of head plates, to determine exactly the principal plate rolling direction because of the probability of extensive cross-rolling of the plate and the method of fabrication of head plates. The usual procedure followed in the specific accident reports was to relate the specimen orientation to either a shell plate weld or to a crack propagation direction. In this summary report, however, the orientation direction has been assigned to the test data based on whether the specimens were aligned closer to what is believed to be either the principal rolling direction (longitudinal) or normal (transverse) to the principal rolling direction. The determination of the principal rolling direction was based on percent elongation and percent reduction in area data of shell plate specimens. Shell plate test data, where there is little ambiguity in the determination of the principal rolling direction, show that the values of percent elongation and percent reduction in area of longitudinal test specimens always exceeded the values for transverse test specimens.

(g) The longitudinal specimens taken from the weldment are all-weldmetal specimens with longitudinal axes that lie in the (circum-ferential) welding direction. The transverse specimens were machined perpendicular to the circumferential weld.

(h) Not determined.

(i) Specification AAR TCl28-65 requires minimum elongation values for 8-inch-gage length specimens only. As it was not possible to use the 8-inch-gage length specimens, some basis for comparing the test results with 0.250 -inch diameter, 1-inch-gage length round specimens with the specification must be used. The basis selected was to apply the specification AAR TCl28-70 which requires identical tensile and yield strength values as AAR TCl28-65. AAR TCl28-70 further requires minimum elongation values for both 2 - and 8-inch gage length, thus a direct comparison was made between the 2-inch-gage length requirement and test data on $0.250-$ inch diameter, l-inch-gage length specimens. However, since AAR TCl28-70 calls for a minimum percent elongation of $16 \%$ in 8 -inch-gage length and $19 \%$ in a 2-inch-gage length, while AAR TCl28-65 calls for a minimum percent elongation of $18 \%$ in an $8-$ inch-gage length, the test results should clearly exceed the 19\% minimum to satisfy the intent of the specification.

(j) Not specified, fine-grain practice required.

(k) These elongation values reported in the particular accident reports were in error. The corrected values are reported here.

(l) The letter/number code refers to the specimen numbers reported in the original accident report. Inclusion length measurements were made to determine the principal rolling direction and the specimen orientation was assigned based on these data. 

Table 4. Abbreviated Summary of Bend Test Results

\begin{tabular}{|c|c|c|c|c|c|}
\hline Steel & $\begin{array}{l}\text { Sample } \\
\text { Location } \\
\end{array}$ & Accident & Passed & Failed & $\begin{array}{l}\text { Specimen } \\
\text { Orientation }\end{array}$ \\
\hline A212-B & Shell & Crescent City & 4 & & $\begin{array}{l}2 \text { longitudinal } \\
\text { and } 2 \text { transverse }\end{array}$ \\
\hline TCl28-B & Shell & South Byron & & 6 & $\begin{array}{l}2 \text { longitudinal } \\
\text { and } 4 \text { transverse }\end{array}$ \\
\hline TCl28-B & Shell & Callao & 4 & & $\begin{array}{l}2 \text { longitudinal } \\
\text { and } 2 \text { transverse }\end{array}$ \\
\hline $\mathrm{TCl} 28-\mathrm{B}$ & Head & Callao & $\begin{array}{l}2 \\
I(a)\end{array}$ & $1(a)$ & $\begin{array}{l}1 \text { long } \& \text { l trans. } \\
1 \text { longitudinal } \\
\text { and } 1 \text { transverse }\end{array}$ \\
\hline A $212 / A 212$ & Weldment & Crescent City & 2 & & side bend \\
\hline $\mathrm{TCl} 28 / \mathrm{TCl} 28$ & Weldment & Callao & 2 & & side bend \\
\hline $\mathrm{TCl} 28-\mathrm{B}$ & Shell & South Bryon & $4(b)$ & $2^{(c)}$ & $\begin{array}{l}4 \text { longitudinal } \\
\text { and } 2 \text { transverse }\end{array}$ \\
\hline
\end{tabular}

(a) These two specimens were tested in a non-standard test with the outer curve of the bend being the inner part (near midthickness) of the plate; the transverse specimen failed.

(b) Non-standard $d / t$ ratio of 4.0 (2 longitudinal and 2 transverse specimens).

(c) Non-standard d/t ratio of 1.7 (longitudinal specimens). 



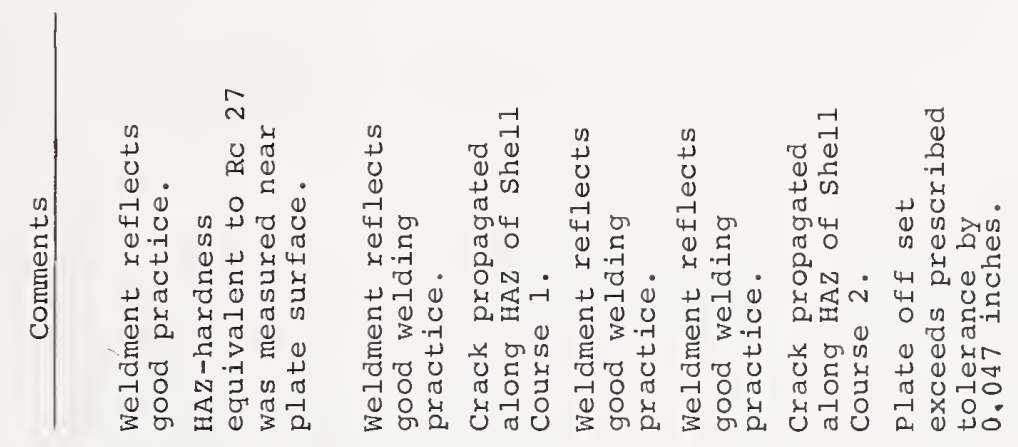

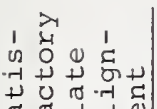

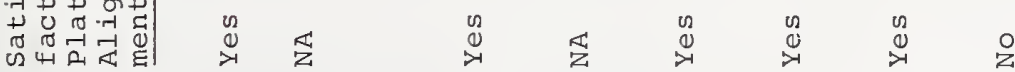
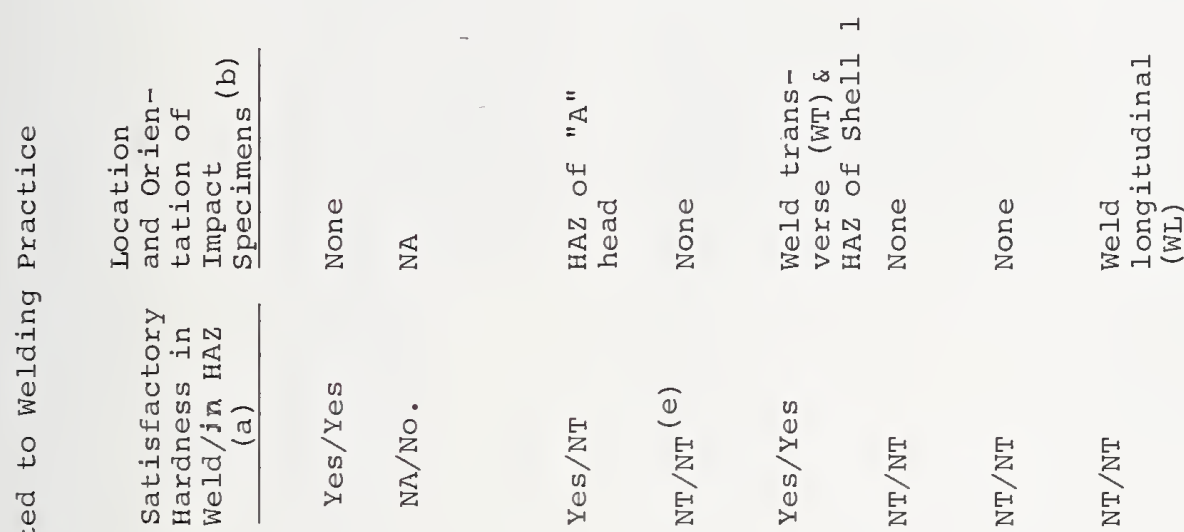

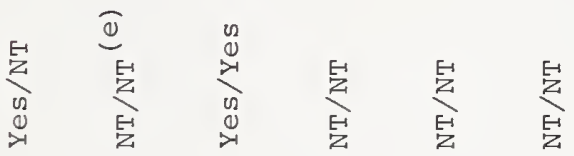

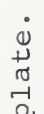

章

范

竞

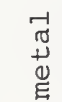

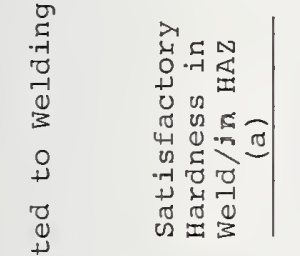

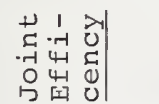

$\stackrel{\circ}{\sim} \underset{z}{Z}$

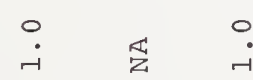

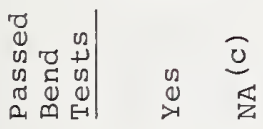

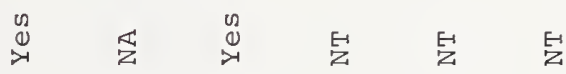

त्र

0

o 0

$\rightarrow-40$

3 ज

거 통

Iु

ठ

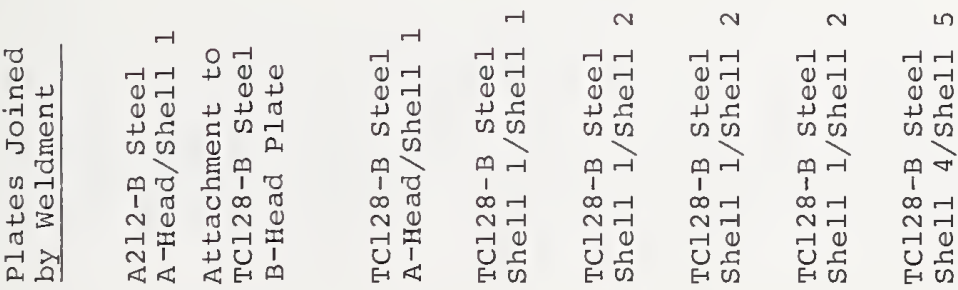

돌

证. E

का

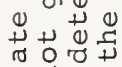

요 04

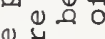

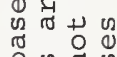

赵 on

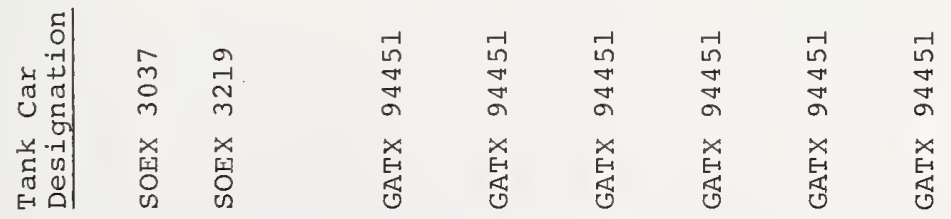

벅국

员司范

¿ 40 U

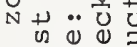

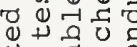

0

(4)

$4 \pi-700$

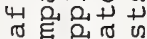

तन बत

तै

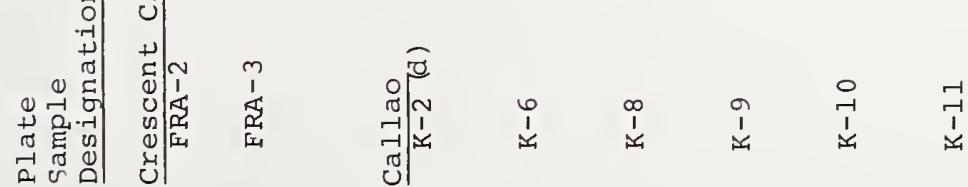

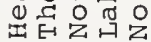



Table 6. Hardness Results

Steel

Specification

ASTM A212-B

ASTM A212-B

ASTM A212-B

ASTM A2 I2-B

AAR TC128-B

AAR TCI 28-B

AAR TCl28-B

AAR. TC128-B

AAR TCl28-B

AAR TCl28-B

AAR TC128-B

AAR TC128-B

AAR TC128-B

AAR TC128-B

AAR TCl28-B

AAR TC128-B

AAR TC128-B

AAR TC128-A

Weld

Weld

HAZ

HAZ
Sample

Accident

Accident

Crescent City

Crescent City

Crescent City

Crescent City

Crescent City

Crescent City

South Byron

South Byron

South Byron

South Byron

South Byron

South Byron

Callao

Callao

Callao

Callao

callao

Belle

Callao

Callao

Callao

Crescent City

$\mathrm{K}-8$

FRA -3
Head or

Identification shell Plate

She11

Shel1

A-Head

Shell

B-Head

Shell

Shell

Shell

Shel1

Shell

Shell

Shel1

A-Head

A-Head

Shel1-1

Shel1-1

She11-2

Head

-

$-$

$-$
Averages

$R_{B}$

80.0

78.8

79.8

82.2

93.5

94.3

92.1

92.5

92.4

93.2

97.8

196.4 *

90.6

92.3

89.5

93.5

89.3

92.0

92.8

92.0

$\begin{array}{ll}\mathrm{R}_{\mathrm{C}} & 24^{* * *} \\ \mathrm{R}_{\mathrm{C}} 28^{* *}\end{array}$

* Brinell value

* Only one plate sample submitted.

*** Knoop hardness measurements were taken and converted to Rockwe11 C values. 


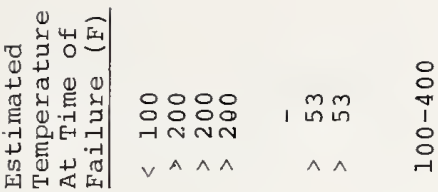

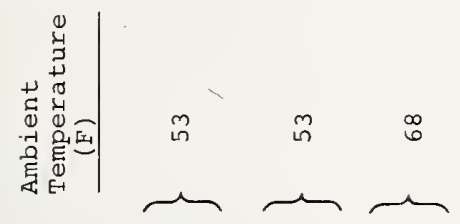

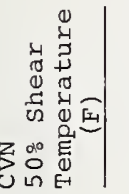

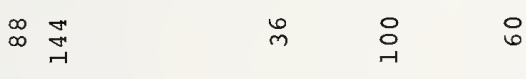

요흐

$\infty \underset{\sim}{m}$

$\stackrel{\infty}{\sim} \quad \stackrel{\infty}{\infty}$

요

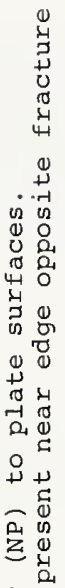

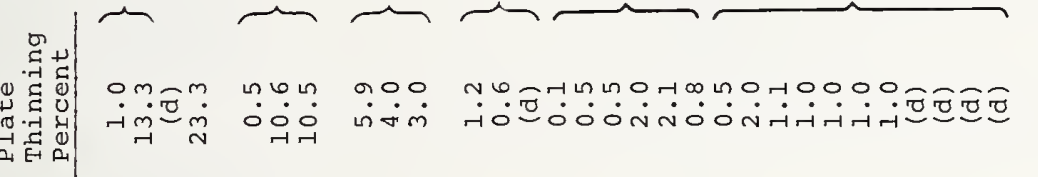

(2)

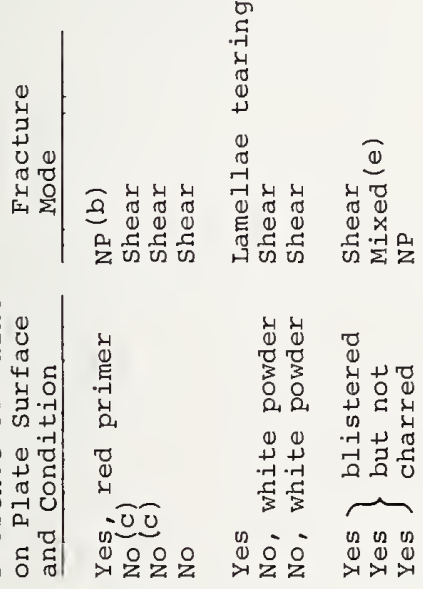

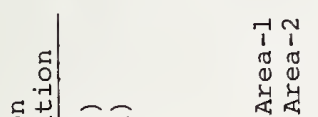

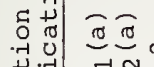

त्व

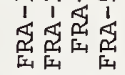

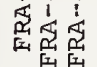

(1)

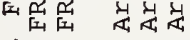

年

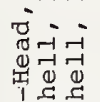

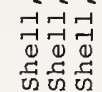

บบ요

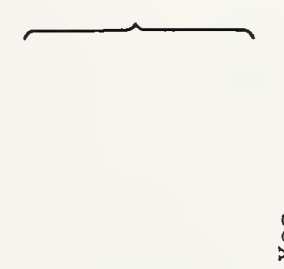

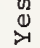

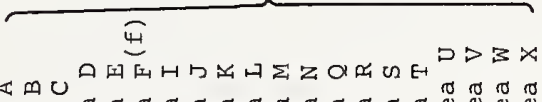

《为

选选这

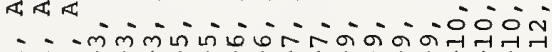

1月-1

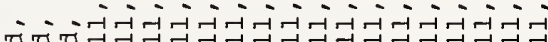

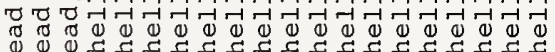

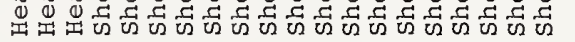

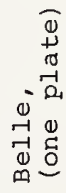

$\stackrel{\sim}{\varphi}$

욤

ำ

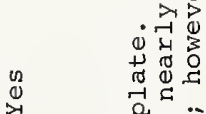

$\operatorname{cic}_{-\rightarrow 10}$

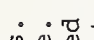

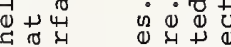

至 虫

兽唗

的范出!

हू,

क्ष का को

द.

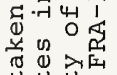

प्रे 00

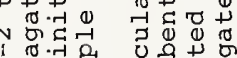

1 0 .

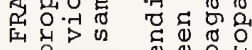

च. द्न

द्व

$7 \rightarrow$ 녕

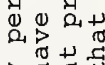

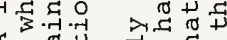

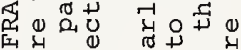

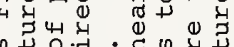
Q

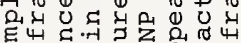

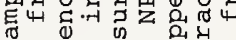

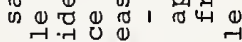



Table 8. Observed Ferrite Grain Size Values

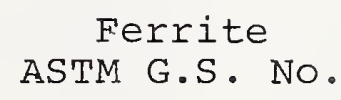

Belle*

South Byron*

Crescent City

Shell FRA-1

Shell FRA-2*

Head FRA -2 *

Shell FRA-3

Shell FRA-4

Shell FRA-5

Callao

Shell course 1

$$
\mathrm{K}-5^{*}
$$

Shell course 2

$$
\mathrm{K}-7
$$$$
\mathrm{K}-8
$$

Shell course 4

$$
\mathrm{K}-12
$$
A Head

$$
\begin{aligned}
& \mathrm{K}-1 \\
& \mathrm{~K}-2
\end{aligned}
$$

8 to 9

8

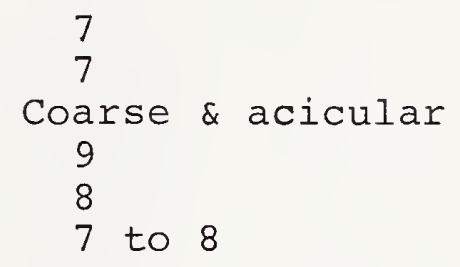

7

8

7

7
$7-9$
8
Grade of Steel

TC128-A

TC128--B

A 212-B

A212-B

$A 212-B$ **

TCl28-B

TCl28-B

A212-B

TC128-- B

TCl28- B

TC128-B

TC128-B

TC128-B

TCl28-B

* Used in studies of mechanical properties.

* Not made to fine grain practice. 



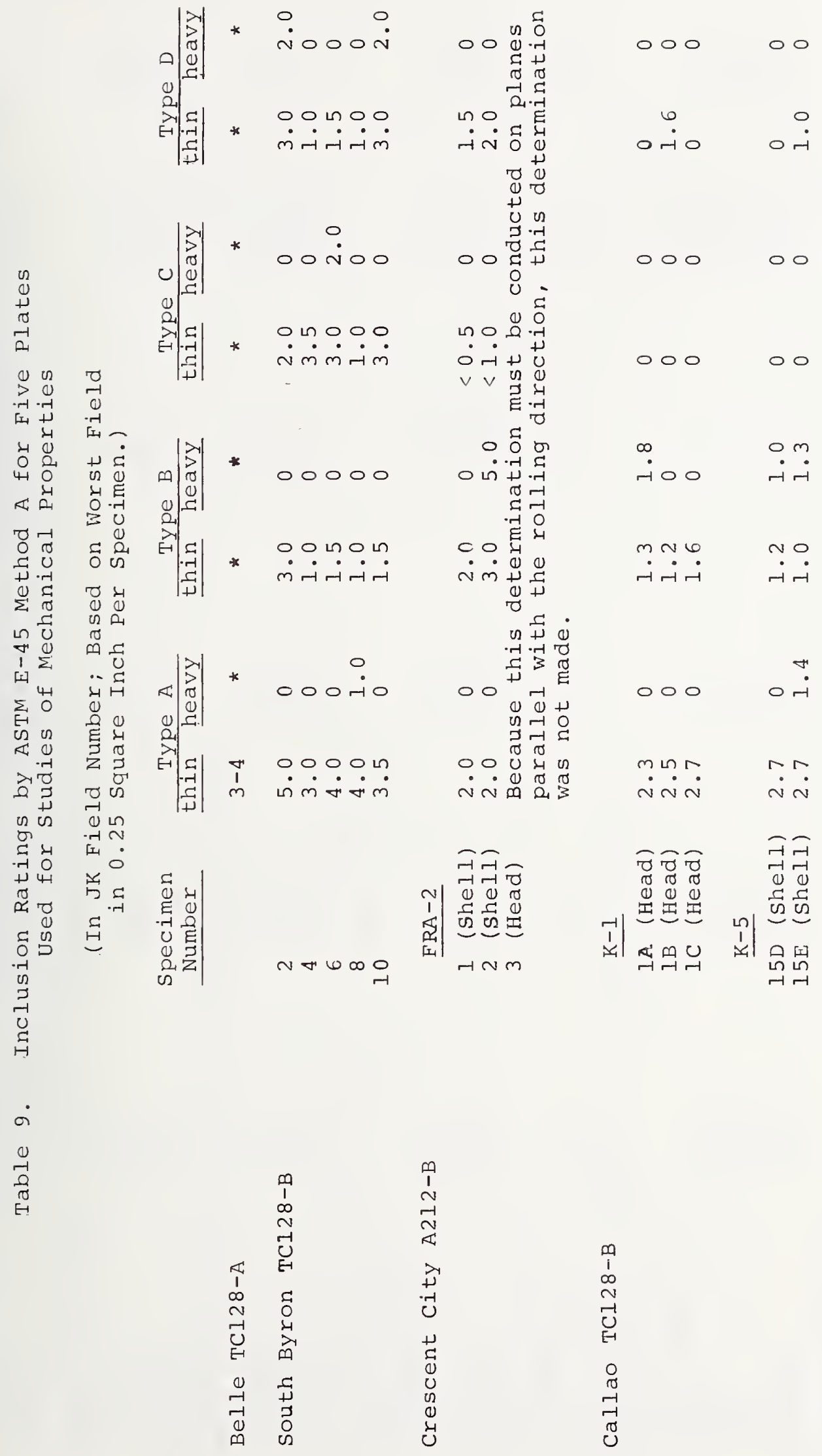





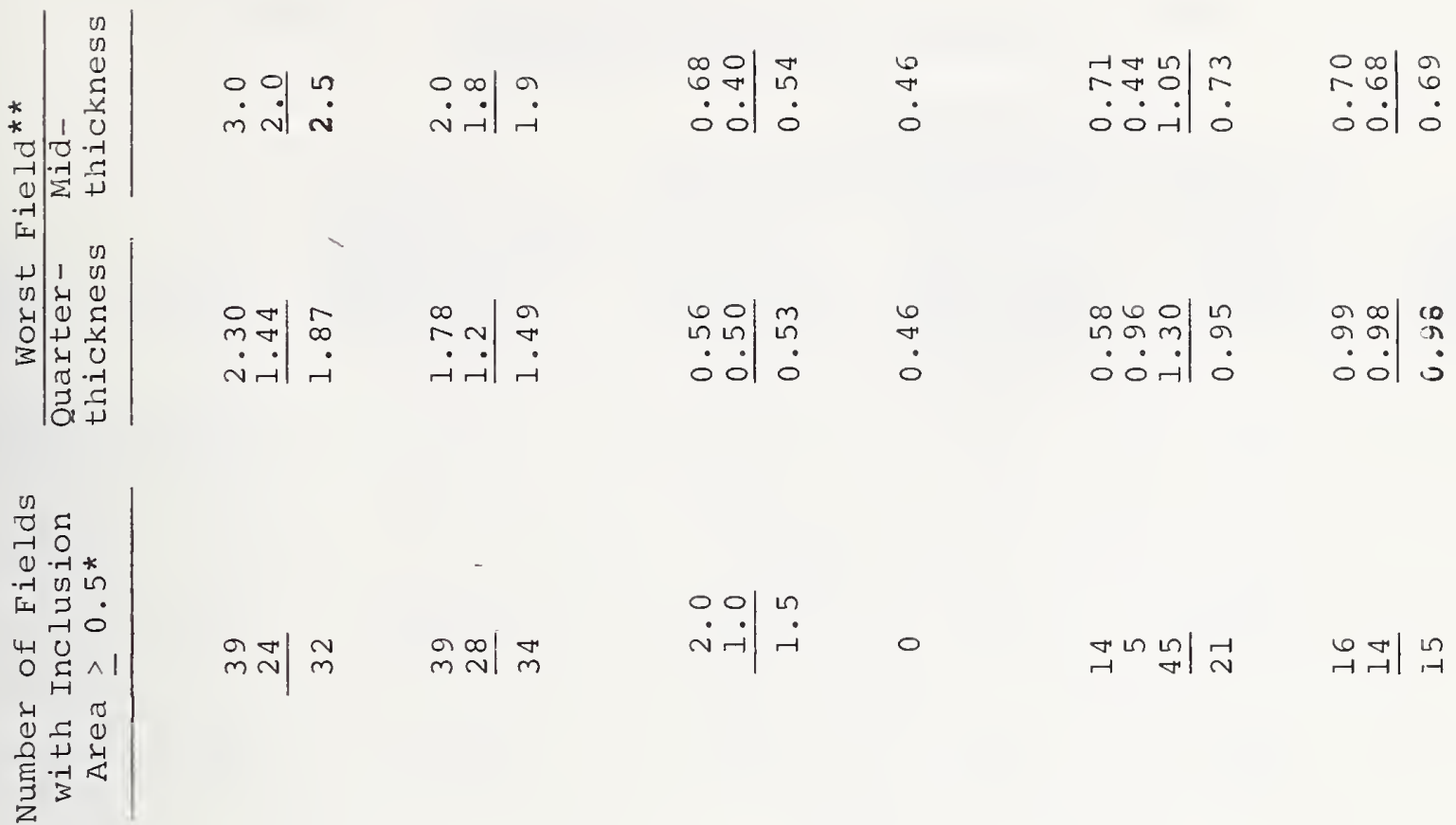

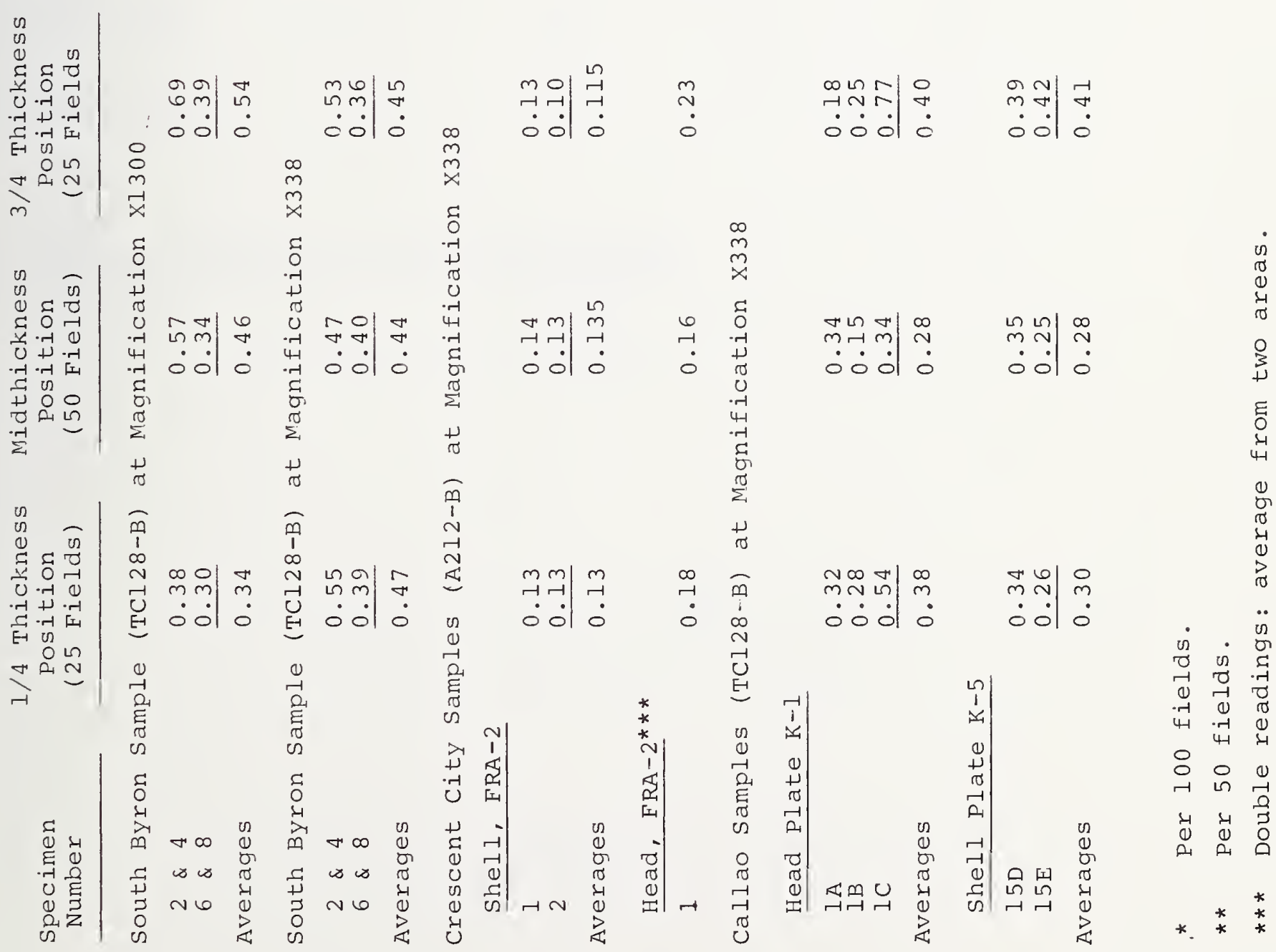



Table 11. Comparisons of Results of Inclusion

Ratings by Various Criteria.

Steel

Identification

TC128-B, Shell, South Byron

TC128-B, Shell, Callao

TC128--B, Head, Callao

TC128-A, Head, Belle

A212-B, Shell

Crescent City

A212-B, Head, Crescent City
Sulfide Rating (thin) Method A, ASTM E-45
QTM Results at Magnification X338

QTM Number of Average

Overall Fields with of QTM

Area Inclusion Worse

Percent* Area $>0.5 *$ Field*

(Average)

.40

29

1.9

3

2.7

.33

15

$1 \cdot 0$

2

$2 \cdot 3-2 \cdot 7$

.35

21

1. 0

2

$3-4$

$\star \star$

$* *$

**

3

2.0

.13

2

.5

1

.19

.5

1

* Average ratings with 100 fields/rating.

** Not rated. 



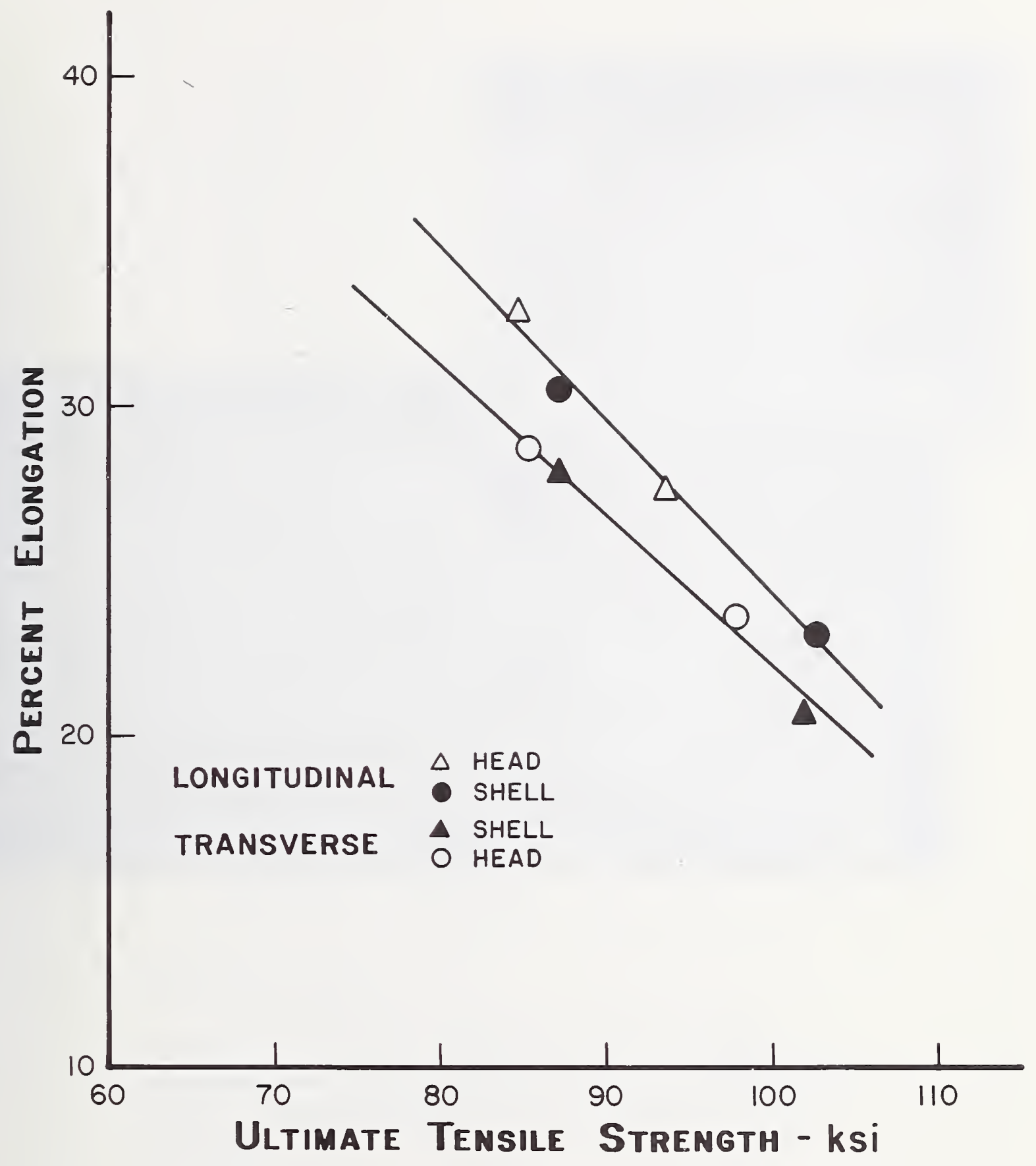

Figure 1. Comparison of Longitudinal and Transverse Ductility of AAR TCl28 Steels of Various Strength Levels. 



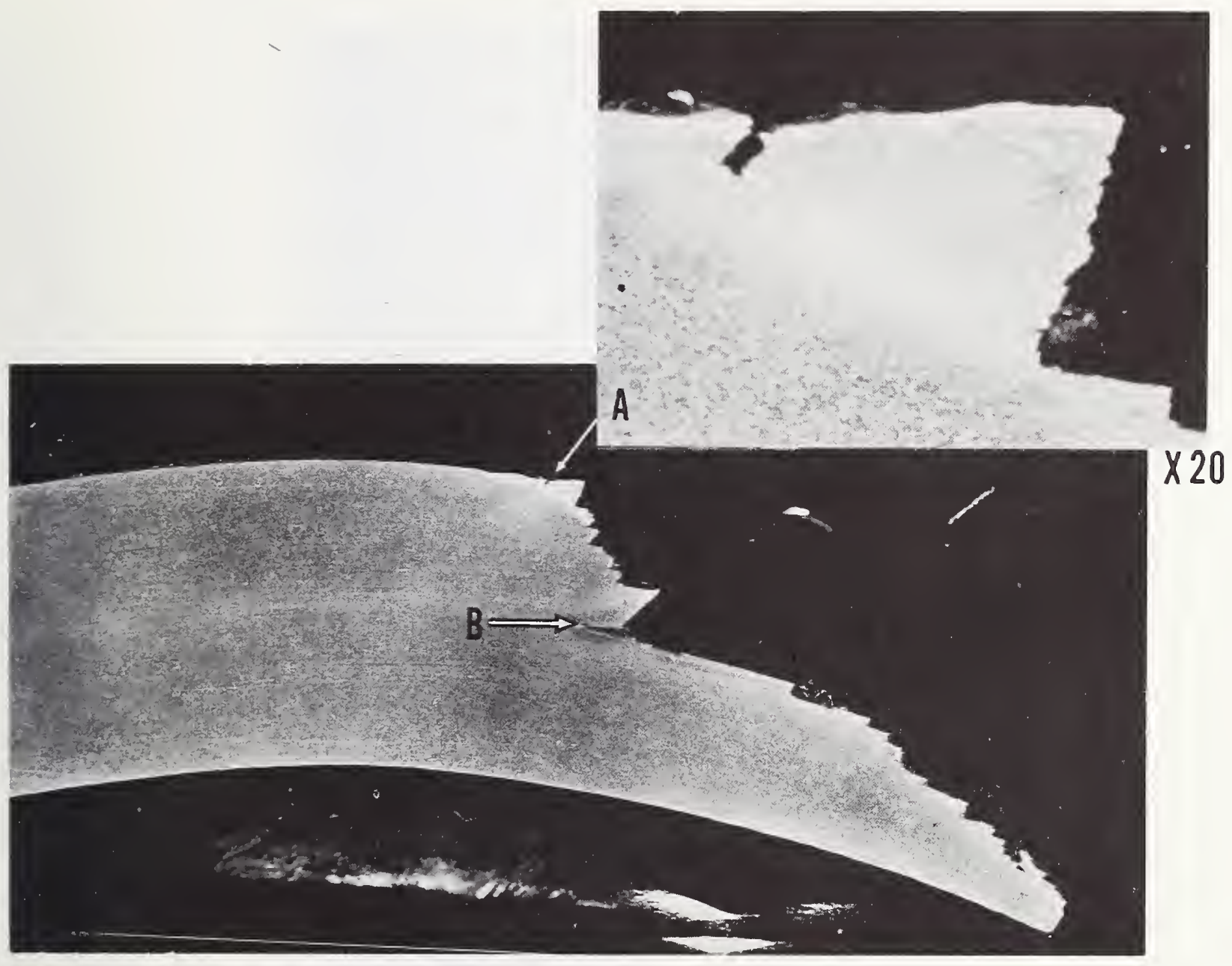

Figure 2. Profile View of Crescent City Sample FRA-3 in the $\mathrm{B}$ plane.

A small crack is observed near the plate surface at $A$, and $B$ shows a crack progressing parallel to the plate surface. The region at $A$ has high hardness and is believed to be an HAZ of a weld attachment. Etched: 1\% nital. $\mathrm{Mag} \cdot \mathrm{X} 2$ 



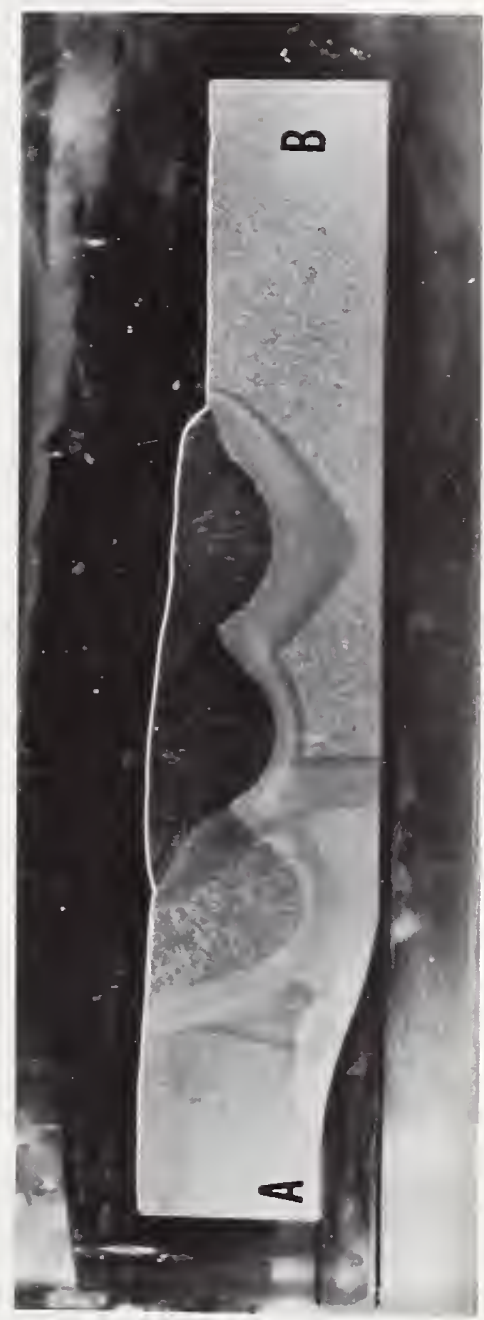

-

0)

㝞的

ฮี శ્ટ

잉

H

$\begin{array}{lll}0 & 0 \\ 0 & 0 & 0 \\ 0 & 0 & 0\end{array}$

घ

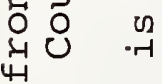

हत 다

(1) व

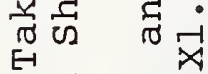

द 5

द 000

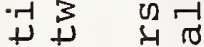

0010

(1) 品 0

in

( )

प 5 .

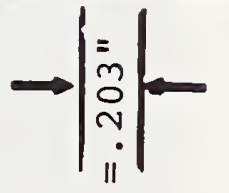

U日

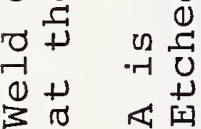

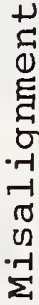

m

光 



\section{HaRONESS MIDTHICKNESS}

R

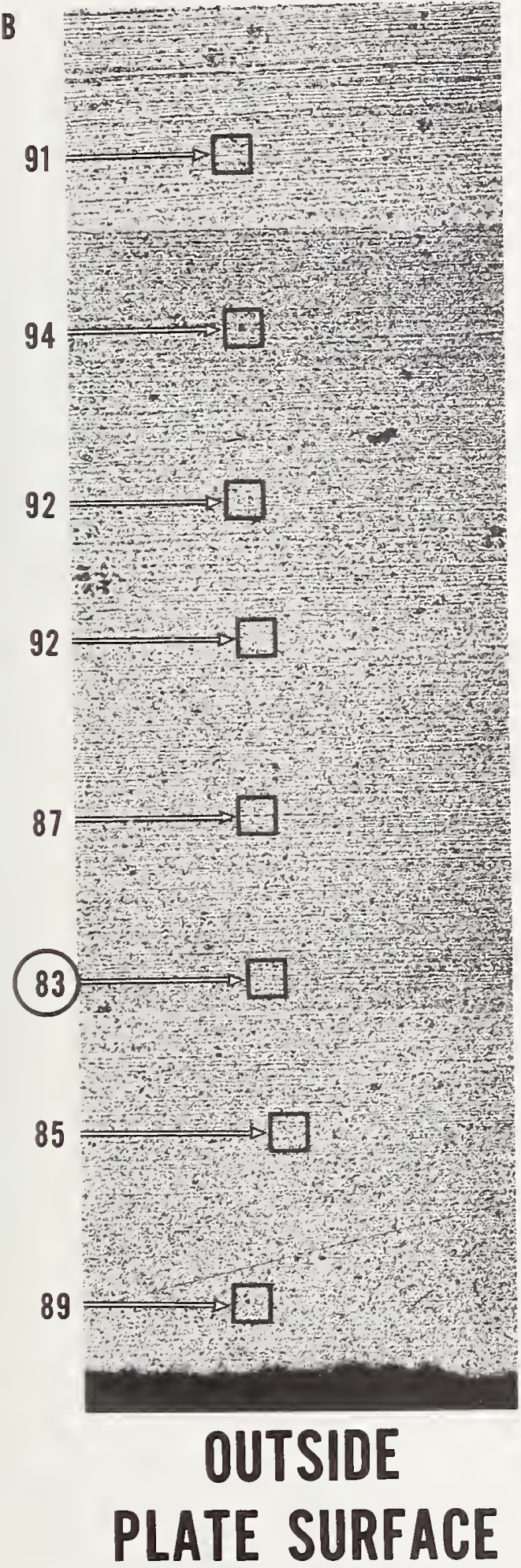

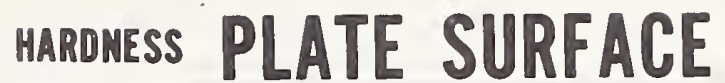

$\mathbb{R}$

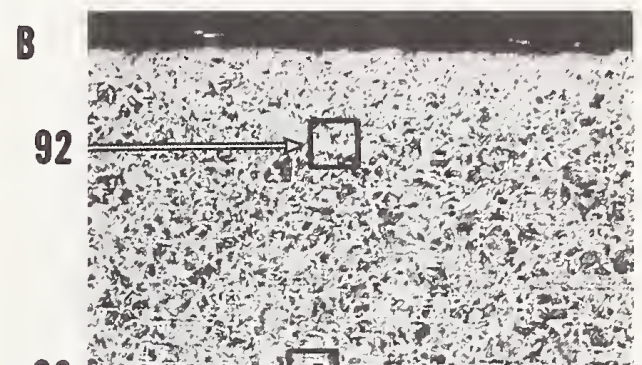

93

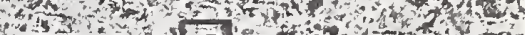
S 2 .

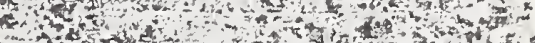

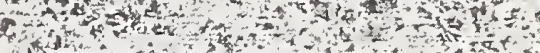

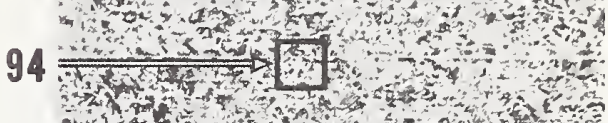

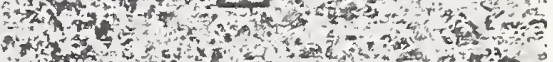

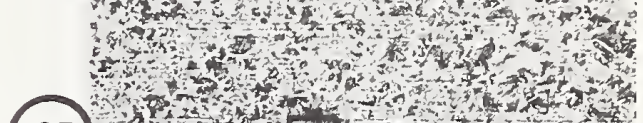

97

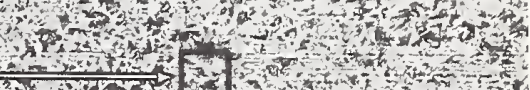

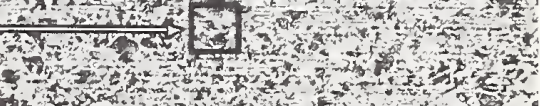

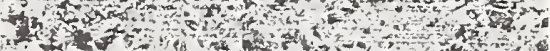

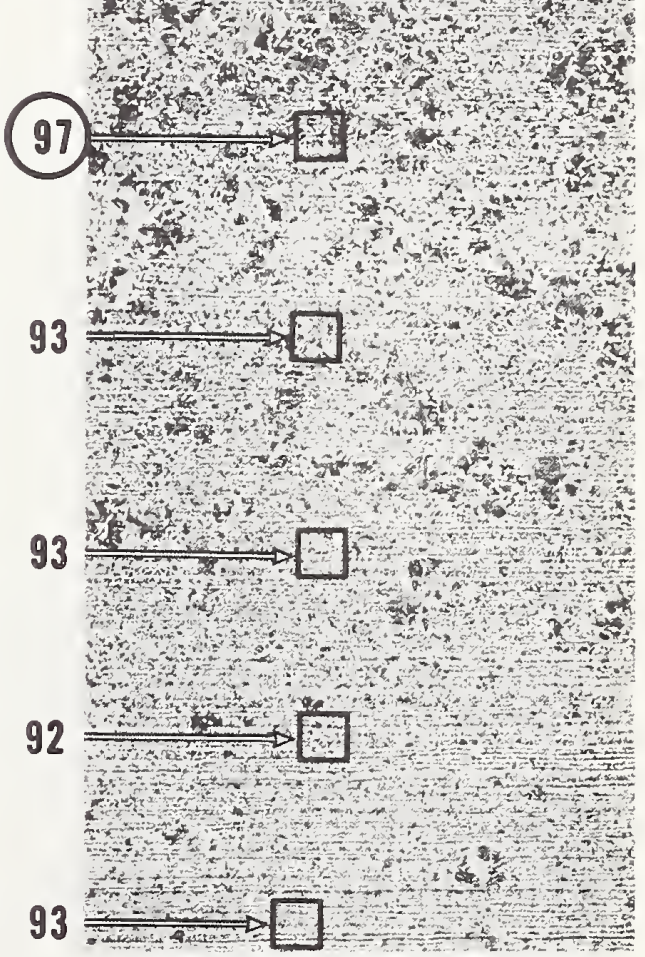

MIDTHICKNESS

Figure 4. Montage of Microstructure Through the Cross-Section of Callao Head Plate K-l with Hardness Values Shown for Specific Areas. The microstructure varies across the thickness with large amounts of pearlite near the inside of the plate and equal amounts of pearlite and ferrite near the outside surface of the plate. Etched: 1\% nital. X30 



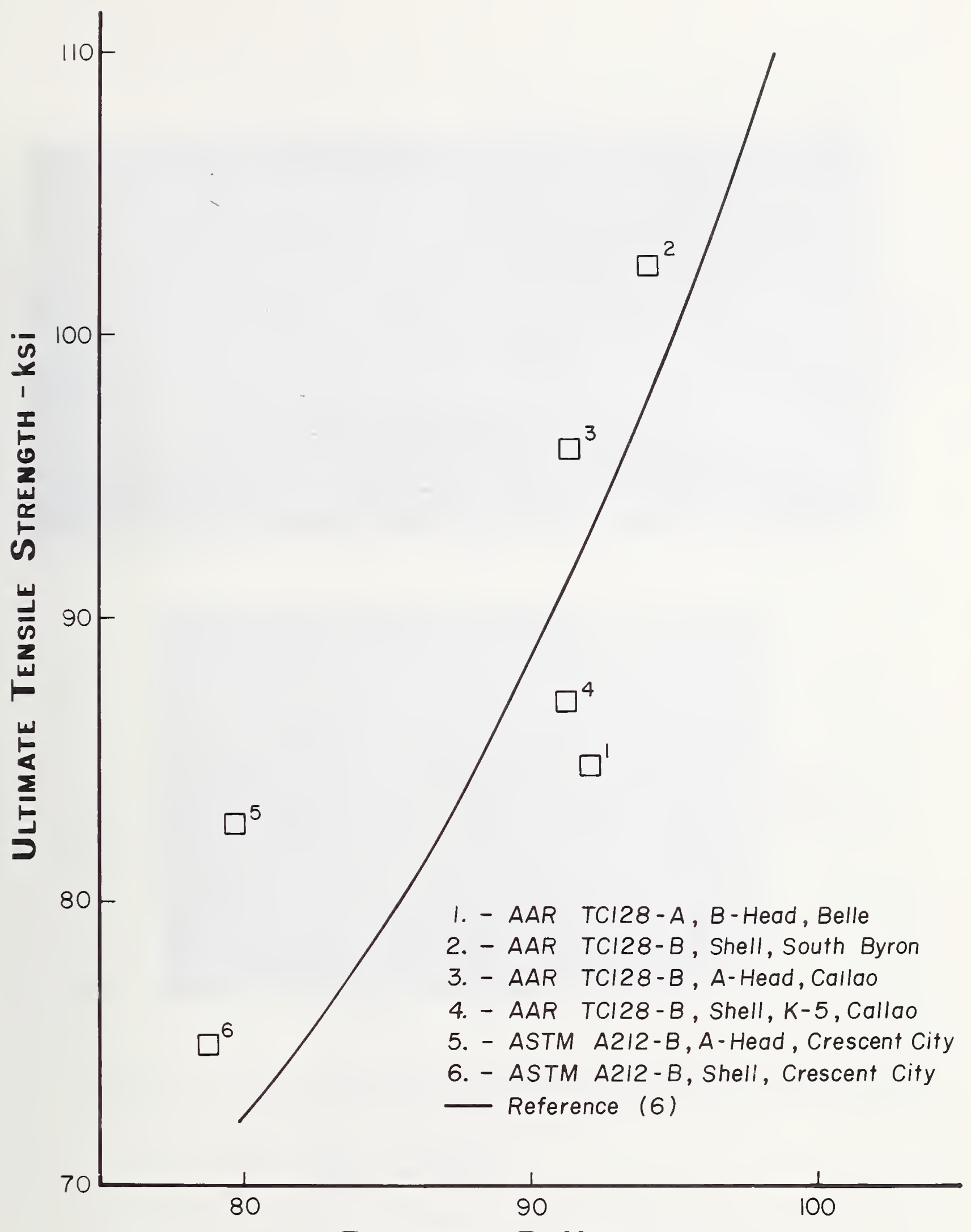

ROCKWELL B HARDNESS

Figure 5. Comparison of Tensile Strength and Hardness of the AAR TC128 and ASTM A212 Steels Tested. (Data of Crescent City, A-Head plate, point 5, is from transverse specimens only.) 

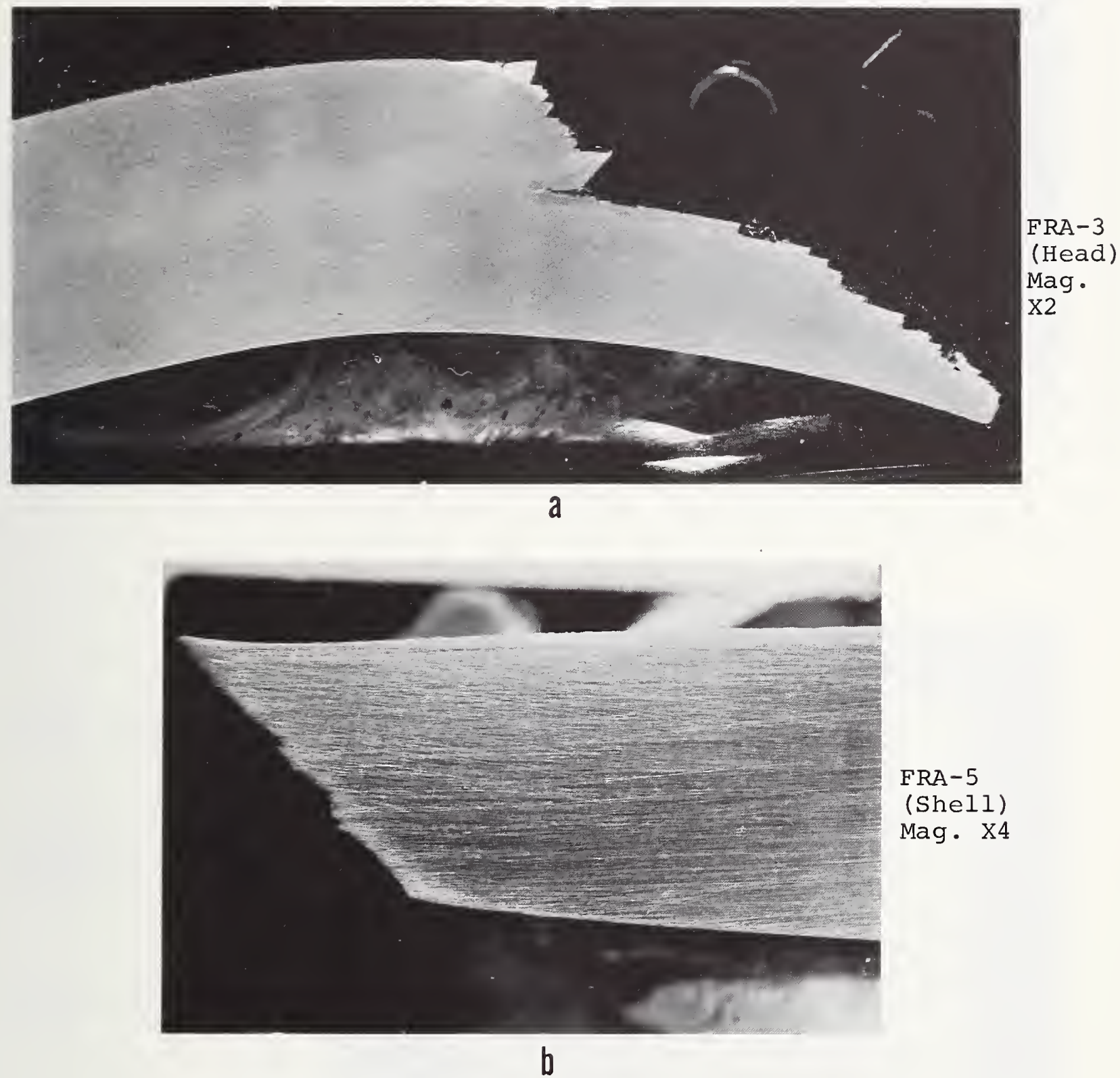

Figure 6. Profile Views of Fractures Taken From Crescent City Accident. ASTM A212-B steel.

(a) lamellar tearing

(b) shear fracture 



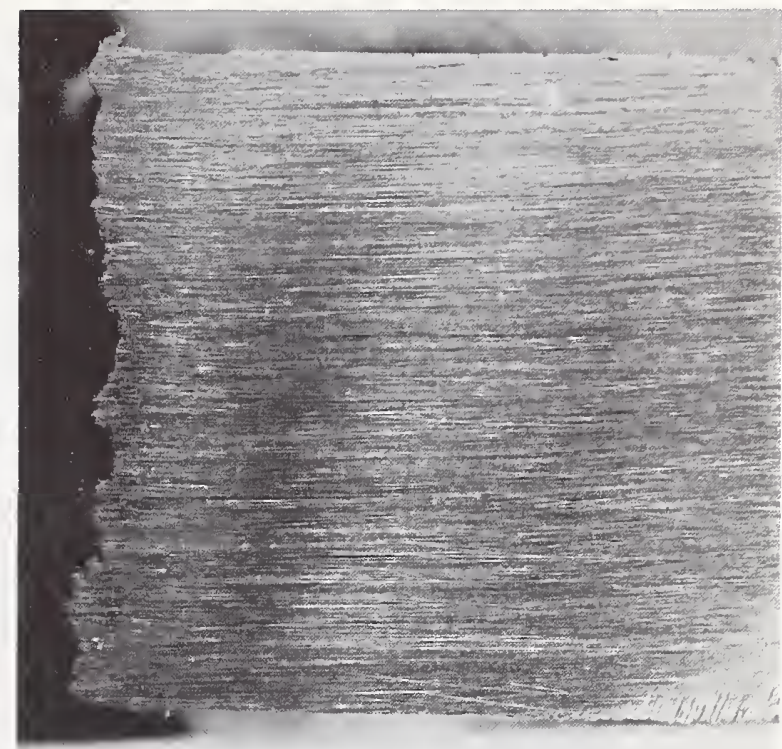

a

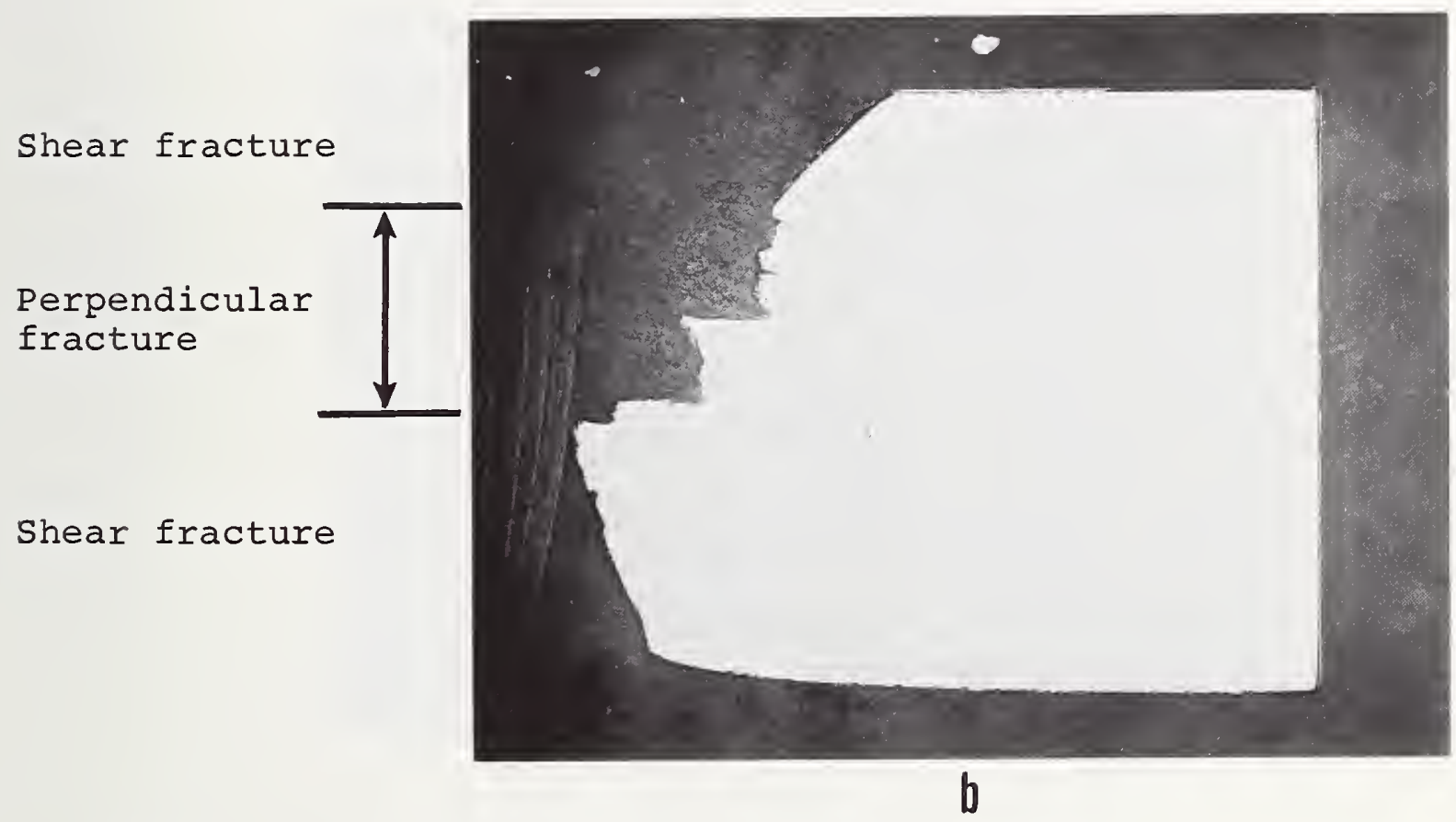

Figure 7. Profile Views of Fractures Taken from the Callao and South Byron Accidents. AAR TCl28-B steel.

(a) NP - nearly perpendicular fracture. X4

(b) mixed mode fracture. $\mathrm{X} 4$ 


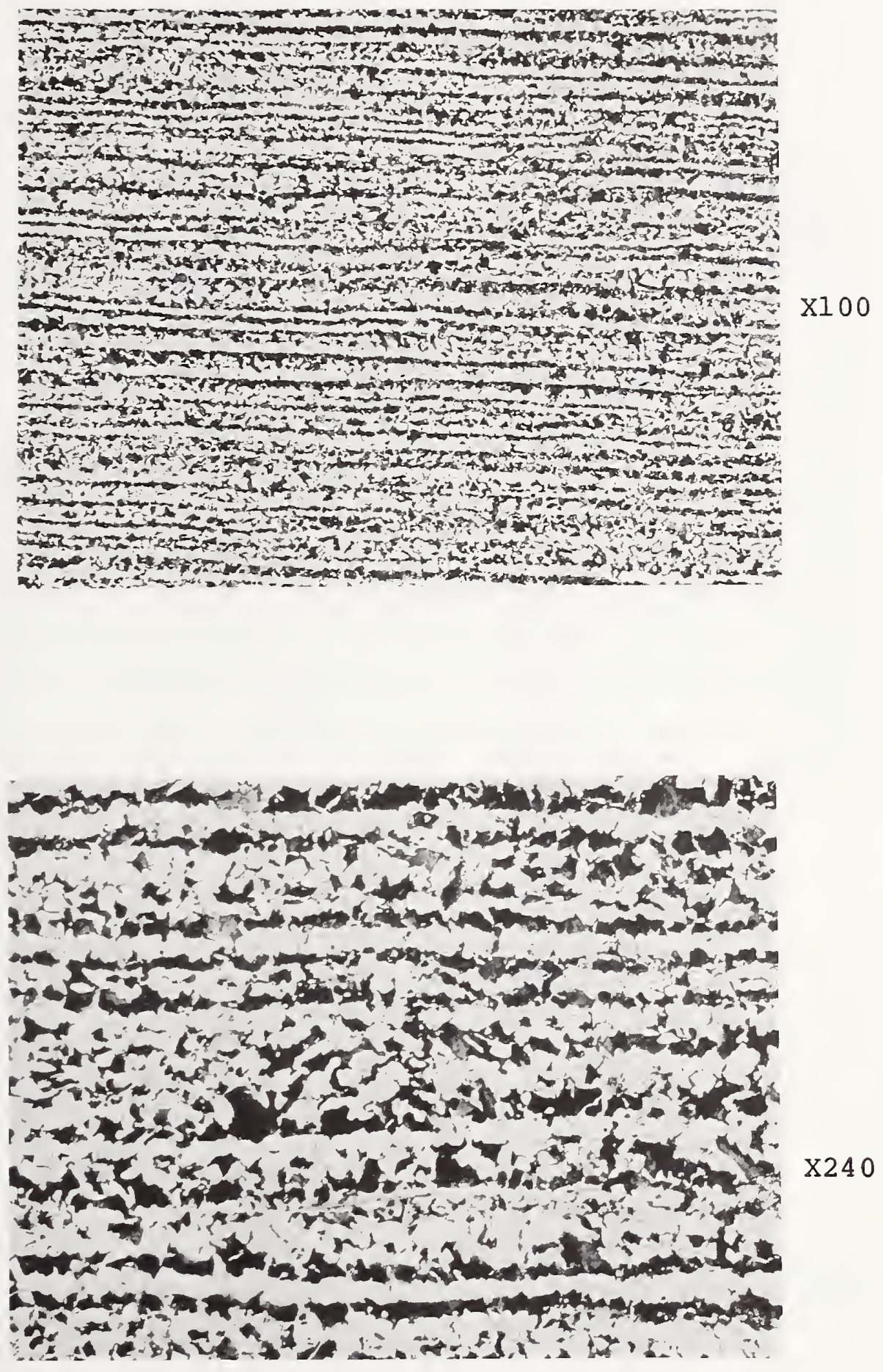

Figure 8. Microstructure of the Belle Sample.

The plane is oriented approximately longitudinally in the head plate of AAR TCl28-A steel with a ferrite grain size of 8 and finer. 



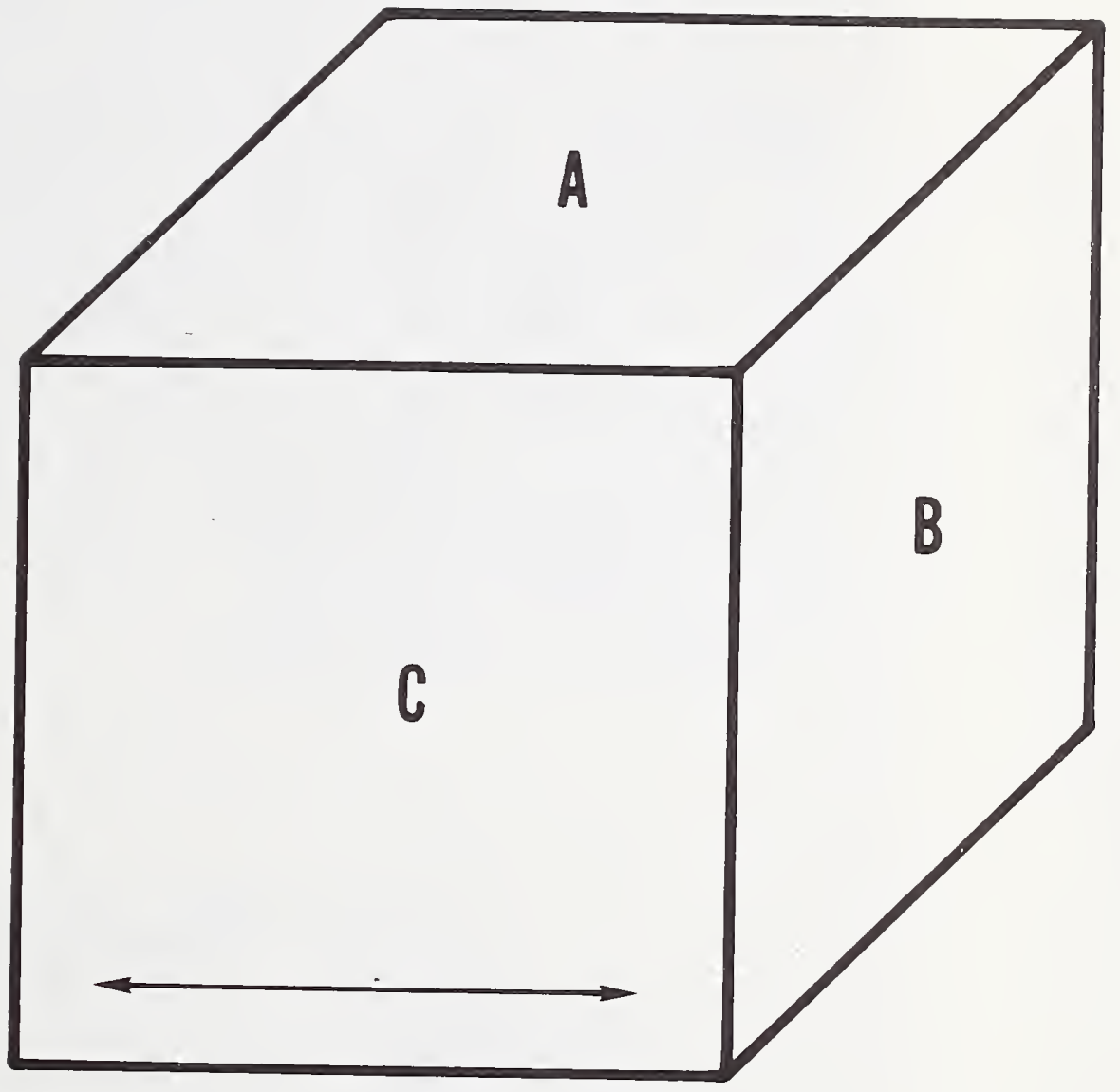

Figure 9. Drawing Showing the Three Mutually Perpendicular Planes Associated With the Rolling Direction in a Plate.

The A plane is parallel to the plate surface. The $\mathrm{C}$ plane contains an arrow which indicates the rolling direction of the plate. 



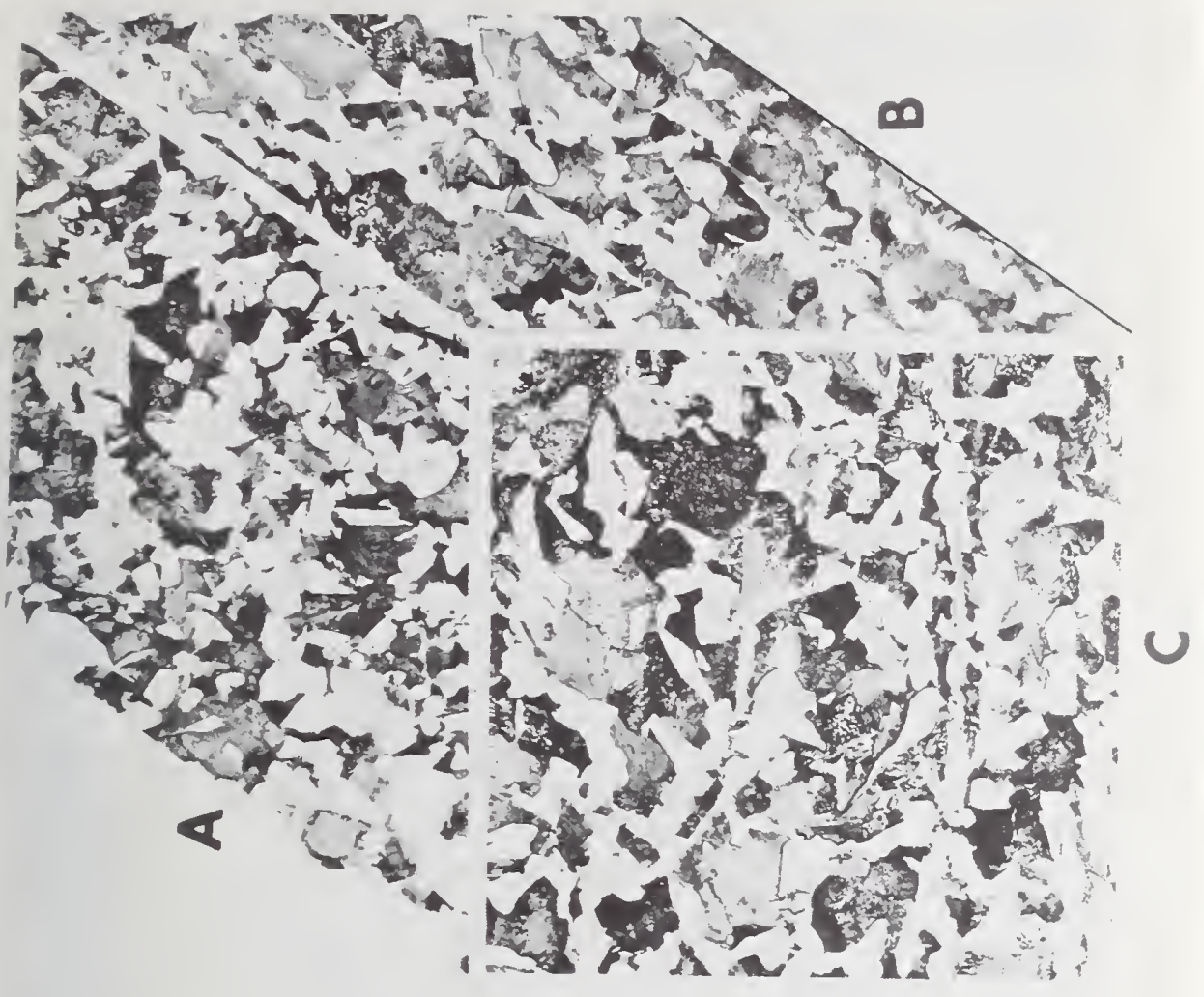

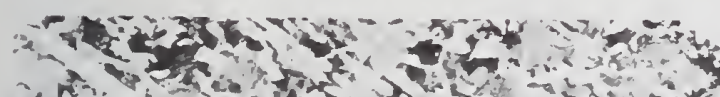

on $-1 / 30$ s.

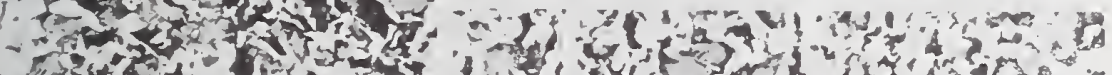

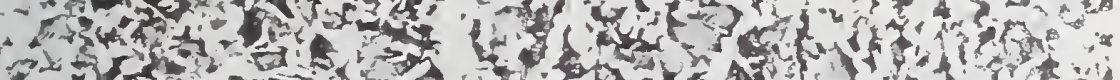

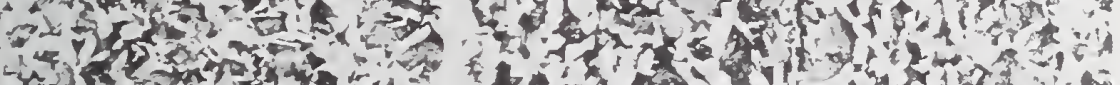
a n 7.

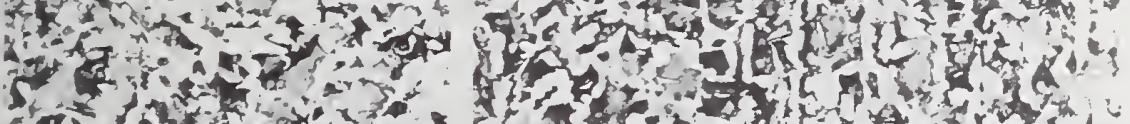

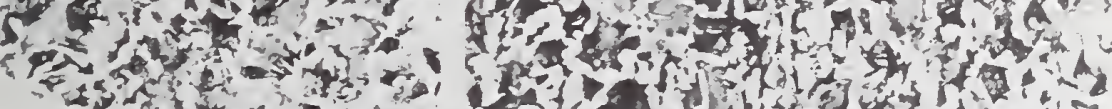

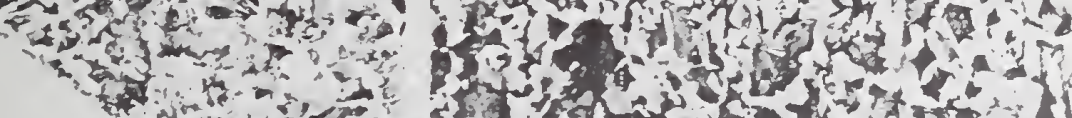

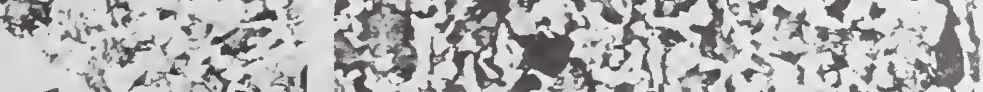
$\leftarrow$ to -

彔

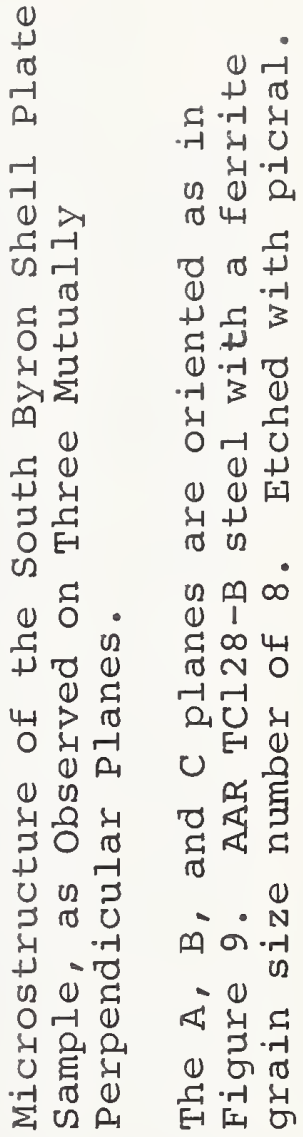

$\stackrel{0}{-1}$

\begin{tabular}{ll} 
& 0 \\
$\circ$ & \multicolumn{1}{c}{} \\
0 & 0 \\
0 & -1 \\
& घ
\end{tabular} 


\section{3.

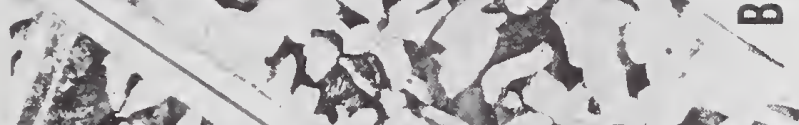

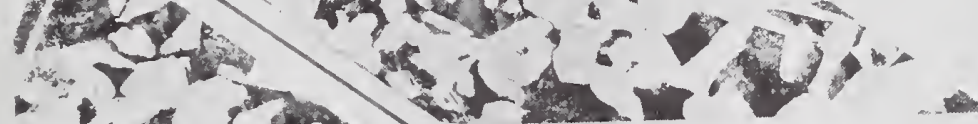

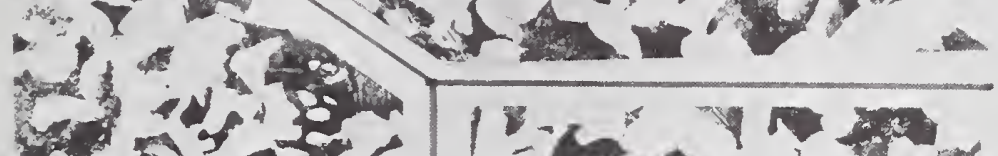

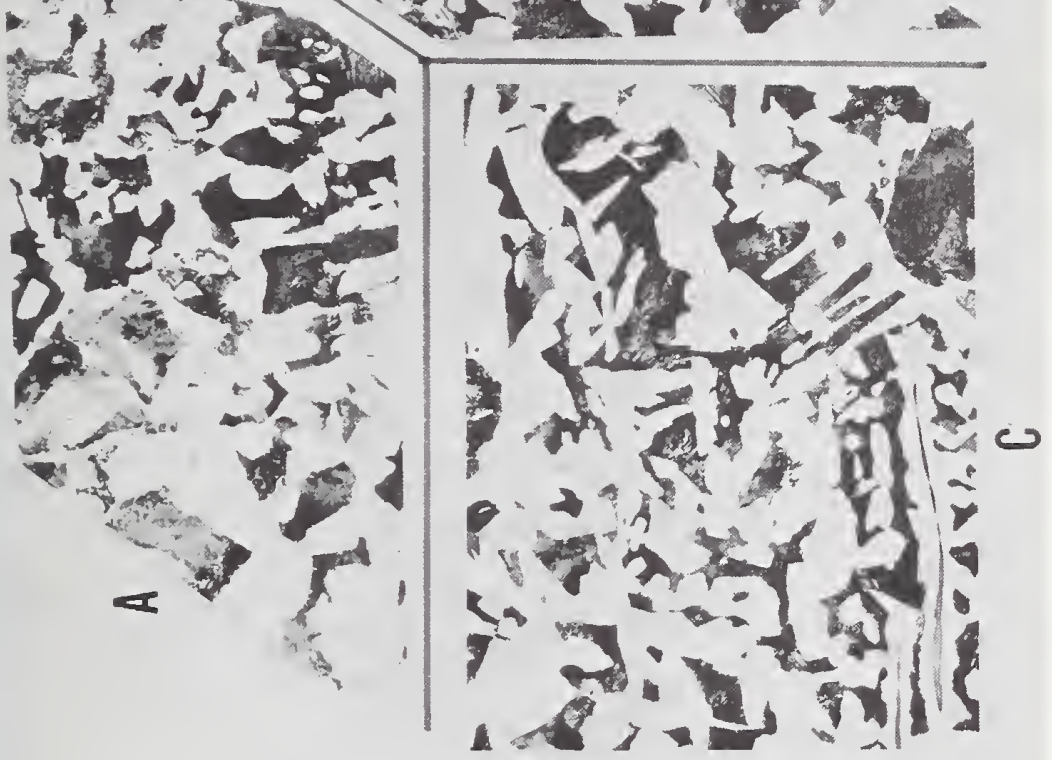

a

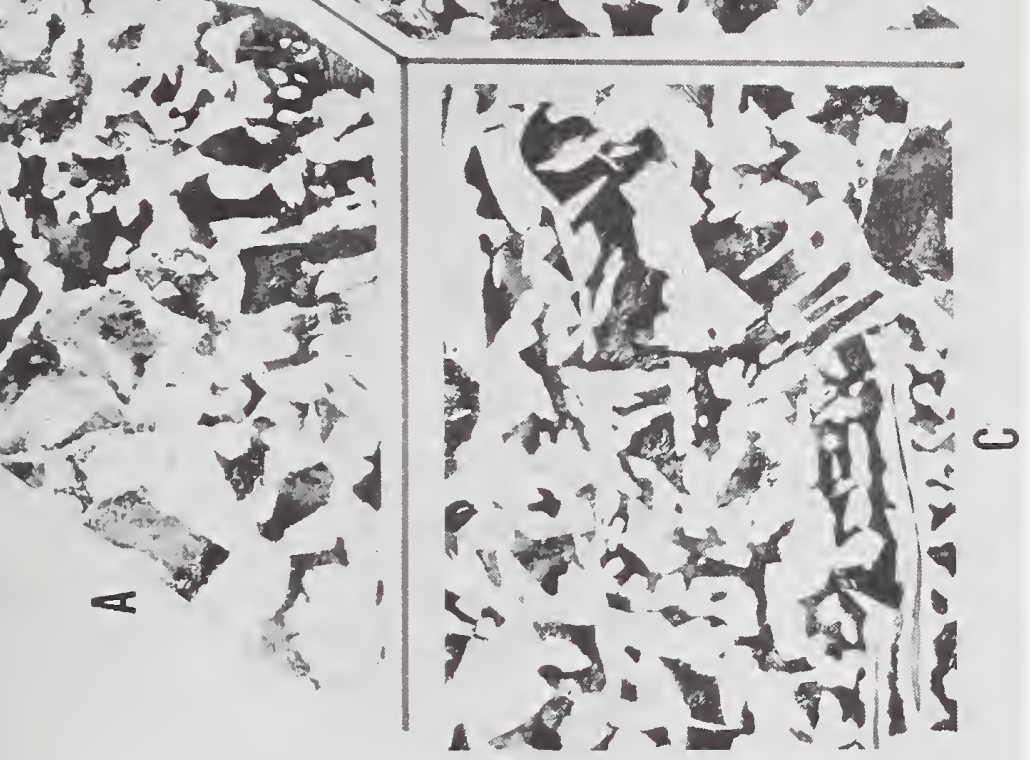

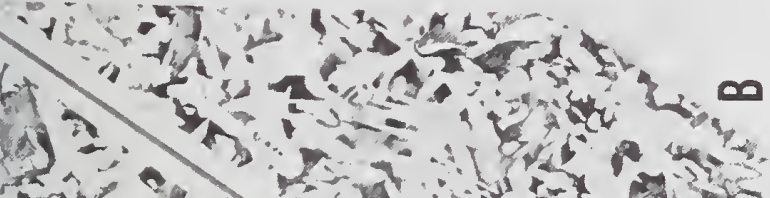

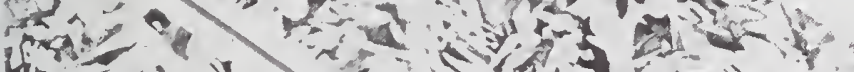

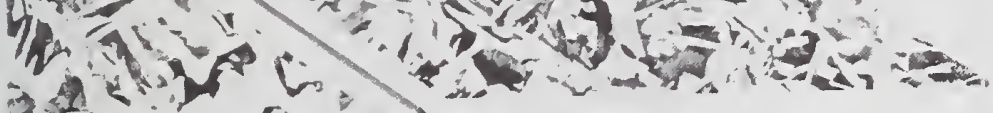
$21<-50$

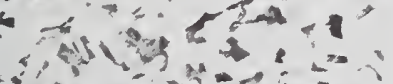
? 10 At 10 ?

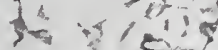
ris

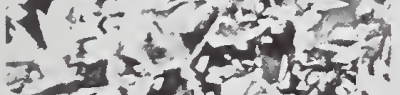
Pint -

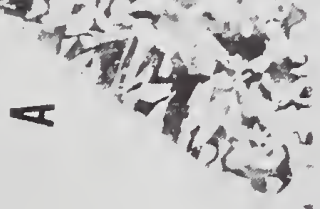
r.,

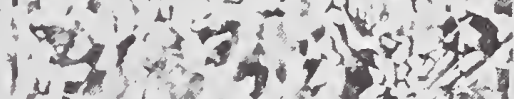
y 5 - s?

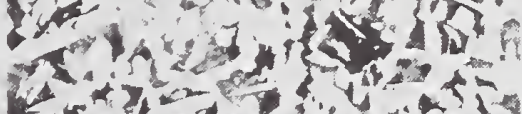

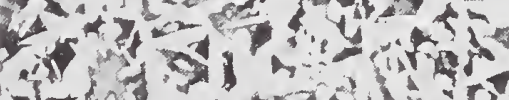

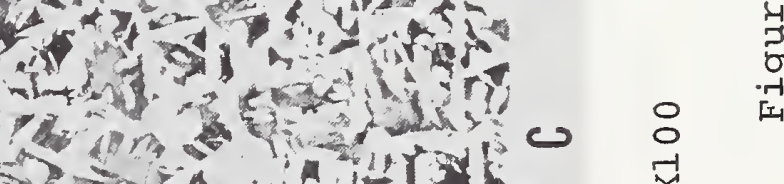

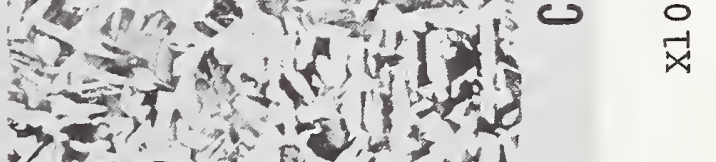
- $5-3+21$ ind

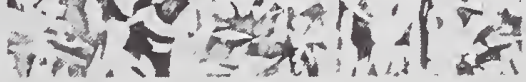

$\underset{\substack{0 \\ \sim}}{\mathbb{4}}$
年

E

出 द⿱

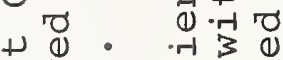

द य प्र

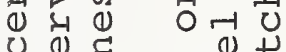

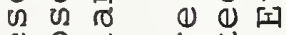

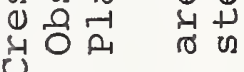

ข 4 of

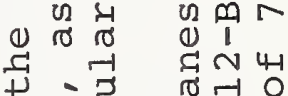

이

प- $1 \cdot 0-1$

0 स

(1) 出 ब1

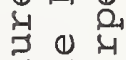

त्रा

U $\sum \stackrel{0}{\Omega}$

त्व

न

记

प्र

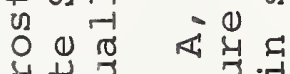

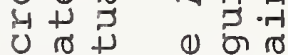

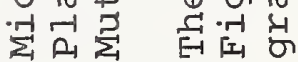

$\underset{-1}{-1}$

(1)

.4 



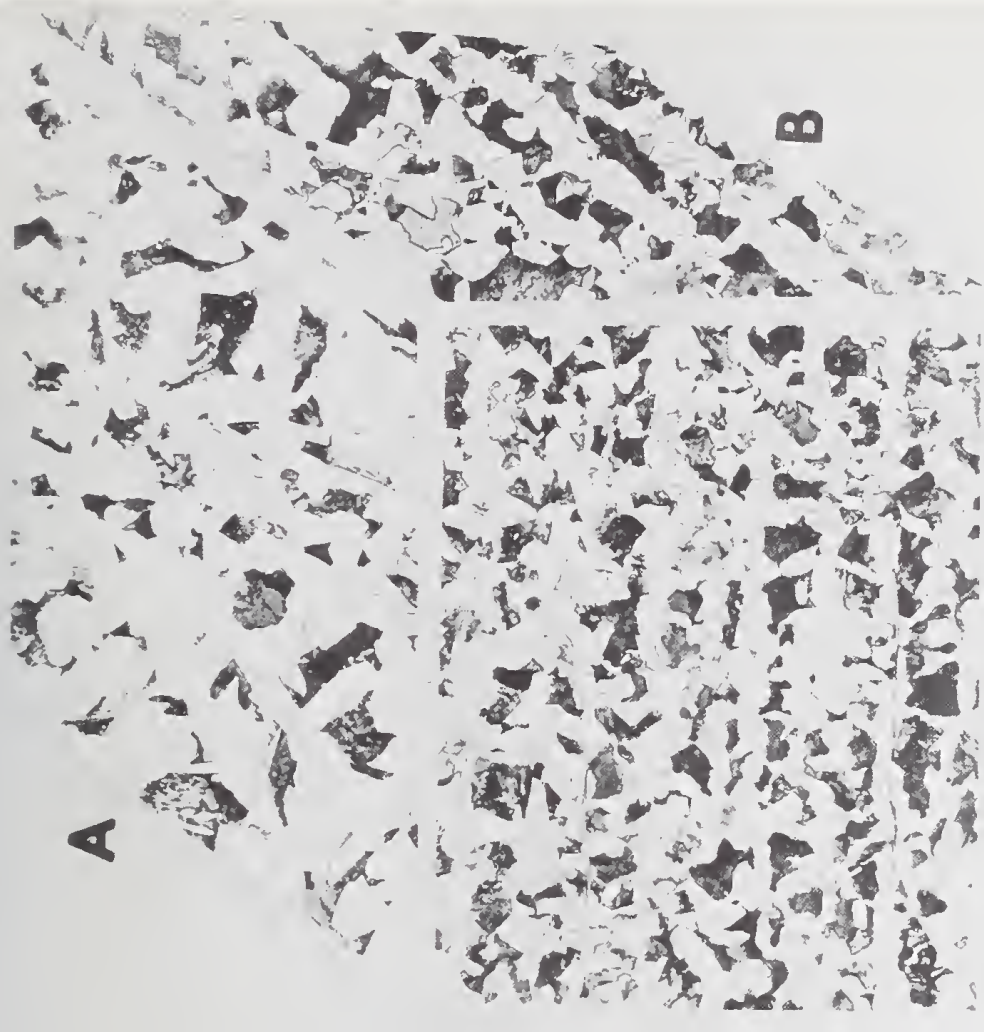

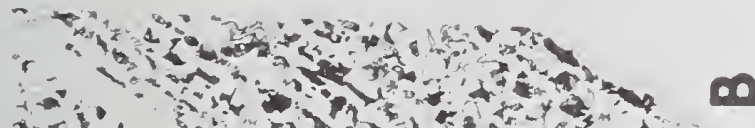

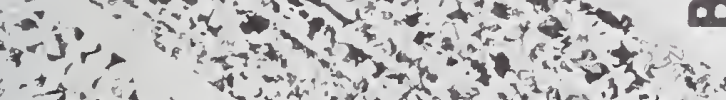

at

ar

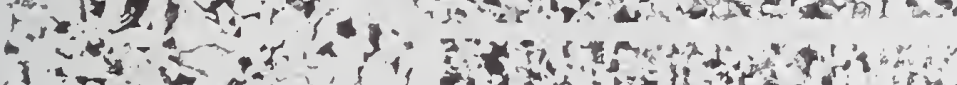
r Do

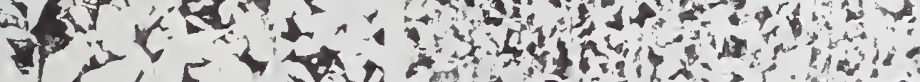
Q $161^{-1}$ 2

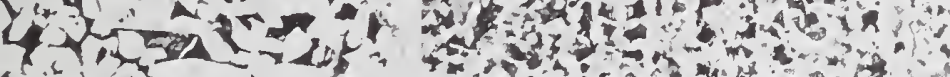

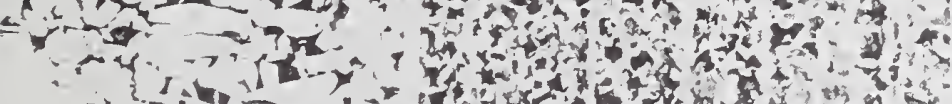
$\therefore$ fir $\rightarrow$ a

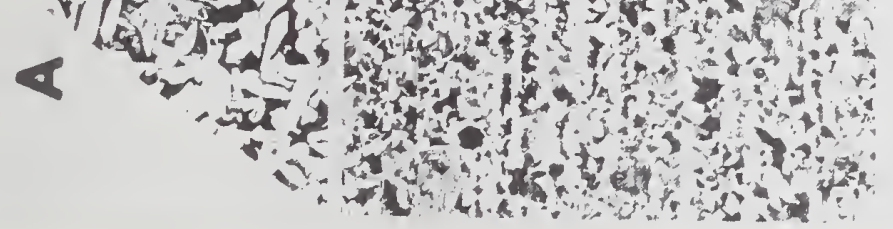





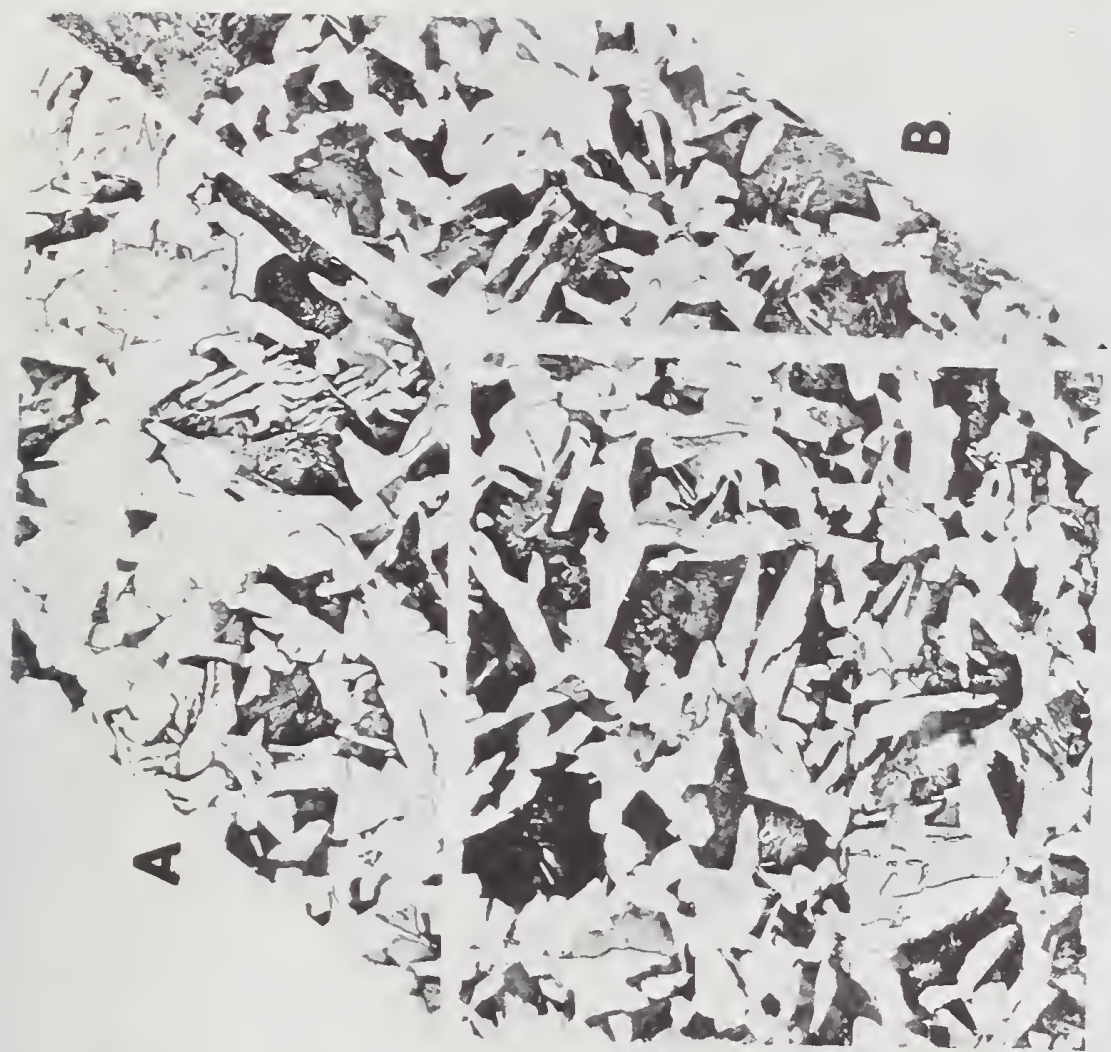

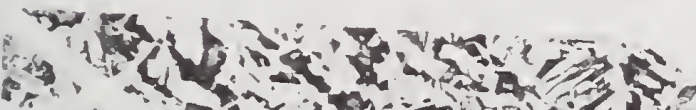

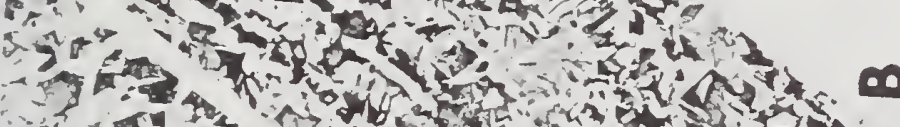

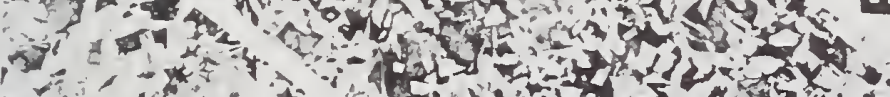

S

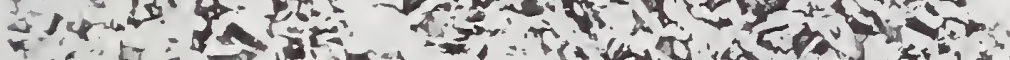

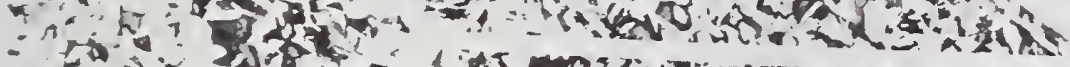

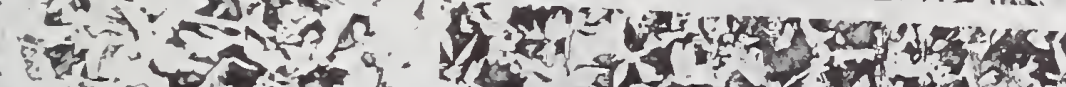

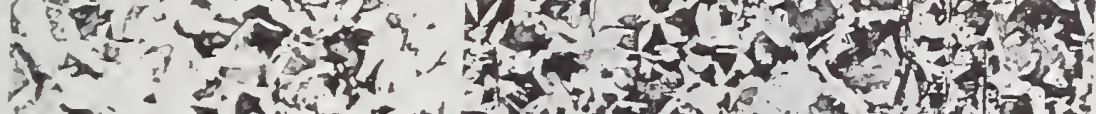

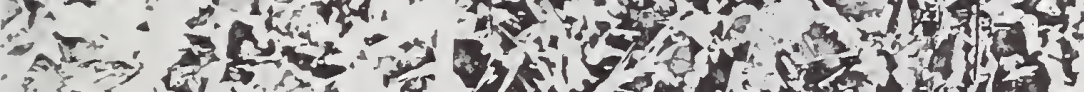
1

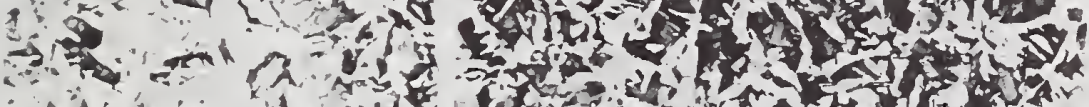
ind

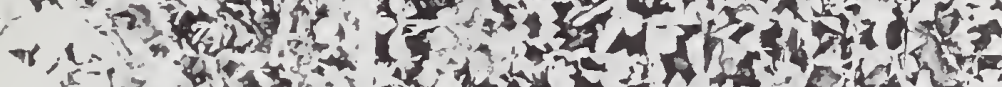

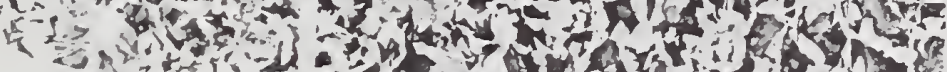

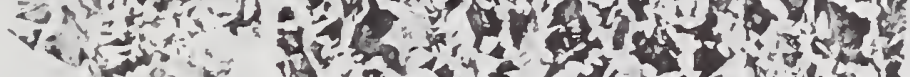
- $\quad$ in

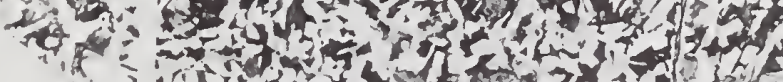

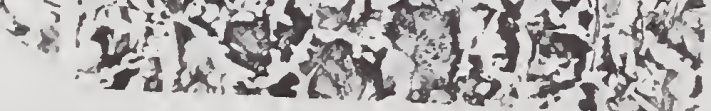





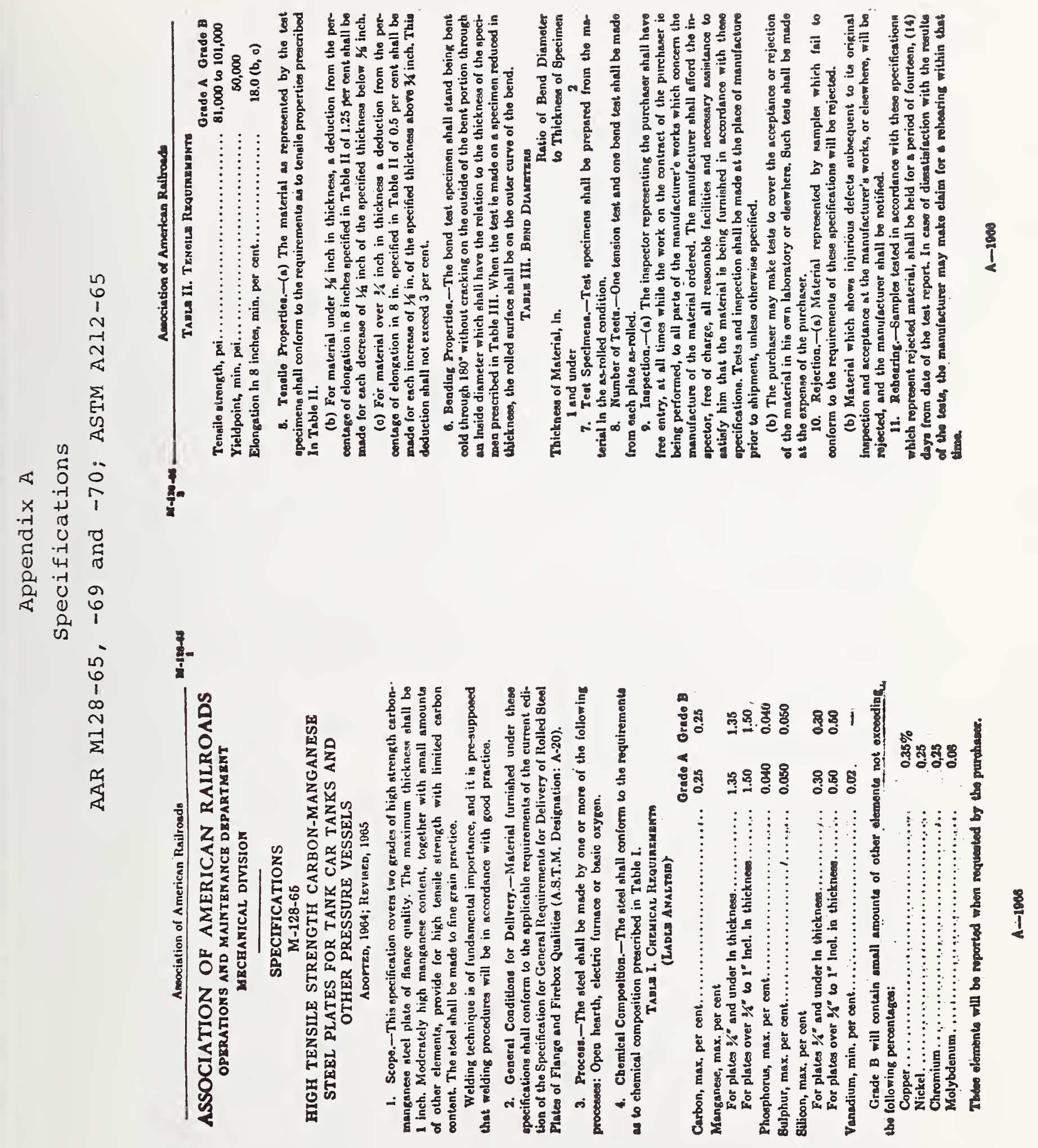


Ai23.0. Specification for high strength carbon mangarese steel plates for tank cars - AAR TC128. 69.

\section{M128.01 Scope}

(a) This specification covers two grades of high trenrah carbon-nianganese steal plate of llange quality. The liaximun thickness shail be 1 inch. Moderately high mincanese content togetner with small amounts of other elenien:s provide for high strength with limited carbon content. The steel shall be made to fine grisin practice. Weldirg technlque is of fundamental importance, and it is presupposed that welding procedures will be is accordance with good practice.

(b) The material shall be furnished in the as rolled conditica. When specilied for low terpereture service the material shall be furchshed armalized to reet, requirements of ASTM Spec1f1. cat1 on $A 300-63$, clegs 1, except thet 1mpect spec1mens shall be Type A Charpy V-Notch as shown In ASTM SFec1fication A $370-67$ and meet impact requirements at the temperature specifled in the tanis car spec1Pleation.

M128.02 General Conditions for Delivery

(a) Material furnished under this specification shall cunform to the apolicable requirenents of ASTM SpeciGcation A2O-67 titiled, "General Requirements for Delivery of Steol Plates for Pressure Vessels."

(b) See M128.01(b)

M128.03 Process

(a) The stcel shall be made by one or more of the folowing processes:

(1) Open-hearth

(2) Electric furrace, or

(3) Basic oxygen.

M128.0A Chemical composition

(a) The steel shall conform to the requirements as to themica: composition prescribed in Table Mi28.04(a).

\section{TABLE M128.04(a) CHEMICAL REOUIREMENTS}

\begin{tabular}{|c|c|c|c|}
\hline \multirow{2}{*}{ Element } & & \multicolumn{2}{|c|}{ Ladre Analyis, Percent } \\
\hline & & Grade A & Grade B \\
\hline 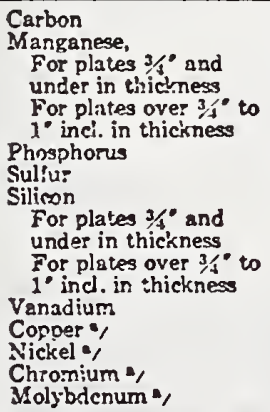 & $\begin{array}{l}\text { Min. } \\
\text { Max. } \\
\text { Max. } \\
\text { Max. } \\
\text { Max. }\end{array}$ & $\begin{array}{l}0.25 \\
1.35 \\
1.50 \\
0.040 \\
0.050 \\
0.30 \\
0.50 \\
0.02 \\
= \\
= \\
=\end{array}$ & $\begin{array}{l}0.25 \\
1.35 \\
1.50 \\
0.040 \\
0.050\end{array}$ \\
\hline
\end{tabular}

$\because$ These elements will be reported when requested by the purchaser.
M128.05 Tensile propertios

(a) The material as represented by the test specimens shall conform to the requirements as to tensile propertien prescribed in Table M128.05(a).

\begin{tabular}{|c|c|}
\hline Freperty & Grade A and Grade B \\
\hline $\begin{array}{l}\text { Tensile strength, psi } \\
\text { Yield point, psi } \\
\text { Elongation in } 8 \text { inches } \\
\text { percent, Min. } \\
\text { Elongation in } 2 \text { inches } \\
\text { percent Min. }\end{array}$ & $\begin{array}{l}81,000 \text { to } 101,000 \\
50,000 \\
16.0 ? \\
19.0\end{array}$ \\
\hline
\end{tabular}

$\because$ For material under $3 / 6$ inch thick a reduction 1 mm the specified percent of elongation of 1.25 percent sinall be made for each decrease of $1 / 5$ inch of shickness below $s / 5$ inch. Fo: material over $3 / 4$ incin thick a reduction from the specified percent elongation of 0.5 percent shall he made for each increase of $1 / 3$ inch of the thickress above made for each increase of $3 / 3$ inch of the thickress

M123.06 Bencing properties

(a) The bend test specimens shall stand being bent cold through $180^{\circ}$ without (riscking on the outside of the bcht portion through an inside diameter which shall have the relation to the thickness of the specimen prescribed in Table M128.06(a). When the test is made on a specimen reduced in thickness, the rolled surface stall be on the outer curve of the bend.

\begin{tabular}{c|c}
\hline \multicolumn{2}{c|}{ TABLE M128.06(a) BEND DIAMETERS } \\
\hline $\begin{array}{c}\text { Thickness of Material, } \\
\text { inches }\end{array}$ & $\begin{array}{c}\text { Ratio of Bend Diamater } \\
\text { to Thickness of Specimen }\end{array}$ \\
\hline 1 and under & 2 \\
\hline
\end{tabular}

M128.07 Test specimens

(a) Test specimens ghall be prepared from the materis! in the as-rolled condition.

M128.08 Number of tests

(a) Onc tension test and one bend test shall be made from each plate as-rolled.

Note: The term "plate as rollcd" used here refers to the unit plate rolled from a slab or directly from an ingot in its relation to the location and number os specimens, not to its condition.

M128.09 Insoection

(a) The inspector representing the purchaser shall have free ertry, at all times while the work on the contract of the purchaser is being performed, to all parts of the manufacturer's works which concern the manufacture of the material ordered. The manufacturer shall afiord the inspector, free of charge, all reasonable facilities and necesspector, free of charge, all reasonable facilities and necessary assistance to satisfy him that the material is being
furnished in accordance with these specifications. Tests and inspection shall be made at the place of manufacture prior to shipment, unless othervise specified.

(b) The purchaser may niske tests to cover the acceptance or rejection of the material in his own laboratory or elsewhere. Such tests shall be made at the expense of the purchaser.

\section{M128.10 Refection}

(a) Material represented hy samples which pail to conform to the requirements of these specifications prill be rejected.

- (b) Material which shows injurious defects subsequent to its original inspection and acceptance at the manufacturer's works, or elsewhere. will be rejected, and the manufacturer shall be notifici.

\section{M125.11 Rehearirin}

(a) Samples tested in accordarce with these sperifica. tions which represent, rcjected material, shall be held for a period of fourteen days from date of the test report. In case of dissatisfaction with the results of the rests, the manuiacturer may make claim for 2 rehearing within that time. 



\section{Specifications}

\section{AAR MI28-65, -69 and -70 ; ASTM A212-65}

M128.00 SPECIFICATION FOR HIGH STRENGTH CARBON MANGANESE STEEL PLATES FOR TANK CARS - AAR TC128-70.

\section{M128.01 SCOPE}

(a) This speclfication covers two grades of hlgh atrength carbon-manfanese steel plate of flange quality. The maximum thickness shall be 1 inch. Moder. tely high manganese content, together with small amounts of other elements provide for high strength - wth llmited carbon content. The steel shall be made to nne rrain practice. Hielding technıque is of fundamental importance, and it is presupposed that weld. Ins procedure will be in accordance with good prac. Unes.

(b) The material shall be furnished in the as rolled condition. When specified for low temperature wervlce the material shall be furmished normalized to meet requirements of ASTM Specification $\mathrm{A} 300-68$, Class $1_{1}$ except that impact specimens shall be Type A Charpy V.Nolch as shown in Asliil Specitication A370-68 and meet impact requirements at the temanture specified in the tank car specification.

\section{M128.02 GENERAL CONDITIONS FOR DELIVERY}

(a) Material furnished under this speclfication chall conform to the applicable requirements of ASTM Specification A20.69a titled, "Ceneral Roqulrements for Delivery of Steel Plates for Pressure Venels."

(b) See M128.01(b).

M128.03 PROCESS

(a) The steel shall be made by one or more of the following processes:

(1) Open-hearth,

(2) Electric fumace, or

(3) Basic oxygen.

\section{M128.04 CHEMICAL COMPOSTTION}

(a) The steel shall conform to the requirements as to chemical composition prescribed in Table M128.04(a).

TABLE M128.04(a) CHEMICAL REQUIREMENTS

\begin{tabular}{|c|c|c|c|}
\hline \multirow[t]{2}{*}{ Blement } & & \multicolumn{2}{|c|}{$\begin{array}{l}\text { Ladle Analysis, } \\
\text { Percent }\end{array}$} \\
\hline & & Grade A & Grade B \\
\hline Carbon & Max. & 0.25 & 0.25 \\
\hline $\begin{array}{l}\text { Manganese, } \\
\text { For plates } 3 / 4 " \text { and }\end{array}$ & Max. & & \\
\hline $\begin{array}{l}\text { under In thickness } \\
\text { For plates over } 3 / 4^{\prime \prime} \text { to }\end{array}$ & & 1.35 & 1.35 \\
\hline $1^{\prime \prime}$ Incl. In thlckness & & 1.50 & 1.50 \\
\hline $\begin{array}{l}\text { Phophorus } \\
\text { Sulfur }\end{array}$ & Max. & 0.040 & 0.040 \\
\hline $\begin{array}{l}\text { Sultur } \\
\text { Silicon }\end{array}$ & $\begin{array}{l}\text { Max. } \\
\text { Max. }\end{array}$ & 0.050 & 0.050 \\
\hline $\begin{array}{l}\text { For plates } 3 / 4 " \text { and } \\
\text { under In thickness } \\
\text { For plates over } 3 / 4 \text { " to }\end{array}$ & & 0.30 & 0.30 \\
\hline $\begin{array}{l}1 \text { "1ncl. In thickness } \\
\text { Vanedium a/ }\end{array}$ & & $\begin{array}{l}0.50 \\
0.02 \mathrm{Min} .\end{array}$ & $\begin{array}{l}0.50 \\
0.08 \mathrm{Max} .\end{array}$ \\
\hline Copper a/ & Max. & $\ldots$ & 0.35 \\
\hline Nickel a/ & Max. & $\ldots$ & 0.25 \\
\hline Chromium a/ & Max. & $\cdots$ & 0.25 \\
\hline Molybdenum a/ & Max. & $\ldots$ & 0.08 \\
\hline
\end{tabular}

- by the purchaser.

\section{M128.05 TENSILE PROPERTIES}

(a) The material as represented by the test speclmens shall conform to the requirements as to tensile properties prescribed in Table M128.05(a).

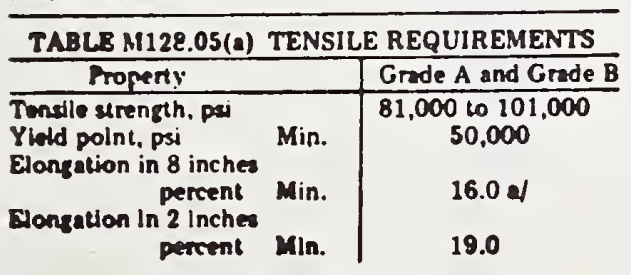

d For material under 5/16 Inch thick a reduction from the specified percent of elongation of 1.25 percent shall be made for each decrease of 1/32 Inch of thickness below 5/16 Inch. Por material over $3 / 4$ Inch thick a reduction from the speci. ned percent elongation of 0.5 percent shall be made for each Increase of $1 / 8$ inch of the thick. neas above $3 / 4$ Inch; this deduction shall not exceed 3 percent.

\section{M128.06 BENDING PROPERTIES}

(a) The bend test specimens shall sland being bent cold through $180^{\circ}$ without cracking on the out. adde of the bent portion through on inside diameter whlch shall have the relation to the thickness of the epeclmen prescribed in Table M128.06(a). When the leat ts made on a speclmen reduced In thickness, the rolled aurface shall be on the outer curve of the bend.

\begin{tabular}{c|c}
\hline \multicolumn{2}{c}{ TABLE M128.06(a) BEND DIAMETERS } \\
\hline $\begin{array}{c}\text { Talckness of Material, } \\
\text { Inches }\end{array}$ & $\begin{array}{c}\text { Ratio of Bend Diameter } \\
\text { to Thlckness of Specimen }\end{array}$ \\
\hline 1 and under & 2 \\
\hline
\end{tabular}

M128.07 TEST SPECIMENS

(a) Test specimens shall be prepared from the material in the as-rolled condition.

\section{M128.08 NUMBER OF TESTS}

(a) One tension test and one bend teat shall be ande from each plate as rolled.

Note: The term "plate as rolled" used here refers to the unlt plate rolled trom a slab or directly from an ingot in lis relation to the location and number of epecimens, not to its condition.

\section{M128.09 INSPECTION}

(a) The Inspector representing the purchaser chall bave free entry, at all tlmes while the work on the contract of the purchaser is being performed, to all parts of the manufacturer's works which concern the manufacture of the material ordered. The manufecturer shall afford the inspector, free of charge, all rewsonable facilities and necessary assistance to satisfy hlm that the material is being furnished in accurdance with these specifications. Tests and inspection shall be made at the place of manufacture prior to ship. ment, unless otherwise specified.

(b) The purchaser may make tests to cover the ceeptance or rejection of the material in his own Inbortory or elsewhere. Such tests shall be made at the experse of the purchaser.

M128.10 REJECTION

(a) Material represented by samples wbich tail to conform to the requliements of these specifications will be rejected.

(b) Material which shows injurious defects subsequent to its original inspection and acceptance at the manufacturer's works, or elsewhere, will be rejected, and the manufacturer shall be notified.

\section{M128.11 REHEARING}

(a) Samples tested in accondance with these epecifications which represent rejected material, shall be held for a period of fourteen days from date of the teat report. In case of dissatisfaction with the results of the tests, the inanufacturer may make claim for a rehearing within that time. 



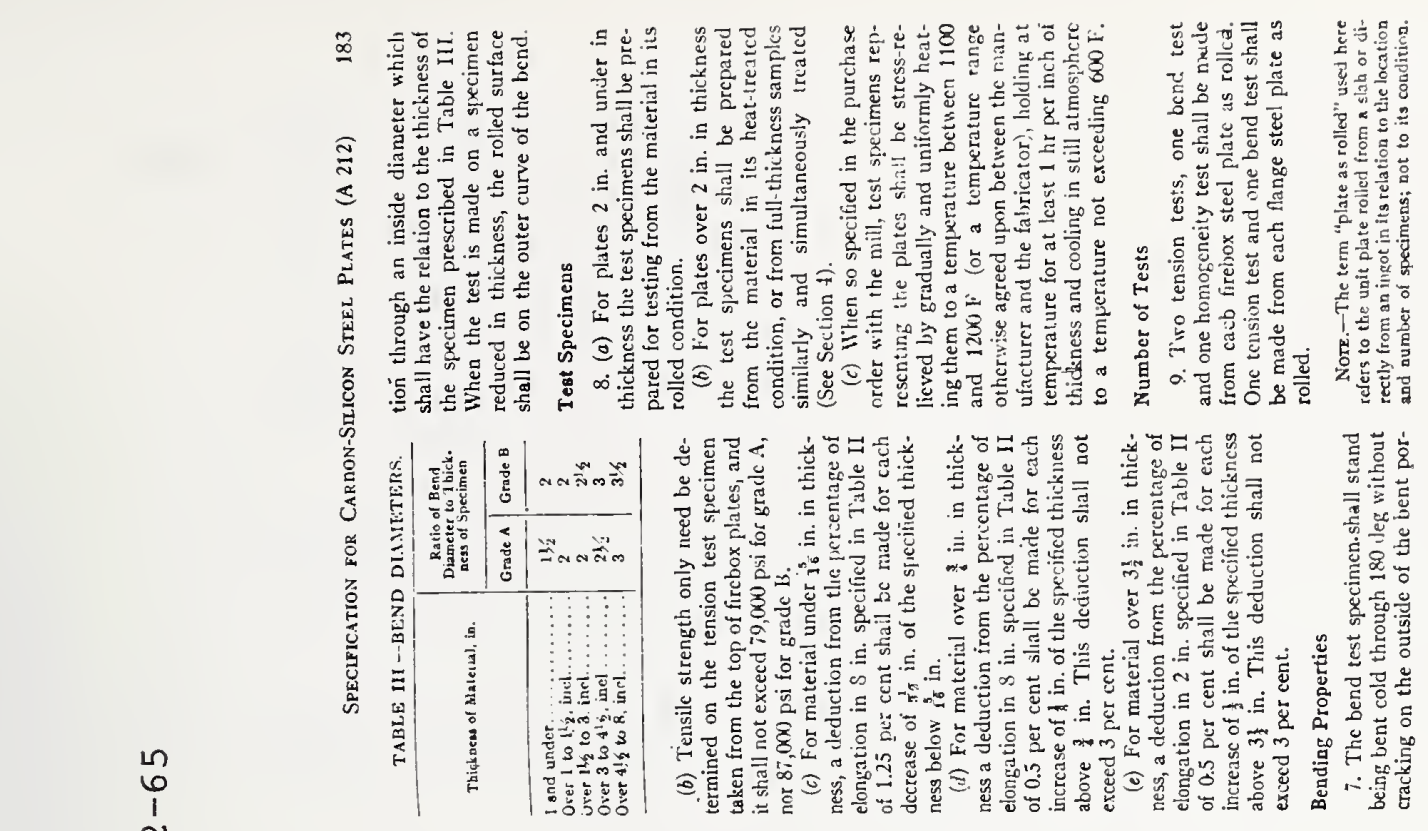

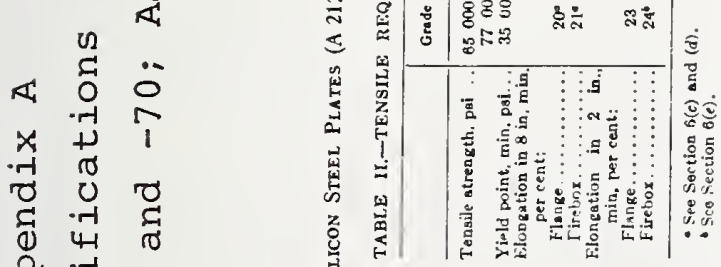

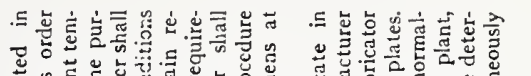

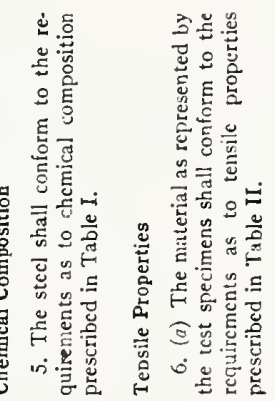

क्ष

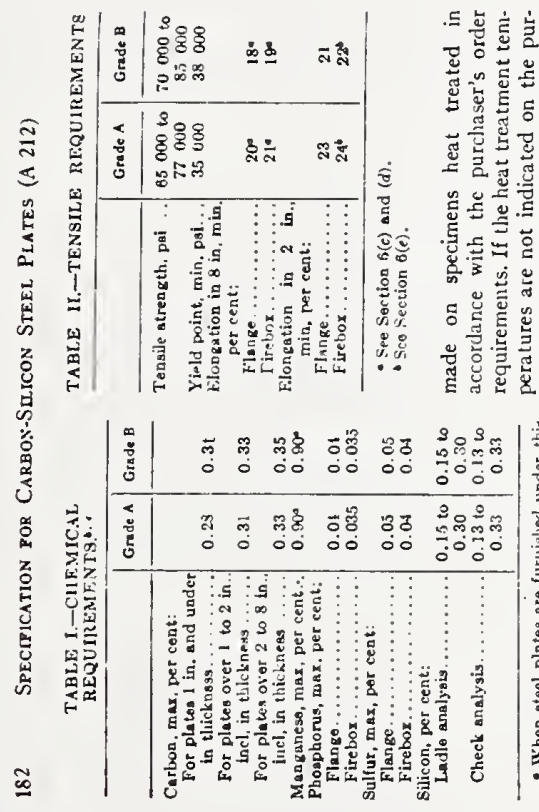

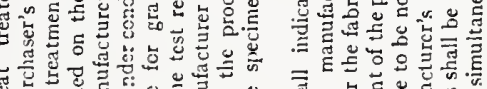

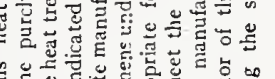

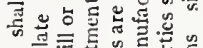

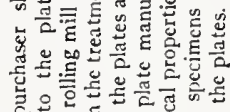

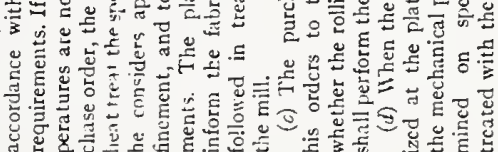

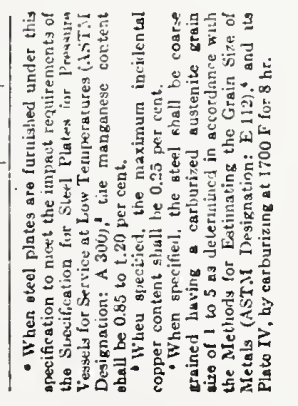

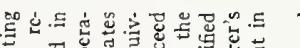

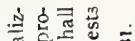

岂 1

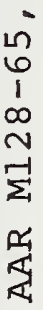

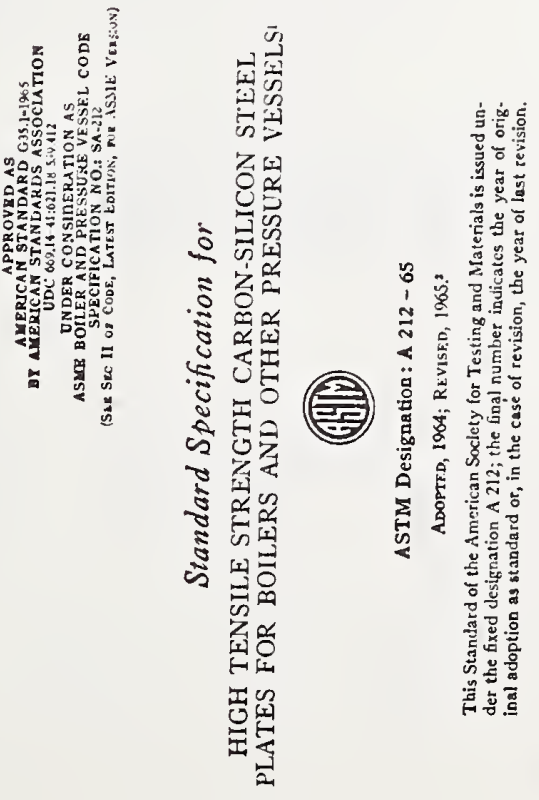

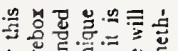

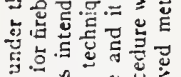

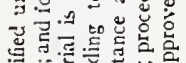

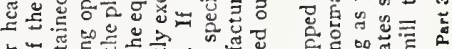

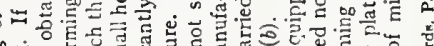

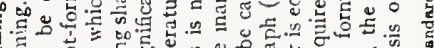

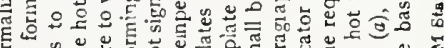

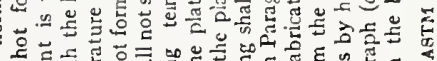

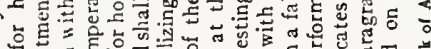

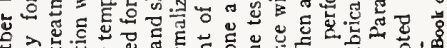

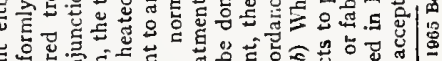
更

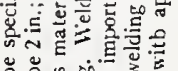

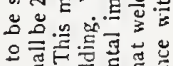

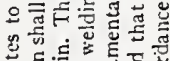

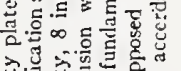

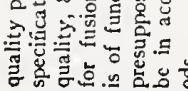

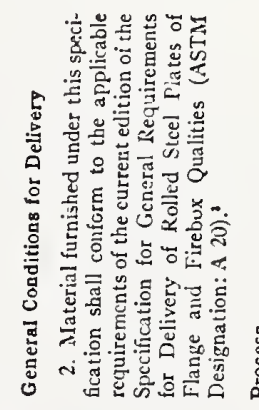

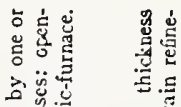
要要

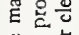
茨然 .

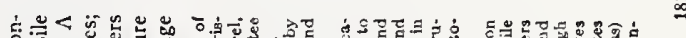

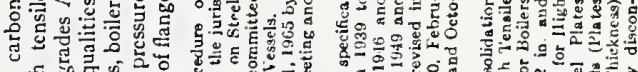

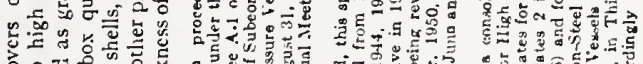

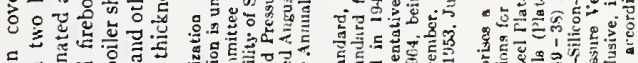

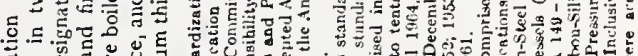

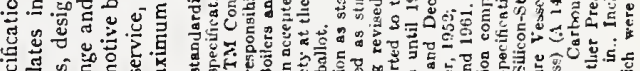

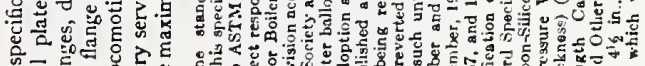

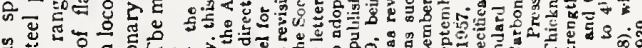

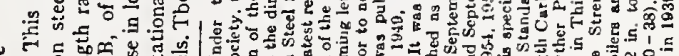

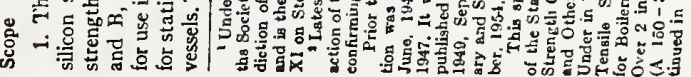





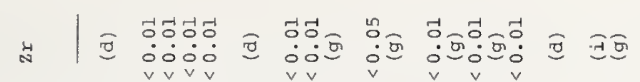

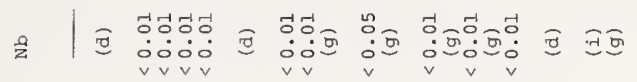

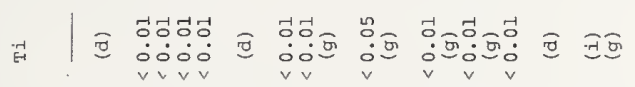

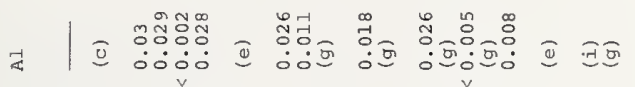

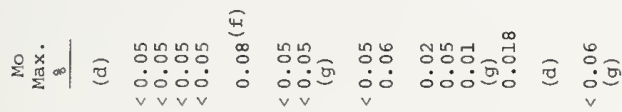

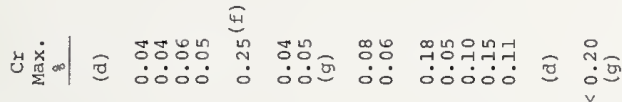

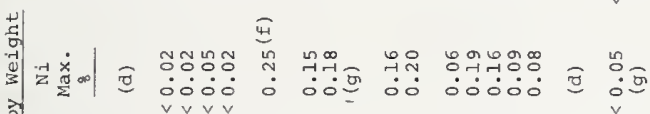

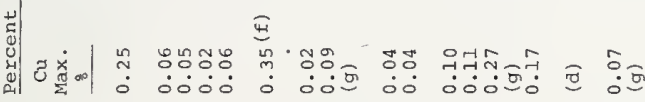

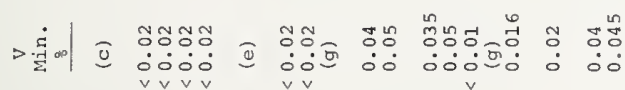

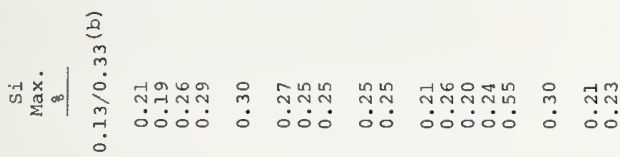

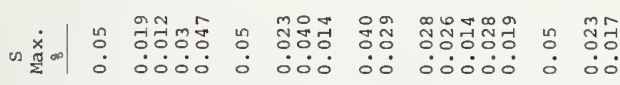

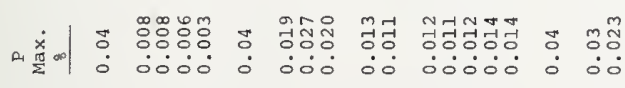

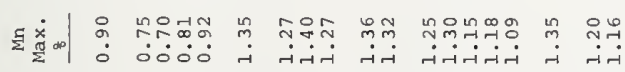

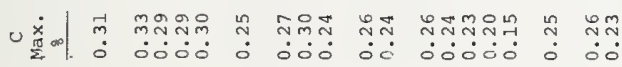

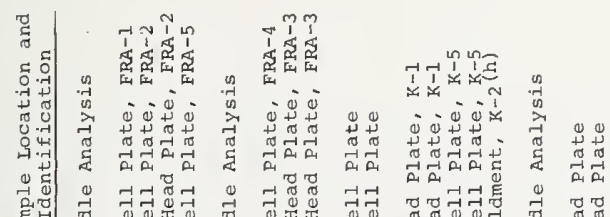

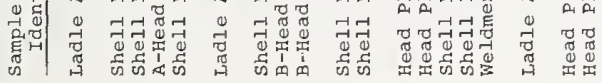

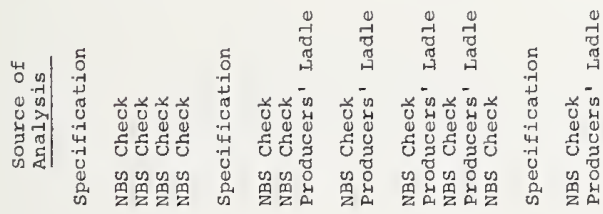

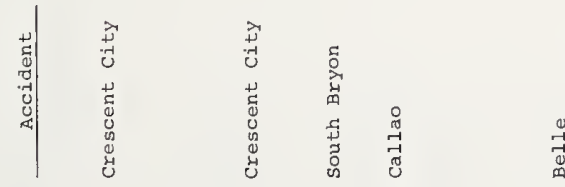

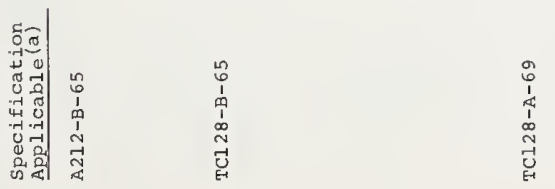

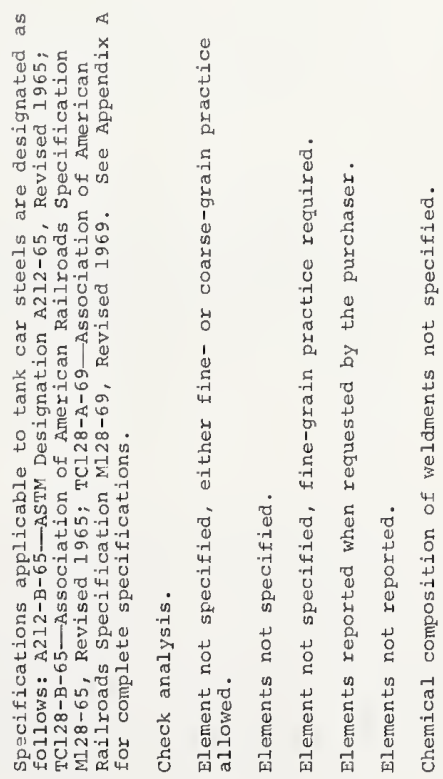





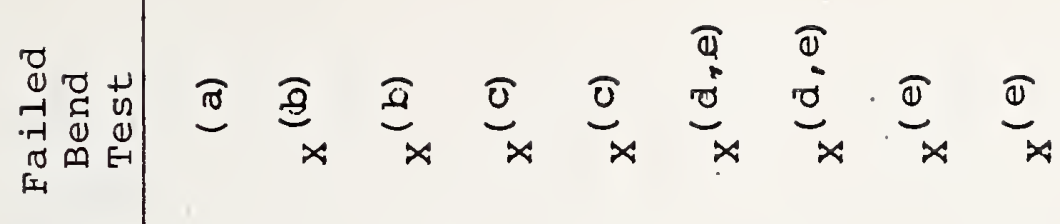

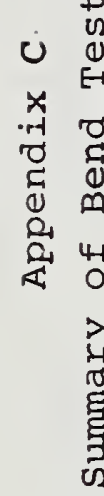

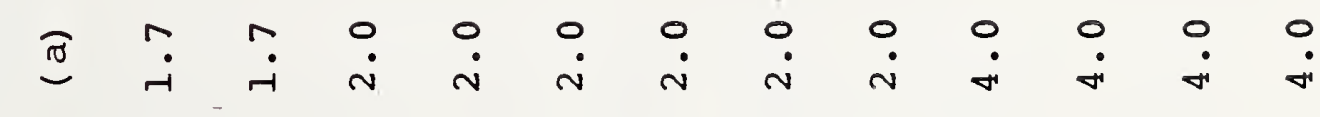





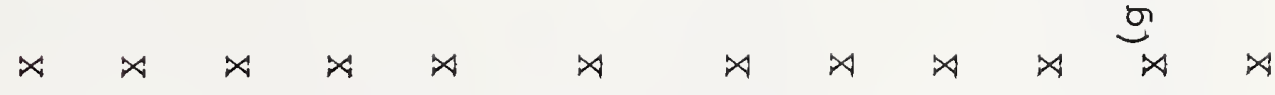

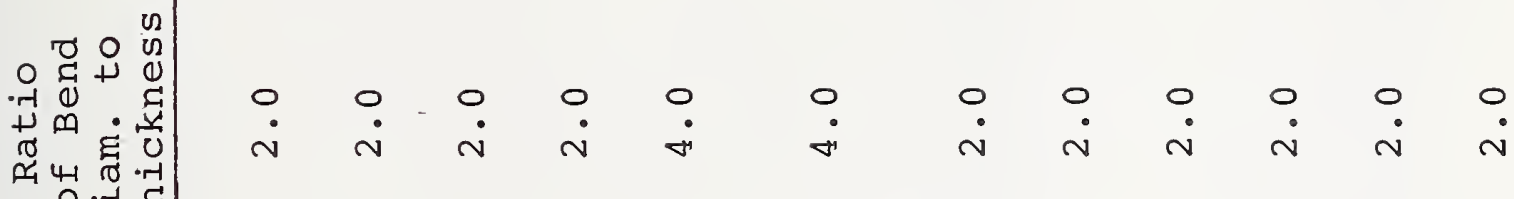

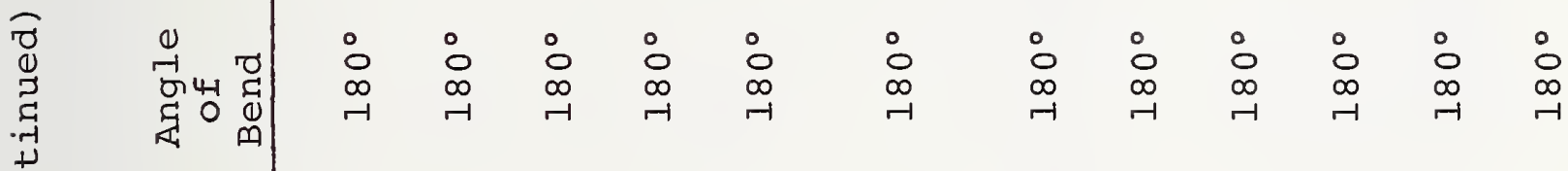

U

U)

$x$

r

(1)<smiles>CCC</smiles>

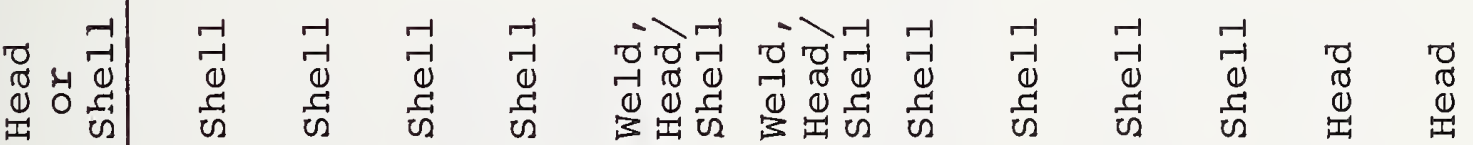

$\stackrel{l}{l} \stackrel{l}{l}$

6 म

录

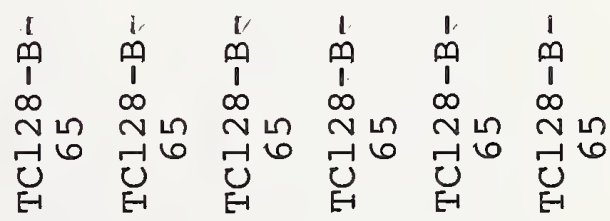

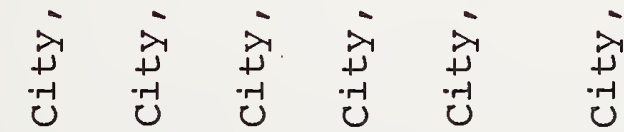

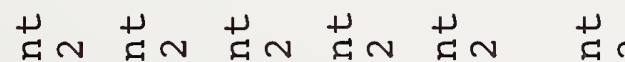





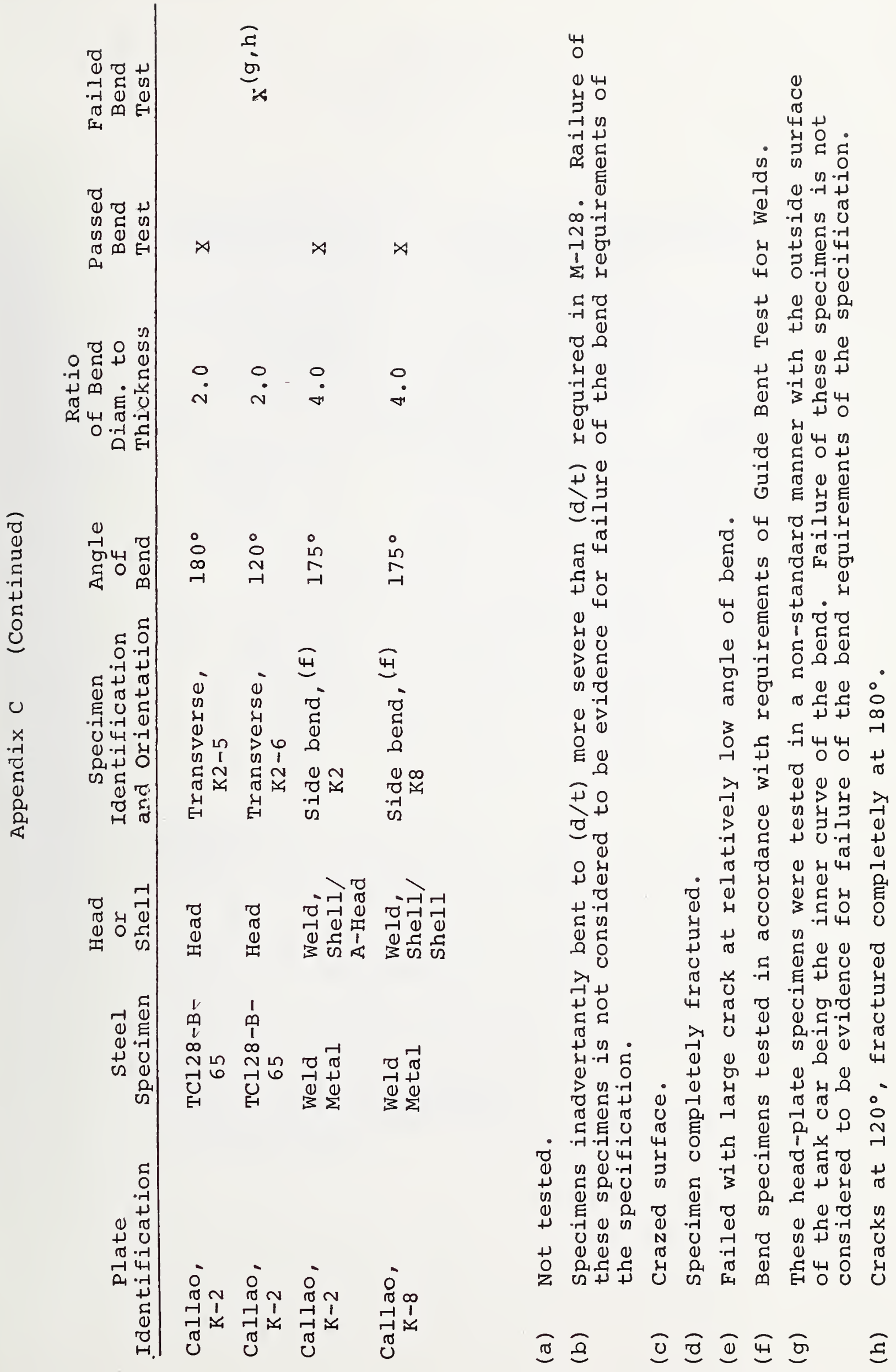





\section{Appendix D}

Guided Bend Test Jig

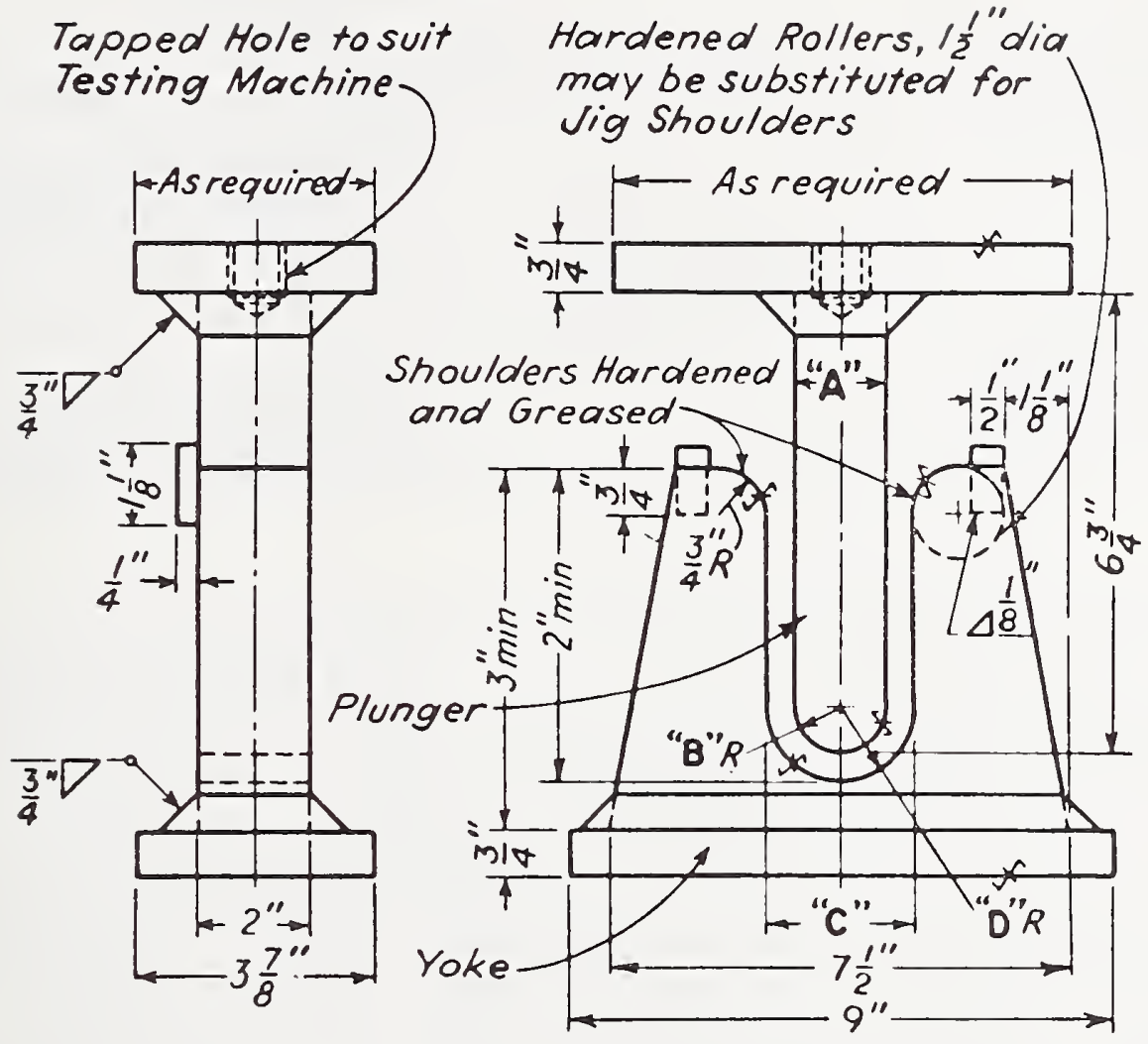

\begin{tabular}{|c|c|c|c|c|}
\hline $\begin{array}{l}\text { PBICKNESS OF } \\
\text { SPECIMENS (in.) }\end{array}$ & $\begin{array}{c}A \\
\left(i n_{0}\right)\end{array}$ & $\begin{array}{c}B \\
\left(i n_{0}\right)\end{array}$ & $\begin{array}{c}c \\
\left(\text { in. }_{0}\right)\end{array}$ & $\begin{array}{c}D \\
\left(i n_{0}\right)\end{array}$ \\
\hline $\begin{array}{cc}3 / 8 & a / \\
t & a\end{array}$ & $\begin{array}{l}11 / 2 \\
4 t\end{array}$ & $\begin{array}{l}3 / 4 \\
2 t\end{array}$ & $\begin{array}{r}23 / 8 \\
6 t+1 / 8\end{array}$ & $\begin{array}{r}13 / 16 \\
3 t+1 / 16\end{array}$ \\
\hline $1 / 8 \mathrm{~b} /$ & $21 / 16$ & $11 / 32$ & $23 / 8$ & $13 / 16$ \\
\hline $\begin{array}{cc}3 / 8 & \mathrm{c} / \\
t & \mathrm{~d} /\end{array}$ & $\begin{array}{r}21 / 2 \\
62 / 3 t\end{array}$ & $\begin{array}{l}11 / 4 \\
31 / 3 t\end{array}$ & $\begin{array}{c}33 / 8 \\
82 / 3 t+1 / 8\end{array}$ & $\begin{array}{c}111 / 16 \\
41 / 3 t+1 / 16 d\end{array}$ \\
\hline
\end{tabular}

NOTES:
a) Use for all materials not otherwise indicated.
b) Use only for P-23 aluminum alloys.
c) Use only for P-25 aluminum alloys.
d) Use only for $\mathrm{P}-25$ aluminum alloys where thickness, $t$, is
loss than $3 / 8$ inch. 


$$
\text { . }
$$


NBS.114A (REV. 7.73)

\begin{tabular}{|c|c|c|}
\hline $\begin{array}{c}\text { U.S. DEPT. OF COMM. } \\
\text { BIBLIOGRAPHIC DATA } \\
\text { SHEET }\end{array}$ & $\begin{array}{c}\text { 1. PUBLICATION OR REPORT NO. } \\
\text { NBS IR 75-655 }\end{array}$ & $\begin{array}{l}\text { 2. Gov't Accession } \\
\text { No. }\end{array}$ \\
\hline 4. TITLE AND SUBTITLE &
\end{tabular}

4. TITLE AND SUBTITLE

Analysis of findings from Four Tank-Car Accident Reports

Report No. 5

7. AUTHOR(S)

C. G. Interrante, J. G. Early and G. E. Hicho

9. PERFORMING ORGANIZATION NAME AND ADDRESS

\section{NATIONAL BUREAU OF STANDARDS DEPARTMENT OF COMMERCE WASHINGTON, D.C. 20234}

12. Sponsoring Organization Name and Complete Address (Street, City, State, ZIP)

Department of Transportation

Federal Railroad Administration

Washington, D. C. 20591

15. SUPPLEMENTARY NOTES
3. Recipient's Accession No.

5. Publication Date

January, 1975

6. Performing Organization Code

8. Performing Organ. Report No. NBS IR 75-655

10. Project/Task/Work Unit No. 3120413

11. Contract/Grant No.

13. Type of Report \& Period Covered

Summary Report

14. Sponsoring Agency Code

16. ABSTRACT (A 200-word or less factual summary of most significant information. If document includes a significant bibliography or literature survey, mention it here.)

A comprehensive overview of the findings and metallurgical analyses of tests conducted at the National Bureau of Standards on samples of tank-car materials submitted by the Federal Railroad Administration is presented. The submitted samples were taken from tank cars which had been involved in accidents during the period January 1970 to January 197 . The testing conducted during the metallurgical analyses included full chemical analyses, ambient temperature tensile tests on longitudinal and transverse specimens, quantitative metallography to determine ferrite grain size, pearlite colony size, and inclusion content, size, and shape hardness tests, bend tests on longitudinal and transverse specimens, and a very comprehensive program of impact testing, which is covered in a separate report on Impact Properties.

The data, which are presented in the Findings section of this report and which are summarized and discussed in the Summary and in the General Discussions, represent a valuable body of information from which the Conclusions were drawn. These summaries and conclusions on the properties of these steels, and the metallurgical factors affecting these properties, when taken in conjunction with the service requirements and the observed behaviors of the materials during the actual service failures, can be useful in making recommendations as to approaches to improved materials

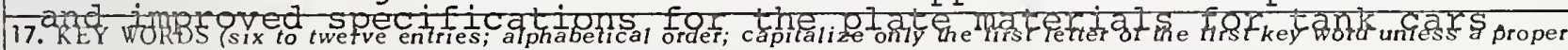
name; separated by semicolons)

Anisotropy; carbon-manganese steels; hardness; inclusions; mechanical properties; pressure-vessel steels; quantitative metallography; tankcar steels; tensile properties;

18. AVAILABILITY $\square$ UnIimited

XX For Official Distribution. Do Not Release to NTIS

[ Order From Sup. of Doc., U.S. Government Printing Office Washington, D.C. 20402, SD Cat. No.C13

\begin{tabular}{|l|c|}
\hline $\begin{array}{l}\text { 19. SECURITY CLASS } \\
\text { (THIS REPURT) }\end{array}$ & 21. NO. OF PAGES \\
UNCLASSIFIED & 69 \\
\hline $\begin{array}{l}\text { 20. SECURITY CLASS } \\
\text { (THIS PAGE) } \\
\text { UNCLASSIFIED }\end{array}$ & 22. Price \\
\hline
\end{tabular}

Order From National Technical Information Service (NTIS) Springfield, Virginia 22151 

(1) 
